\title{
A New Vision for Therapeutic Hypothermia in the Era of Targeted Temperature Management: A Speculative Synthesis
}

\author{
Travis C. Jackson, $\mathrm{PhD}{ }^{1,2}$ and Patrick M. Kochanek, MD, MCCM ${ }^{1,2}$
}

Three decades of animal studies have reproducibly shown that hypothermia is profoundly cerebroprotective during or after a central nervous system (CNS) insult. The success of hypothermia in preclinical acute brain injury has not only fostered continued interest in research on the classic secondary injury mechanisms that are prevented or blunted by hypothermia but has also sparked a surge of new interest in elucidating beneficial signaling molecules that are increased by cooling. Ironically, while research into cold-induced neuroprotection is enjoying newfound interest in chronic neurodegenerative disease, conversely, the scope of the utility of therapeutic hypothermia (TH) across the field of acute brain injury is somewhat controversial and remains to be fully defined. This has led to the era of Targeted Temperature Management, which emphasizes a wider range of temperatures $\left(33-36^{\circ} \mathrm{C}\right)$ showing benefit in acute brain injury. In this comprehensive review, we focus on our current understandings of the novel neuroprotective mechanisms activated by $\mathrm{TH}$, and discuss the critical importance of developmental age germane to its clinical efficacy. We review emerging data on four cold stress hormones and three cold shock proteins that have generated new interest in hypothermia in the field of CNS injury, to create a framework for new frontiers in $\mathrm{TH}$ research. We make the case that further elucidation of novel cold responsive pathways might lead to major breakthroughs in the treatment of acute brain injury, chronic neurological diseases, and have broad potential implications for medicines of the distant future, including scenarios such as the prevention of adverse effects of long-duration spaceflight, among others. Finally, we introduce several new phrases that readily summarize the essence of the major concepts outlined by this review—namely, Ultramild Hypothermia, the "Responsivity of Cold Stress Pathways," and "Hypothermia in a Syringe."

Keywords: therapeutic hypothermia, targeted temperature management, FGF21, RBM3, hypoxic/ischemic encephalopathy, space

\section{Introduction}

$\mathbf{T}$ He Egyptians ReCOgnized the medical utility of hypothermia 5000 years ago, local head cooling for traumatic brain injury (TBI) was used by Phelps in the late 1800s, and total body cooling for the treatment of head injury was first applied in 1938 by the neurosurgeon Temple Fay (Phelps, 1897; Wang et al., 2006; Karnatovskaia et al., 2014). In contemporary practice, therapeutic hypothermia (TH) is highly neuroprotective when applied at $33.5^{\circ} \mathrm{C}$ for 72 hours in selected term newborns with hypoxic/ischemic encepha- lopathy (HIE), where it is standard of care (Martinello et al., 2017). Moreover, current guidelines recommend a targeted temperature management (TTM) of $32-36^{\circ} \mathrm{C}$ for $24-48$ hours in the treatment of neurological injury in comatose adults with out-of-hospital cardiac arrest (Callaway et al., 2015). Also, prophylactic moderate-to-deep TH is standard of care in surgeries that impair cerebral blood flow (CBF) such as for brain aneurysms or aortic arch repair (Hanel and Spetzler, 2008; Tian et al., 2013). Profound hypothermia is also in clinical trials (NCT01042015) for emergency perseveration and resuscitation (EPR) of cardiac arrest from trauma

\footnotetext{
${ }^{1}$ John G. Rangos Research Center, UPMC Children's Hospital of Pittsburgh, Safar Center for Resuscitation Research, University of Pittsburgh, School of Medicine, Pittsburgh, Pennsylvania.

${ }^{2}$ Department of Critical Care Medicine, University of Pittsburgh, School of Medicine, Pittsburgh, Pennsylvania.

(c) Travis C. Jackson and Patrick M. Kochanek, 2019; Published by Mary Ann Liebert, Inc. This Open Access article is distributed under the terms of the Creative Commons License (http://creativecommons.org/licenses/by/4.0), which permits unrestricted use, distribution, and reproduction in any medium, provided the original work is properly cited.
} 
(Wu et al., 2006; Kutcher et al., 2016). However, despite widespread use of cooling in neurocritical care, recent randomized controlled trials (RCTs) suggest that fever prevention (therapeutic normothermia or TTM in the normothermic range), or rigorous control of patient temperature at $36^{\circ} \mathrm{C}$, may be equally effective versus mild $\mathrm{TH}$ to $\sim 33^{\circ} \mathrm{C}$ on longterm neurological outcomes in adults/children with brain injury (Adelson et al., 2013; Nielsen et al., 2013; Maekawa et al., 2015; Moler et al., 2015, 2017; Cooper et al., 2018). Thus, mounting evidence suggests that the adult human brain is less protected by hypothermia compared with rodents (van der Worp et al., 2007). Many factors may explain the discrepancy in preclinical data versus human trials on $\mathrm{TH}$ and include important age-related differences that confer greater protection in the immature brain, time to initiate cooling, which can be achieved much more easily and rapidly in rodents versus humans, duration of cooling, depth of cooling, differences in medical devices used to induce/maintain hypothermia across studies, rate of rewarming, managing adverse side effects, injury heterogeneity, differences in background care between rodents and critically ill patients, including risk of side effects such as bleeding, nosocomical infection, and concurrent drug use, existence of clinical confounders impacting data analysis, and, of course, speciesspecific differences.

Here we propose adding, "Responsivity of Cold Stress Pathways," to TH as another (new) factor that may influence the success of TH in clinical care (Fig. 1). It is the concept that an interaction of variables (e.g., age and/or other unidentified signaling processes) determines the magnitude by which hypothermia increases the levels/activation of cold stress molecules in biological systems. The goal of this review is to link emerging evidence in endocrinology, hibernation, neurocritical care, and brain injury research, often viewed in isolation, but together suggesting that cold stress pathways may alter brain physiology during TH and that they may need to be tailored to the individual to optimize the body's response to hypothermia. We begin with a brief overview of the classic neuroprotective mechanisms that are known to operate during $\mathrm{TH}$, based on preclinical studies in models of brain injury and studies in patients, and also highlight the notable success of TH in humans for the treatment of HIE in infants. Next, to begin to link those traditional findings to the concept of "Responsivity of Cold Stress Pathways," to TH, we review four cold stress hormones (CSHs) and three cold shock proteins (CSPs), discuss their prominent role in the developing brain, and speculate on the manner in which modulating their levels may be an important step in optimizing TH-mediated neuroprotection in adult humans to compensate for a limited Responsivity of Cold Stress Pathways. Specifically, we review data supporting the notion that baseline Responsivity of Cold Stress Pathways is

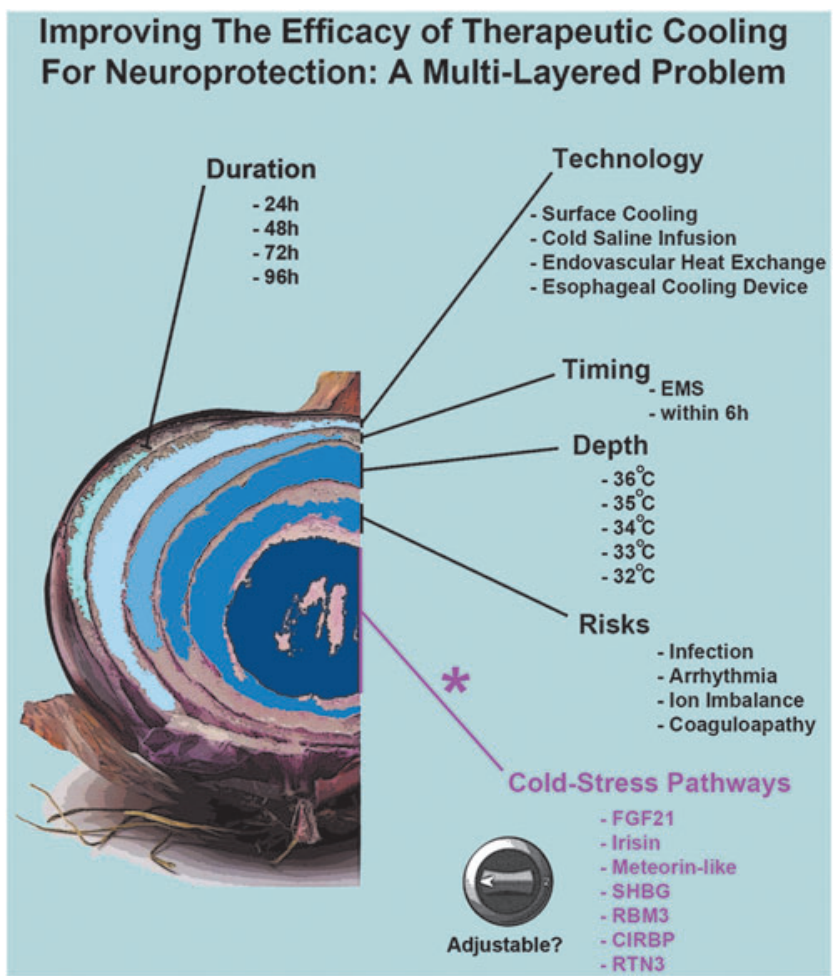

FIG. 1. The many layers of cerebroprotective cooling: the "Responsivity of Cold Stress Pathways" is an additional (new) concept for optimizing TH. Multiple interdependent factors affect the efficacy of neuroprotective $\mathrm{TH}$ in patients. Major variables include the duration of cooling, the device/instrumentation used to induce hypothermia, the time to reach target temperature, the depth of cooling, and the prevention of detrimental side effects. Purple text: the optimal hypothermia protocol(s) that increase tissue/plasma levels of neuroprotective CSHs remain to be elucidated. Nor is it known if $\mathrm{TH}$ is able to increase CSPs in the brain in human adults. Age-dependent and other patient-specific differences may alter (increase or decrease) the induction of CSHs/CSPs by TH, which in turn may influence neurological recovery after a CNS injury. Furthermore, additional work is needed to determine if CSHs/CSPs can be optimized (i.e., adjusted) using noncooling interventions such as pharmacological approaches. CNS, central nervous system; CSHs, cold stress hormones; CSPs, cold shock proteins; TH, therapeutic hypothermia.

markedly increased in infants versus adults (where it is nearly absent), and may contribute to the greater efficacy of neuroprotective TH in that population. Finally, we conclude with a discussion of "Hypothermia in a Syringe" - which is the concept that facets of neuroprotective cooling might be formulated into an intravenous (IV) infusion of molecules that

FIG. 2. Important (classic) mechanisms of neuroprotective hypothermia and potential side effects of total body cooling. Upper-left/white text: a broad group of neuroprotective mechanisms mediate neuroprotection by cooling in the CNS. Bottom-left: the magnitude of induction of different neuroprotective mechanisms depends, in part, on the depth of cooling. Clinically, the temperature ranges are divided into mild, moderate, deep, and profound. Recently, the term UMH was introduced to include therapeutic temperatures ranging above $>35^{\circ} \mathrm{C}$ and below $<36^{\circ} \mathrm{C}$. Bottom-right: total body cooling is a complex "drug" that affects almost every organ/tissue in the body. Maximizing the clinical benefits of cerebral cooling depends, in part, on monitoring/controlling adverse side effects of hypothermia, germane to functional changes in other organ systems, which may inadvertently pose a risk to patient survival and/or CNS recovery after an injury. UMH, Ultramild Hypothermia. 


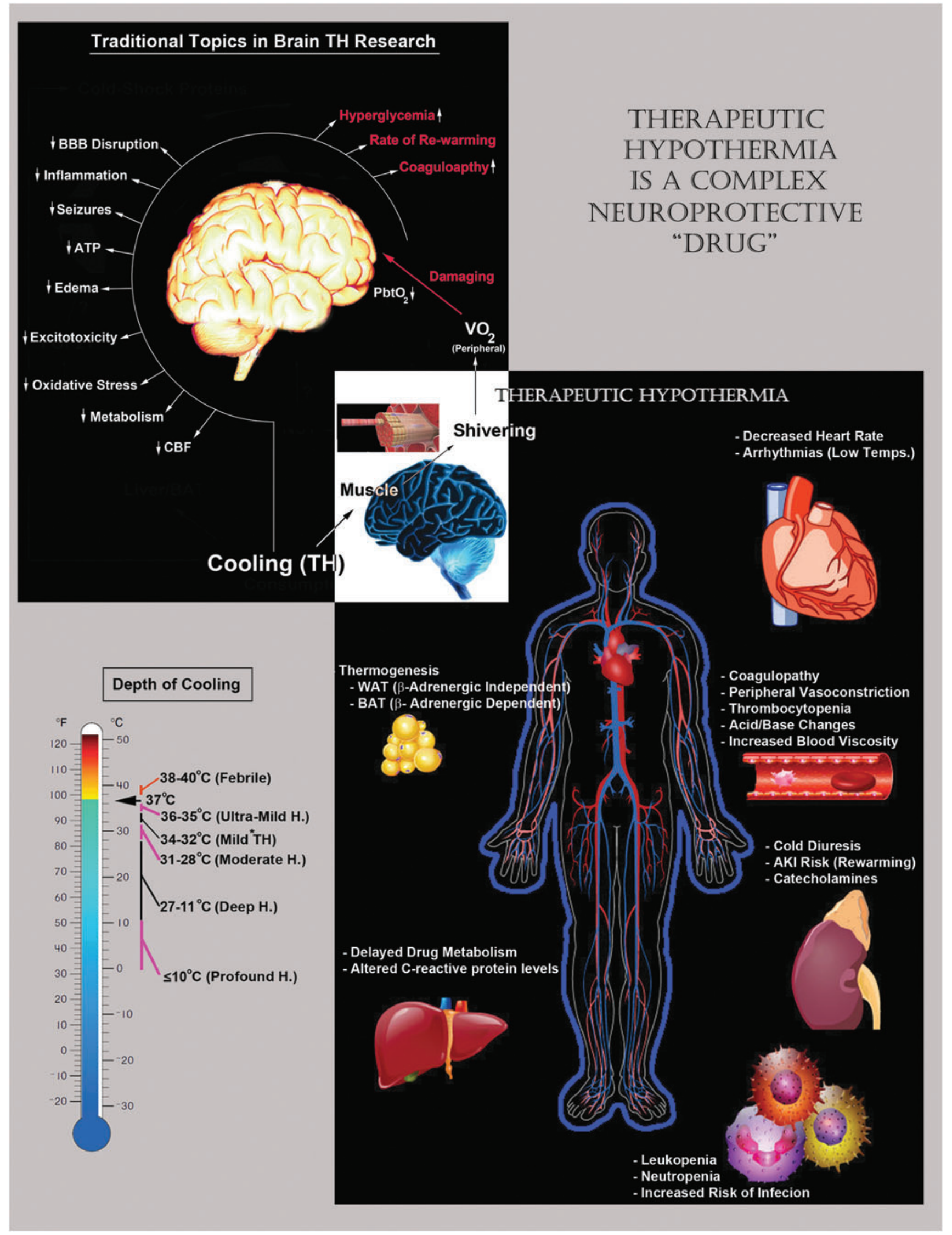


induce molecular components of the cold stress response, increasing neuroprotective effectors despite maintaining the organism at $37^{\circ} \mathrm{C}$. We envision a potential broad range of medical applications for Hypothermia in a Syringe, such as for the treatment of normothermic patients with chronic neurodegenerative diseases. However, to emphasize its potential applications in settings well beyond existent medical needs, and to envision the risks and benefits of this strategy under injury conditions that would affect the entire organism (brain and body), we close by discussing the futuristic possibilities of using Hypothermia in a Syringe to target cellular pathways that defend against the detrimental effects associated with long-duration spaceflight.

\section{Classic Mechanisms Mediating Neuroprotective Hypothermia}

Clinically, the depth of hypothermia is stratified into mild $\left(34-32^{\circ} \mathrm{C}\right)$, moderate $\left(31-28^{\circ} \mathrm{C}\right)$, deep $\left(27-11^{\circ} \mathrm{C}\right)$, and profound $\left(<10^{\circ} \mathrm{C}\right)$ (Fig. 2, lower left). More recently (2015), we introduced the term Ultramild Hypothermia (UMH) for temperatures $>35^{\circ} \mathrm{C}$ and $\leq 36^{\circ} \mathrm{C}$ based on evidence that (1) $36^{\circ} \mathrm{C}$ versus $37^{\circ} \mathrm{C}$ induced a bona fide intracellular cold shock response in cultured primary neurons in vitro (Jackson et al., 2015), (2) Berntman et al. (1981) showed that $36^{\circ} \mathrm{C}$ versus $37^{\circ} \mathrm{C}$ improved biochemical markers of brain damage after hypoxic/ischemic injury in adult rats, and (3) as discussed earlier, rigorous clamping of patients at $36^{\circ} \mathrm{C}$ confers benefit after cardiac arrest, an effect that may not simply represent prevention of fever (Nielsen et al., 2013).

Numerous mechanisms mediate the cerebroprotective effects of cooling. Although in this review we have focused on the potential role of CSPs/CSHs in acute brain injury and chronic neurodegeneration, it is important to briefly summarize the classic neuroprotective mechanisms induced by hypothermia, to provide a base of understanding, and to clarify the integration of novel concepts posed here into the full scheme of hypothermic neuroprotection (Fig. 2, upper left). Notably, some neuroprotective mechanisms provide increased benefit with deeper levels of cooling (e.g., decreased cerebral metabolic rate $[\mathrm{CMR}]$ ), whereas others do not scale with temperature depth and may become inhibited at very low levels of hypothermia (e.g., CSPs-discussed later). Furthermore, modest differences in the target temperature can robustly alter if $\mathrm{TH}$ therapy is protective, or conversely, exacerbates damage after a brain injury (Alonso-Alconada et al., 2015). Thus, the depth of hypothermia is an important factor that modulates the fractional contribution of each mechanism on the total cumulative benefits of cooling. These interactions and their link to specific levels of $\mathrm{TH}$, along with different central nervous system (CNS) insults and insult severity among other factors, can be rather complex. However, for the purpose of this brief overview, we omit an expansive discussion on the optimal temperature(s) that may maximally target different (classic) neuroprotective mechanisms.

Brain ischemia mediates neuronal injury after a cardiac arrest or stroke, for example, and contributes to secondary injury after a TBI (particularly if comorbid with hypoxemia and/or hypotension) (Kaufmann et al., 1999; Coles et al., 2004; Hlatky et al., 2004; Cunningham et al., 2005; Iordanova et al., 2017). The amount of ATP (cellular energy) that neurons require to survive is proportional to CMR. Ischemic cell death is caused by an imbalance in ATP supply (i.e., hypoxia-mediated loss of oxidative phosphorylation) versus demand (high oxygen consumption $\left[\mathrm{CMRO}_{2}\right]$ of brain tissue). Germane to $\mathrm{TH}$, each $1^{\circ} \mathrm{C}$ drop in brain temperature $\left(37-27^{\circ} \mathrm{C}\right.$ ) decreases $\mathrm{CMRO}_{2} \sim 6-7 \%$ (Edgar and Bering, 1961; Steen et al., 1983). Therefore, hypothermia can limit or prevent the development of ischemia during episodes of disturbed or severely compromised CBF by decreasing the ATP utilization and oxygen tension thresholds required to sustain tissue viability (Metz et al., 1996).

Other derangements in CBF physiology are also improved and/or impacted by hypothermia, but their role in mediating hypothermic protection is much more complex, less compelling, and less well understood. For instance, after a TBI, delayed hyperemia (luxury perfusion) exacerbates vasogenic tissue edema and promotes intracranial hypertension (intracranial pressure $[\mathrm{ICP}]>20 \mathrm{mmHg}$ ) in brain regions that have lost cerebral autoregulation (Obrist et al., 1984). Treatment with hypothermia decreased reactive hyperemia after reperfusion in a feline balloon inflation model of severe intracranial hypertension (i.e., ICP was raised to a level that produced brain ischemia) (Mori et al., 1998). The mechanism of protection may have involved decreased CMR (with cooling) and a resultant decrease in CBF due to metabolic/flow coupling. In addition, hypothermia decreased cytotoxic edema formation by downregulating brain aquaporin 4 (AQP4) water channels in a model of cerebral ischemia/reperfusion injury, which would also help lower ICP and improve CBF (Kurisu et al., 2016). Conversely, hypothermia increased membrane levels of AQP4 in astrocytes in vitro (Salman et al., 2017). This type of complexity in response to TH mandates the need for additional studies to clarify if cooling the brain promotes CNS recovery by targeting edema and/or high ICP in certain patients. However, a recent RCT reported that $\mathrm{TH}$ failed to improve long-term neurologic outcomes in a severe TBI cohort of adults with intracranial hypertension (Andrews et al., 2015; Flynn et al., 2015).

Oxidative stress also mediates tissue damage after a brain injury and is a mechanism where there is substantial support for a role of $\mathrm{TH}$ in limiting its deleterious consequences. It results from increased production of toxic oxidizing agents (reactive oxygen species [ROS] or reactive nitrogen species [RNS]) versus decreased capacity of intracellular scavenging mechanisms to neutralize oxygen $\left(\mathrm{O}_{2}{ }^{\bullet-}, \mathrm{OH}^{\bullet}\right.$, and $\left.\mathrm{H}_{2} \mathrm{O}_{2}\right)$, nitrogen $\left(\mathrm{ONOO}^{-}\right)$, and additional radical intermediates via antioxidant defenses (Kohen and Nyska, 2002). Oxidative damage in the CNS after an acute injury, or in chronic neurodegenerative disease, has been extensively reviewed elsewhere (Chen et al., 2011a; Cornelius et al., 2013; Tonnies and Trushina, 2017). There are numerous ROS and/or RNS generating mechanisms, including disruption in the mitochondrial respiratory chain, activation of enzymes that promote ROS (e.g., xanthine oxidase, NADPH oxidase), and redox cycling agents (e.g., free iron), among others (Kohen and Nyska, 2002). The cumulative effect is direct damage (oxidation) to proteins, lipids, and RNA/DNA (Kohen and Nyska, 2002). Moreover, depletion of endogenous antioxidants after an injury (e.g., consumption of reduced glutathione) further exacerbates oxidative stress (Kohen and Nyska, 2002). TH inhibits oxidative brain damage by decreasing these generating processes (Lei et al., 1994, 1997; Globus 
et al., 1995; Kil et al., 1996; Chatzipanteli et al., 1999) and limiting consumption of antioxidant defenses, shown in both preclinical models and in patients across a number of CNS insults (Bayir et al., 2009; Hackenhaar et al., 2017).

Excessive neuronal depolarization after a brain injury results in intracellular $\mathrm{Ca}^{2+}$ overload and sustained glutamate release (excitotoxicity) (Chamoun et al., 2010; Schober et al., 2016). Moreover, extracellular glutamate levels are further increased by pathological reversal of astrocytic glutamate transporters (Gouix et al., 2009). The cumulative effect is rapid activation of extrasynaptic N-methyl-D-aspartate (NMDA) receptors (NMDARs), triggering intracellular apoptotic/necrotic signaling cascades leading to neuronal death (Hardingham et al., 2002). In addition, synaptic NMDARs promote hypoxic cell death or (conversely) stimulate neuroprotective pathways (Hardingham and Bading, 2010; Wroge et al., 2012). TH potently inhibits neuronal death induced by direct intraparenchymal injection of glutamate into the brain (Suehiro et al., 1999). Furthermore, cerebral cooling prevents postinjury spikes in extracellular glutamate in models of ischemia (Mitani and Kataoka, 1991; Ooboshi et al., 2000; Campos et al., 2012), fluid percussion TBI (Globus et al., 1995), subarachnoid hemorrhage (Shuaib et al., 1996; Schubert et al., 2008), and bacterial meningitis (Irazuzta et al., 1999a). In contrast, cooling had no effect on postinjury glutamate levels in a model of controlled cortical impact (CCI), TBI but was cerebroprotective (Palmer et al., 1993). Finally, hypothermia $\left(32^{\circ} \mathrm{C}\right)$ paradoxically increased postinjury glutamate levels above normothermic controls in a rat weightdrop contusion model of TBI (Koizumi et al., 1997). Thus, cooling potently blocks glutamate-mediated neuronal death in many (but not all) brain insult types. Also, concerns have been raised that targeting excitotoxicity may have limited efficacy in brain-injured patients due to the transient therapeutic time window available to prevent the intracellular catastrophe induced by $\mathrm{Ca}^{2+} /$ glutamate overload. This concern may be particularly important for $\mathrm{TH}$ due to the technical challenges involved in initiating cooling in critically ill patients, and the resulting time delay to reach target temperature. Indeed, in a rat cardiac arrest model, brief $\mathrm{TH}\left(31^{\circ} \mathrm{C}\right)$ blocked glutamate release if applied before ischemia or at the time of return of spontaneous circulation (ROSC), but was ineffective if initiated $\sim 5$ minutes postresuscitation (Takata et al., 2005). Similarly, in a dog ventricular fibrillation (VF) cardiac arrest model, the beneficial effects of mild $\mathrm{TH}\left(34^{\circ} \mathrm{C}\right)$ on neurological outcome and survival were negated if cooling was delayed 20 minutes postresuscitation (Nozari et al., 2006). Finally, cerebral cooling also shows great promise to prevent early/chronic seizures (e.g., refractory status epilepticus or cortical spreading depolarization), which similarly arise, in part, from dysregulation of glutamatergic neurotransmission, but have a much broader time window for therapeutic intervention after a brain injury (Takaoka et al., 1996; Corry et al., 2008; Hartings et al., 2009; Barker-Haliski and White, 2015; Niquet et al., 2015; Schiefecker et al., 2018).

Excitotoxic and oxidative injury mechanisms initiate a cascade of events, which lead to a potent neuroinflammatory response- the molecular underpinnings of inflammation in the brain were recently reviewed by our group (Simon et al., 2017). Liberation of intracellular DNA and debris from dying cells into the extracellular space, and release of additional damage-associated molecular patterns (DAMPs), triggers an immediate (within minutes/h) proinflammatory cytokine response in the brain (e.g., increased TNF, IFN $\gamma$, and IL-6) (Frugier et al., 2010; Ansari, 2015). Moreover, neutrophils rapidly accumulate in the early acute phase following a TBI, and after the reperfusion phase in cerebral ischemia (Garcia et al., 1994; Carlos et al., 1997; Price et al., 2004).

Later, evolving time-dependent changes in the release of additional downstream cytokines/chemokines, and in response to neuronal death, alters the extracellular milieu days/weeks postinjury and initially promotes a proinflammatory (M1/M1like) phenotype in infiltrating macrophages and resident microglia (Harting et al., 2008; Hu et al., 2012; Boddaert et al., 2018). In the chronic phase, ideally, macrophages and microglia switch to an anti-inflammatory (M2/M2-like) phenotype, promoting wound healing and injury resolution. However, recent findings suggest that M2/M2-like responses peak in the subacute/early chronic phase after a TBI, followed by a prolonged and detrimental shift toward an M1/M1-like phenotype (Loane and Kumar, 2016). Furthermore, the evolving trajectory of pro- versus anti-inflammatory functions of immune cells differs among individuals (e.g., by insult mechanism, tissue type [white vs. gray matter], and additional factors effecting patient heterogeneity), and a significant fraction of severe TBI victims develop chronic/ persistent neuroinflammation that temporally and spatially matches progressive axonal injury (Ramlackhansingh et al., 2011). TH decreases neuroinflammation by blocking its triggers (e.g., preventing cell death mechanisms). In addition, cooling the brain shifts monocytes toward an antiinflammatory M2 phenotype (Truettner et al., 2017; Liu et al., 2018). However, in some instances, cooling might aggravate inflammation. Indeed, TH in piglets precipitated a proinflammatory cytokine surge after rewarming versus normothermic controls, and underscores the need for additional research to define the optimal rewarming protocol(s) in different patient cohorts (Rocha-Ferreira et al., 2017).

The blood/brain barrier (BBB) maintains the chemical composition of the brain interstitial fluid and is critical for normal CNS function (Sweeney et al., 2019). Increased BBB permeability due to mechanical disruption after a TBI, or by other disease processes, increases extravasation of harmful pathogens and toxic micro/macro molecules (e.g., bilirubin) into the underlying brain parenchyma (Wennberg and Hance, 1986; Kristensson, 2011). Also, leakage of erythrocytes into the perivascular space, followed by subsequent hemolysis, results in increased extracellular hemoglobin and free iron, exacerbating ROS-mediated injury (Rifkind et al., 2014). TH decreased BBB damage in models of head trauma (Smith and Hall, 1996; Lotocki et al., 2009), stroke (Tang et al., 2013; Liu et al., 2017), bacterial meningitis (Irazuzta et al., 1999b, 2000), and intracerebral hemorrhage (Song et al., 2018), among others. The mechanisms of hypothermia-mediated protection of the BBB involve inhibition of matrix metalloproteinases (Lee et al., 2005), preservation of tight-junction proteins (Li et al., 2017b), and downregulation of intracellular adhesion molecule 1 on the surface of vascular endothelium, preventing leukocyte diapedesis (Lotocki et al., 2009; Choi et al., 2011b). Maintaining BBB integrity is also important to maximize the benefits of hyperosmolar therapies used to decrease brain water content/edema and prevent possible "rebound ICP" in the treatment of intracranial hypertension (Torre-Healy et al., 2012). 
Activation of upstream insults (reviewed above) stimulates a diverse set of downstream cell signaling pathways, which engage different types of cell death mechanisms and collectively result in secondary brain injury. Each cell death mechanism has its own unique "molecular signature," which involves specific effector molecules and signaling cascades. A comprehensive review of the manner in which hypothermia alters individual components of each cell death pathway is outside the scope of this focused article. In general, there is abundant evidence across a spectrum of brain injury models demonstrating that mild/moderate hypothermia inhibits either the protein levels and/or activation of molecular targets that mediate apoptosis (Edwards et al., 1995; Gong et al., 2013; Eroglu et al., 2017), necrosis (Buki et al., 1999; Liebetrau et al., 2004), autophagy (Lu et al., 2014; Song et al., 2018), necroptosis (Liu et al., 2016), or pyroptosis (Tomura et al., 2012; Zhou et al., 2018). Conversely, profound hypothermia can decrease tissue viability, and the mechanisms mediating this phenomenon are under investigation; Hattori et al. (2017) reported that temperatures less than $\sim 10-8^{\circ} \mathrm{C}$ robustly activate ferroptosis in a broad range of cell types in vitro (i.e., $\mathrm{Fe}^{+} / \mathrm{MAPK}$-dependent and lipid peroxidationmediated cell death). A greater understanding of cell death mechanisms activated by deep or profound hypothermia may improve the efficacy of treatments such as deep hypothermic circulatory arrest (DHCA), in which longer surgery time is well-known to increase the risk of cognitive impairment postresuscitation (Kumral et al., 2001).

Finally, mitigating adverse side effects of TH is also critical for improving the clinical efficacy of cooling in the treatment of brain injury (Fig. 2, bottom right). Key health risks include coagulopathy, increased rates of infection, intense shivering (which may activate a stress response and increase metabolic demands), arrhythmias, and hyperglycemia, among others (Noyes and Lundbye, 2015). In general, these adverse events are exacerbated by greater depths of cooling but can typically be well managed at temperatures spanning the mild TH range (Polderman, 2009).

\section{The Influence of Developmental Age on the Efficacy of TH in Humans}

Developmental age robustly alters gene expression, protein levels, epigenetic/post-transcriptional modifications, and connectivity in the brain (Cheung et al., 2010; Colantuoni et al., 2011; Lipovich et al., 2014; Walhovd et al., 2016). A similar CNS insult (e.g., mechanism and magnitude) may elicit different cell signaling and biochemical responses in damaged tissue from patients at different ages (e.g., toddlers vs. adults). In addition, patient age is a major factor that affects the efficacy of neuroprotective therapies in clinical trials (e.g., NIH's "Inclusion Across the Lifespan Policy"), and suggests that the benefits of an intervention depend, in part, on the unique molecular framework at a given age versus the extent that a treatment is optimal for that particular time point. For instance, caspases and other proapoptotic proteins are abundant in the newborn brain and facilitate homeostatic pruning of surplus synapses/dendrites (Shimohama et al., 2001; Soane et al., 2008; Yamaguchi and Miura, 2015). Following CNS injury, increased baseline expression of caspases in the infant brain can be maladaptive and indiscriminately enhance apoptotic cell death in otherwise salvageable tissue. Therapies that block caspase-mediated cell death are particularly robust in models of developmental brain injury (Li et al., 2000; Han et al., 2002; Chauvier et al., 2011). Numerous additional examples include age-dependent vulnerabilities and/or differences in oligodendrocytes (Salter and Fern, 2005), antioxidant defenses (Ditelberg et al., 1995; Nanda et al., 1996; Fan et al., 2003), and changes in excitatory neurotransmission that affect the magnitude of $\mathrm{Ca}^{2+}$ influx through voltage/ligand-gated ion channels (Ramoa and Mccormick, 1994; Zhou and Baudry, 2006; Henson et al., 2008), among others.

The neuroprotective efficacy of TH is also robustly influenced by age. The cerebroprotective effects of TH in humans are greatest in newborns, based on meta-analysis of clinical trials in moderate/severe HIE, and seven is the number needed to treat to observe one beneficial outcome (NNTB) on combined mortality or long-term neurodevelopmental disability (Jacobs et al., 2013). However, the efficacy of TH in the setting of mild HIE is unclear, and currently is not recommended as standard of care in advance of additional research (Kariholu et al., 2018). In contrast, recent trials in adults and children with cardiac arrest or TBI reported that patients managed with $\mathrm{TH}\left(33^{\circ} \mathrm{C}\right.$ for $\sim 24-48$ hours) had similar long-term neurologic outcomes versus those given standard of care (TTM/fever prevention) (Adelson et al., 2013; Nielsen et al., 2013; Maekawa et al., 2015; Moler et al., 2015, 2017; Cooper et al., 2018). The biological underpinnings mediating age-dependent discrepancies in the efficacy of neuroprotective TH have not been fully elucidated. Identifying the relevant cell signaling pathways (1) may lead to novel approaches to augment the efficacy of TH in newborns (i.e., an NNTB of 7 indicates that many newborns with moderate/severe HIE are not protected by cooling), (2) aids development of biomarker-based tests to predict which patients will benefit most from cooling, and (3) determines if adults lack key molecular substrates expressed in the young that (in part) mediate neuroprotective effects of $\mathrm{TH}$ and thus represent a viable target to enhance the efficacy of TH across the spectrum of CNS injuries.

In addition, germane to both age and species, results of rodent brain injury models have tended to overestimate the anticipated success of $\mathrm{TH}$ in human adults. Indeed, brain injury studies in rats and mice indicate that newborn and adults are similarly (robustly) protected by cerebral cooling (contrary to findings in human trials) (Dietrich, 2000; van der Worp et al., 2007). Animal homogeneity (e.g., inbred rodent strains) and the time it takes to initiate cooling, which can be achieved almost immediately in the laboratory, are a few of the potential factors contributing to discrepancies in preclinical versus clinical findings (Nozari et al., 2006; RochaFerreira et al., 2018). However, species-specific differences likely play a role as well (Mestas and Hughes, 2004; Ellenbroek and Youn, 2016; Montenegro et al., 2016; Reitman, 2018). One strategy for improving the efficacy of TH in adult humans is to elucidate which classic neuroprotective mechanisms might be better targeted by cooling in rodents versus humans, and then determine if it is feasible to transiently "rewire" human physiology to better match rodents to maximize the benefits of cooling, or augment $\mathrm{TH}$ with combination therapy with a drug or drugs targeting those mechanisms. An alternative and more novel strategy is to find neuroprotective cold-induced mechanisms that are poorly 
activated by TH in both adult rodents and in humans (i.e., highly conserved maladaptive physiology). Novel drug/treatments able to reanimate a latent/ "resistant" cold-induced neuroprotective mechanism in rodents may then have an opportunity to translate into patients due to conserved biology. This implies that the full potential of neuroprotective $\mathrm{TH}$ has not yet been realized even in adult rodents (despite its well-known efficacy), given that the full spectrum of beneficial pathways has not been engaged. We think that CSPs, and in particular RNA binding motif 3 (RBM3; discussed below), are good examples of conserved TH-regulated targets that have not been optimized in either adult rodents or in humans. The sections that follow explore the utility of CSHs and CSPs to improve the efficacy of TH in humans, and this concept is reviewed to a large extent independent of the age(s) at which targeting these pathways may work best. Nevertheless, accumulating evidence suggests that baseline levels/activity of CSHs/CSPs are increased in newborns (rodents and humans) and thus represent a key age group for initial exploration germane to their therapeutic manipulation.

\section{The CSH Response During Cold Stress: Potential Applications for Neuroprotection}

Beyond the aforementioned classic acute neuroprotective mechanisms of TH/TTM, a cascade of mechanisms and events is also linked to the use of TH that is mediated by CSHs and CSPs. CSHs activate thermogenic pathways and help to maintain core body temperature $\left(\mathrm{T}_{\mathrm{b}}\right)$. Emerging evidence suggests that CSHs evoke a broad set of molecular and biochemical changes, which may boost neuroprotective cooling. Brain researchers have only begun to study the involvement of CSHs on neurological outcomes in the setting of TH/TTM. The increased interest may relate to underwhelming results of clinical trials on $\mathrm{TH}$ in adult human studies, compared with the highly compelling data obtained by preclinical animal experiments, and a shift in thinking leading to a renaissance or return to focus on understudied cell signaling pathways affected by systemic cooling, which might directly or indirectly impact the brain. Here we review four CSHs that may represent low-hanging fruit for additional investigation as to their potential as novel agents to augment hypothermic neuroprotection in neurocritical care, or to decrease neuropathology in normothermic patients with chronic neurodegenerative diseases (Figs. 3 and 4).

\section{Fibroblast growth factor 21}

Most fibroblast growth factors (FGFs) are paracrine hormones (reviewed elsewhere; Itoh and Ornitz, 2008; Ornitz and Itoh, 2015). A conserved heparin-sulfate proteoglycan binding domain (HSPBD) restricts their activity to near the site of release (Thompson et al., 1994). In contrast, FGF21 is a member of the endocrine subfamily of FGFs. Endocrine hormone FGFs (FGF19, FGF21, and FGF23) lost their heparin binding function during evolution causing them to circulate freely on release (Itoh and Ornitz, 2008). Consequently, they utilize transmembrane klotho proteins as coreceptors $(\alpha$-klotho and/or $\beta$-klotho), which function as molecular scaffolds to promote/stabilize the interaction between extracellular ligand and tissue receptor (Chen et al., 2018a; Lee et al., 2018b). $\beta$ klotho is the obligatory coreceptor for FGF21 and is required for ligand binding and activation of FGF1Rc in vivo (Kurosu et al., 2007; Adams et al., 2012). Also, in vitro studies show that $\beta$-klotho increases the affinity of FGF21 to bind multiple FGF receptor isoforms, but the magnitude of activation of downstream targets varies by receptor type (FGFR1c $>$ FGFR2c $>$ FGFR3c) (Kurosu et al., 2007). Furthermore, $\beta$ klotho expression in adults is limited to the liver, pancreas, adipose tissue, and a few neuronal populations within the hypothalamus/hindbrain (Tacer et al., 2010; Bookout et al., 2013). The near absence of $\beta$-klotho messenger RNA (mRNA) in most regions of the adult brain has been confirmed in mice and in 13-lined ground squirrels (Tacer et al., 2010; Bookout et al., 2013; Nelson et al., 2013). Also, our group confirmed that $\beta$-klotho protein levels are negligible in the frontal cortex and in the hippocampus of human adolescent or adult subjects (Jackson et al., 2018). In contrast, $\beta$-klotho is unexpectedly abundant in the cortex and in the hippocampus in infants, and is also expressed in toddlers (Jackson et al., 2018). The potential importance of this discovery is addressed later.

FGF21 is an integral hormone in the mammalian metabolic response to cold stress. $T_{b}$ affects FGF21 levels and vice versa. Inagaki et al. (2007) were the first to report that FGF21 has a direct effect on $\mathrm{T}_{\mathrm{b}}$. FGF21 mRNA overexpression in the liver induced torpor on 24 hours of fasting in transgenic mice (Inagaki et al., 2007). During the 12-hour-light cycle phase of the experiment, $\mathrm{T}_{\mathrm{b}}$ was $1-2^{\circ} \mathrm{C}$ lower in fasted transgenic mice versus wild types. During the 12-hour-dark cycle phase, $\mathrm{T}_{\mathrm{b}}$ plummeted to $<28^{\circ} \mathrm{C}$ in fasted transgenic mice, which became physically inactive, whereas $\mathrm{T}_{\mathrm{b}}$ in wild-type mice remained $\geq 34^{\circ} \mathrm{C}$ and torpor was not induced. Also, the absence of torpor in fed transgenic mice suggests that FGF21 pathways interact with starvation-stimulated signaling mechanisms, which together coordinate decreased $\mathrm{T}_{\mathrm{b}}$. The FGF21 transgene was under control of an APOE promoter, which caused an $\sim 50$-fold increase in FGF21 mRNA levels in the liver of transgenic versus wild-type mice (Inagaki et al., 2007). The brain is the second highest expresser of APOE, and it is abundant in astrocytes, cells of the choroid plexus, and in smooth muscle surrounding CNS blood vessels (Srivastava et al., 1996; Xu et al., 2006). Thus, presumably, brain FGF21 levels also greatly increased in transgenic mice during the fasting period. The contribution of brain-derived FGF21 to affect torpor/ $\mathrm{T}_{\mathrm{b}}$ in this study, potentially by acting on $\beta$-klotho expressing neurons in the hypothalamus, was not explored.

Nelson et al. (2013) directly tested the hypothesis that peripherally derived FGF21 is a key inducer of hibernation in 13-lined ground squirrels. Adenovirus-mediated FGF21 overexpression, delivered via the femoral artery, failed to increase the number of squirrels entering torpor during simulated hibernation (fasting/24-hour darkness $/ 5^{\circ} \mathrm{C}$ for 7 days). Interestingly, FGF21 overexpression decreased the meanminimum $\mathrm{T}_{\mathrm{b}}$ in active squirrels maintained at normal ambient temperature $\left(23^{\circ} \mathrm{C}\right)$ but conversely increased total mean $\mathrm{T}_{\mathrm{b}}$ in squirrels subjected to simulated hibernation; potentially due to increased thermogenesis in the latter (Nelson et al., 2013). Thus, FGF21 modifies facets of $\mathrm{T}_{\mathrm{b}}$ regulation (up or down) depending on the season, environmental conditions, and thermoregulatory need. Also, naive squirrels had very low endogenous blood FGF21 levels during active months, but the levels increased during winter torpor and were maximal (approximately eight- to ninefold higher vs. active months) 


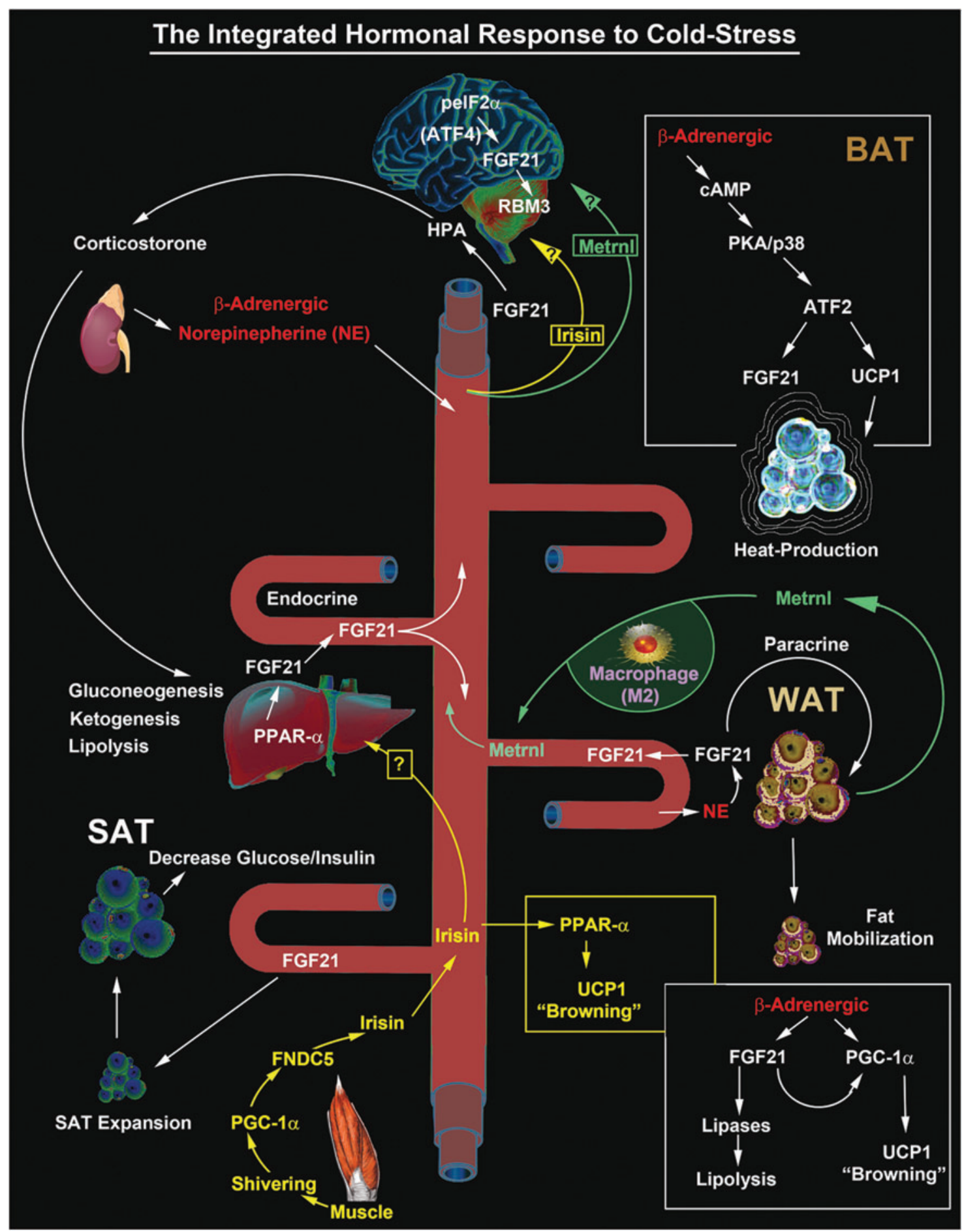

FIG. 3. The complex interplay/release of cold stress hormones (FGF21, Irisin, and Metrnl) by thermogenesis-regulating organs after cold exposure and possible targeting to the brain. The diagram shows the major sources of key circulating CSHs. FGF21-regulated mechanisms are illustrated in white text. Irisin-regulated mechanisms are illustrated in yellow text. Metrnl-regulated mechanisms are illustrated in green text. Potential unknown intersections (?) of paracrine effects on target tissues are indicated. All known signaling links and molecular targets are supported by research articles cited in the primary text. ATF, activating transcription factor; BAT, brown adipose tissue; eIF2 $\alpha$, eukaryotic initiation factor 2-alpha; FGF21, fibroblast growth factor 21; Metrnl, Meteorin-like; PKA, protein kinase A; PPAR $\alpha$, peroxisome proliferator-activated receptor-alpha; RBM3, RNA binding motif 3; SAT, subcutaneous adipose tissue; UCP, uncoupling protein; WAT, white adipose tissue. 


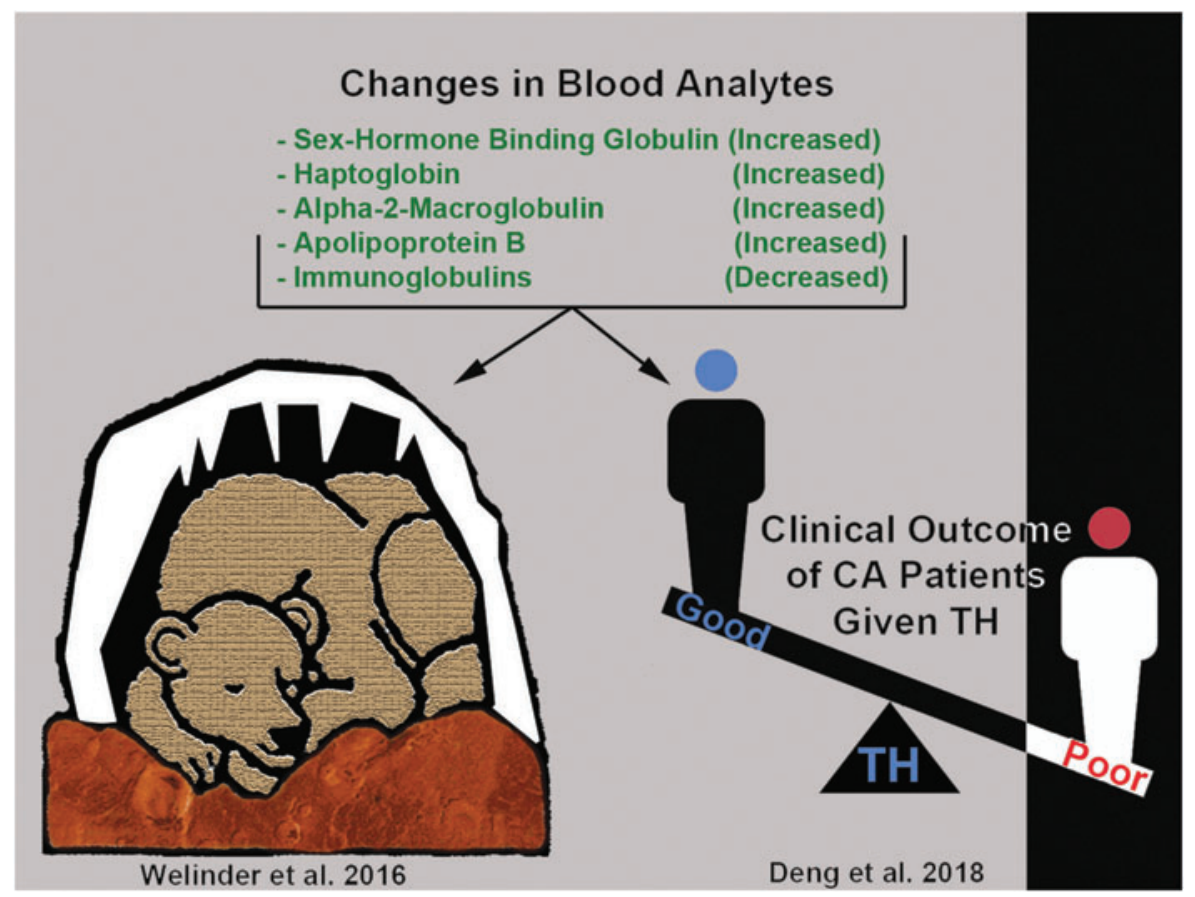

FIG. 4. SHBG is a novel target of hypothermia with unknown function(s) postcooling in humans and in bears. Illustration shows protein targets that are similarly altered (increased or decreased) by cooling in juvenile hibernating bears (Welinder et al., 2016) versus adult human CA patients treated with TH and who had a good neurological outcome (Deng et al., 2018). In both studies, proteomic changes were detected by mass spectrometry of blood plasma, and SHBG levels were among the highest fold change (compared with respective controls) among the identified proteins. CA, cardiac arrest; SHBG, sex hormone binding globulin.

during interbout arousals (IBAs), which are brief 24-hour periods of rapid rewarming followed by re-entering hypothermic torpor for 10 days (Nelson et al., 2013). Whether the robust increase of FGF21 during IBA (1) is strictly related to the activation of heat producing thermogenesis, (2) protects animals against the negative aspects of rapid rewarming, or (3) activates cold adaptive signaling programs that improve organ health during deep hypothermia is unknown. Thus, the work of Nelson et al. (2013) did not establish that FGF21 is a key inducer of hibernation, but supports the notion that FGF21 is involved in the mammalian defense and/or tolerance to hypothermia.

Circulating FGF21 levels increase in rodents and in humans during cold stress. Lee et al. (2013) were the first to show this in humans. Patients subjected to a mild environmental cold challenge of $19^{\circ} \mathrm{C}$ for 12 hours, wearing only hospital scrubs, had increased plasma FGF21 levels versus subjects maintained under thermoneutral conditions $\left(24^{\circ} \mathrm{C}\right)$. The same research team later confirmed these findings in a separate cohort of human subjects (Lee et al., 2014). Of note, blood FGF21 levels are greatly affected by diurnal rhythms in humans; plasma levels are highest in the early morning and then decrease to a nadir in late afternoon (Yu et al., 2011; Lee et al., 2013, 2014). Cold stress blunts the diurnal decrease but does not prevent it (Lee et al., 2013, 2014). Thus, future studies should take into account the time of day samples are collected, and consider the impact of diurnal changes across comparison groups if serum FGF21 levels are measured in brain-injured patients.

Cold stress also increases blood FGF21 levels in rodents. Chartoumpekis et al. (2011) showed in mice that a decreased environmental temperature to $4^{\circ} \mathrm{C}$ for 4 hours robustly increased FGF21 mRNA levels in brown adipose tissue (BAT), however, plasma FGF21 protein levels were not elevated at that time point. Hondares et al. (2011) showed that mice housed at $4^{\circ} \mathrm{C}$ (environmental temperature) for 6 hours, 24 hours, or 30 days had increased FGF21 mRNA levels in BAT at all three time points. Plasma FGF21 levels were not elevated by 6 hours of cooling but increased by 24 hours, and were markedly increased by chronic cooling for 30 days. Thus, cold stress increases FGF21 expression in BAT in mice, and, after a subacute delay ( $<1$ day), leads to increased circulating FGF21 protein levels in the blood.

What are the intracellular signaling mechanisms mediating increased FGF21 levels during cold stress and what are the downstream physiological consequences of FGF21 receptor activation? The majority of experiments addressing these questions used tissues/cells, which constitutively express $\beta$-klotho in adults (i.e., liver, pancreas, adipose). Thus, most information on FGF21 signaling mechanisms may be biased to understanding the function in those organs; therefore, we refer to this as the "canonical pathway" for the sake of this review. We speculate that additional FGF21 signaling mechanisms are yet to be brought to light, such as in tissues like the infant hippocampus or cerebral cortex, also expressing $\beta$-klotho, but in which we would not expect the role of FGF21 to be increased stimulation of intracellular lipolysis or enhanced heat production, as is the case for organs involved in thermal homeostasis.

In the liver, FGF21 gene expression is regulated by the activation of nuclear peroxisome proliferator-activated receptor alpha (PPAR $\alpha)$, the latter is powerfully induced by starvation (Inagaki et al., 2007). Cold shivering also increases the circulating hormone irisin, which stimulates nuclear PPAR $\alpha$ in white adipose tissue (WAT; discussed in greater detail in the next section) (Bostrom et al., 2012). To our knowledge it has not been tested if increased blood irisin levels activate PPAR $\alpha$ in the liver; however, it could theoretically further stimulate FGF21-mediated cold stress mechanisms (i.e., muscle shivering induced release of hepatic FGF21). In BAT, FGF21 gene expression is regulated by cold-induced activation of the sympathetic nervous system, resulting in increased catecholamine release (e.g., norepinephrine), in turn activating adrenergic receptors, which 
stimulates activating transcription factor 2 (ATF2) (Chartoumpekis et al., 2011; Hondares et al., 2011). Inhibition of PPAR $\alpha$ in BAT does not block cold-induced or $\beta$-adrenergic agonist-induced FGF21 expression (Chartoumpekis et al., 2011; Hondares et al., 2011).

Starvation and/or cold stress increase the activation of FGFR1c/ $\beta$-klotho signaling complexes in the liver, pancreas, adipose (BAT, WAT, and subcutaneous adipose tissue [SAT]), and hypothalamus. The broad physiological effects of FGF21 on metabolism have been comprehensively reviewed elsewhere (Fisher and Maratos-Flier, 2016). In the liver, FGF21 promotes ketogenesis (synthesis of ketone bodies), lipolysis, and stimulates gluconeogenesis (Inagaki et al., 2007; Liang et al., 2014). In WAT, FGF21 increases the expression of lipases that mobilize fat stores, and also increases enzymes that catabolize fatty acids to make acetylCoA (Inagaki et al., 2007; De Sousa-Coelho et al., 2013). Furthermore, in WAT, FGF21 increases uncoupling protein 1 (UCP1) levels via a post-transcriptional mechanism, which promotes browning and heat generation during cold adaptation (Fisher et al., 2012). In BAT, FGF21 acts to increase glucose clearance and to sensitize insulin signaling (Kwon et al., 2015; BonDurant et al., 2017). More recently, it was discovered that FGF21 increased the expansion of SAT, which appeared to partially mediate its beneficial insulin/ glucose-lowering effects (Li et al., 2018); intriguingly, germane to cold adaptation, SAT thickness determines the extent to which adult humans can withstand extremely cold water and maintain normal $\mathrm{T}_{\mathrm{b}}$ (Hayward and Keatinge, 1981). Thus, FGF21-mediated stimulation of SAT expansion may serve a dual purpose by promoting cold tolerance. Furthermore, the relationship between FGF21 levels and SAT in newborns merits additional investigation. Healthy human infants have high levels of circulating FGF21 in the first year of life, presumably due to increased PPAR $\alpha$-mediated expression in the liver based on animal studies in rodent neonates, and also, SAT thickness during the same growth period in human babies positively correlates with rates of motor development (Hondares et al., 2010; Kanazawa et al., 2014; Sanchez-Infantes et al., 2015). In the pancreas, FGF21 represses growth hormone $(\mathrm{GH})$-mediated synthesis and the release of insulin from islet cells (So et al., 2015). Finally, in the brain, FGF21 stimulates the hypothalamic/pituitary/ adrenal (HPA) axis, which in turn stimulates gluconeogenesis in the liver via corticosterone (Liang et al., 2014).

Evidence suggests that increased FGF21 levels may improve brain health after an acute CNS injury or in chronic neurodegenerative conditions. We consider the evidence to support both direct and indirect mechanisms of CNS benefit. Also, germane to the clinical practicalities of drug administration for brain-targeted therapies, it is highly desirable that FGF21 has been shown to cross the BBB. Radiolabeled ${ }^{125}$ I-FGF21 is detected in cortical brain tissue 10 minutes after IV injection and reaches the brain parenchyma by simple diffusion (Hsuchou et al., 2007). Furthermore, in order for FGF21 to activate direct mechanisms of neuroprotection, $\beta$-klotho must be present in brain regions targeted by the therapy, such as in the hippocampus, a brain region that is known to be highly vulnerable to ischemic, traumatic, and other insults. In adults, this appears to be a major limitation to the potential utility of FGF21 as a neuroprotectant, because $\beta$-klotho is restricted to the hypothalamus/hindbrain. In contrast, we have reported that in infants and in toddlers, $\beta$-klotho expression is more widespread, including in the cortex and in the hippocampus (Jackson et al., 2018). Thus, very-young brain-injured patients could be a key group that might benefit most from the direct neuroprotective effects of FGF21. Surprisingly, the distribution of $\beta$-klotho among different cell types in the infant brain is unknown (e.g., neurons, astrocytes, microglia, oligodendrocytes, pericytes, or endothelial cells). We are currently addressing this knowledge gap via ongoing experiments on human tissues.

FGF21 is directly neuroprotective. Leng et al. (2015) showed that 6 days pretreatment with $5 \mathrm{nM}$ FGF21 decreased subsequent cell death induced by glutamate toxicity in immature day in vitro (DIV) 6 primary rat cortical neurons maintained at $37^{\circ} \mathrm{C}$. FGF21 treatment also increased phosphorylation of neuronal AKT, ERK, and GSK-3 $\beta$ (Leng et al., 2015). We reported that FGF21 augments the induction of the neuroprotective CSP RBM3 after 24 hours UMH to $36^{\circ} \mathrm{C}$ in DIV6-7 primary rat cortical neurons (Jackson et al., 2015); interestingly, this synergistic effect was not observed in mature DIV26 neurons treated with FGF21 at $36^{\circ} \mathrm{C}$. Kuroda et al. (2017) reported that peripherally derived FGF21 in adult mice promoted CNS remyelination after lysophosphatidylcholine (LPC)-induced injury/demyelination in the brain and in the spinal cord white matter; the mechanism of protection involved increased $\beta$-klotho expression in oligodendrocyte precursor cells, which was induced by LPC injury. Amiri et al. (2018) showed in vitro that FGF21 pretreatment decreased neuronal death of human neuronal SHSY5Y cells injured by $\mathrm{A} \beta_{1-42}$ - directly linking to the possible benefits of FGF21 therapy in the setting of Alzheimer's disease. Chen et al. (2018b) showed that administration of recombinant FGF21 in adult normothermic mice increased BBB integrity, decreased brain edema and histological damage, and ameliorated neurological deficits after a CCITBI. Given that $\beta$-klotho is absent in brain regions damaged by a CCI-TBI in vivo, it is unclear if the benefits were due to the direct activation of unidentified FGF21-regulated pathways or the result of numerous peripheral effects, which could have improved outcomes by indirect mechanisms (Tacer et al., 2010; Bookout et al., 2013). Jiang et al. (2018) demonstrated that 14 days of treatment with $1.5 \mathrm{mg} / \mathrm{kg}$ rFGF21 (initiated 6 hours postinjury) decreased metabolic dysfunction, neuroinflammation, brain infract size, white matter injury, and improved neurological outcomes after a focal ischemic stroke in 10-week-old diabetic mice. Finally, Restelli et al. (2018) demonstrated in vivo that increased endoplasmic reticulum (ER) stress in neurons of the brain caused phosphorylation of eukaryotic initiation factor 2 alpha (peIF $2 \alpha$ ), which in turn stimulated activating transcription factor 4 (ATF4), and subsequently increased neuronal FGF21 expression. Increased hippocampal FGF21 mRNA levels were seen in adult mice with frontotemporal dementia (i.e., P301L Tau mutant mice), and also in $\operatorname{tg} 37$ mice inoculated with prions to induce severe neurodegeneration (Restelli et al., 2018). Interestingly, clinically relevant levels of hypothermia potently increased neuronal peIF $2 \alpha$ levels in vitro (Jackson et al., 2015). Likewise, peIF2 $\alpha$ levels are robustly increased in the brain of hibernating squirrels (Frerichs et al., 1998). Thus, the discovery that peIF $2 \alpha$ regulates FGF21 expression in the brain reveals a fascinating mechanistic link between the fundamental mechanisms involved in the 
molecular adaptation to severe hypothermia (i.e., decreased global protein synthesis [GPS] due to increased peIF2 $\alpha$ ) versus thermogenic singling pathways, which contribute to $\mathrm{T}_{\mathrm{b}}$ maintenance during mild environmental cold stress (i.e., FGF21). Nevertheless, brain $\beta$-klotho was not assessed by Restelli et al. (2018), and it is not expected to be present in the hippocampus given the age of animals used in their experiments. Thus, the manner in which increased local FGF21 expression in the adult brain might mediate a direct (paracrinelike) effect is unclear.

FGF21 may improve brain health by indirect mechanisms as well. It stimulates ketogenesis in the liver. ${ }^{11}$ Ketone bodies (acetone, acetoacetate, $\beta$-hydroxybutyrate) are efficiently transported into the brain where they serve as an alternative fuel source for oxidative metabolism (Ruderman et al., 1974). Exogenous administration of $\beta$-hydroxybutyrate in a rodent model of neonatal HIE decreased neurological injury (Lee et al., 2018a). In the same "Rice-Vannucci" model, Takenouchi et al. (2015) showed that hypothermia decreased $\beta$-hydroxybutyrate and acetyl-CoA levels in the brain. Similarly, $\beta$-hydroxybutyrate levels are slightly decreased in the gray matter in human neonates with HIE during $\mathrm{TH}$, relative to levels after rewarming (Wisnowski et al., 2016). Studies are needed to test if FGF21 supplementation during $\mathrm{TH}$ augments ketone substrate availability in the injured brain. Finally, landmark studies by Pawlosky et al. (2017) showed that dietary ketone supplementation with an ester of $\beta$-hydroxybutyrate for 8 months had remarkable benefits on the brain in 3xTgAD mice (a model of severe Alzheimer's disease). B-hydroxybutyrate supplementation was initiated at 8.5 months of age, which is after the onset of cognitive deficits and neuropathology in these mice ( $\sim 6.5$ months). B-hydroxybutyrate improved neurological outcome as measured by multiple cognitive tests, decreased pathological $\beta$ amyloid and pTau levels, decreased markers of protein/lipid oxidation, and increased levels of $\mathrm{N}$-acetyl aspartate in the hippocampus (Kashiwaya et al., 2013; Pawlosky et al., 2017). FGF21 analogues increased blood $\beta$-hydroxybutyrate levels in humans, and thus have potential to target ketogenic neuroprotective mechanisms in the clinic (Gaich et al., 2013).

Blood glucose is another important physiological target of FGF21, and a potential mechanism of its indirect benefits on brain health. Induced hyperglycemia is a complication of $\mathrm{TH}$ therapy, which might worsen brain injury outcomes (CueniVilloz et al., 2011; Kobata et al., 2017). However, hyperglycemia is managed with trepidation in the neuro-intensive care unit (ICU) because of the risk of exacerbating CNS damage by induced hypoglycemia in the brain with insulin therapy (Forni et al., 2015). FGF21 also decreases blood glucose (Kwon et al., 2015). However, unlike insulin, studies in rodents and primates showed that FGF21 normalizes blood glucose levels without inducing hypoglycemia even at a very high dose (Kharitonenkov et al., 2007) (i.e., there is a ceiling effect by which FGF21 decreases blood glucose no further). Thus, FGF21 might be a far safer drug versus insulin to control glycemia in neurocritically ill patients. Of note, the glucose-lowering actions of FGF21 are not as potent in obese human subjects versus in preclinical animal studies (Gaich et al., 2013). This may relate to species-specific differences in FGF21 signaling, or perhaps result from FGF21 resistance seen in obesity (Markan et al., 2017). Thus, the glucoselowering action of FGF21 may be more potent in metaboli- cally healthy (younger) humans suffering from acute injuries such as TBI. Furthermore, the contribution of metabolic disturbances in glucose homoeostasis and insulin insensitivity is well recognized in Alzheimer's' disease, and FGF21 may have the utility to reverse that component of pathogenesis (Yarchoan and Arnold, 2014; Willette et al., 2015; Rodriguez-Rodriguez et al., 2017).

The therapeutic time window is another important factor to consider germane to FGF21's potential for neuroprotection via direct and/or indirect mechanisms. It might be that promoting brain recovery by targeting global improvements in baseline metabolism will have the greatest success in chronic neurodegenerative diseases because therapies can be applied long term, and thus, the benefits of FGF21 would be allowed to evolve over weeks, months, or years. In contrast, in the setting of acute neurocritcal care, the therapeutic time window is comparatively short-particularly if using FGF21 as an adjuvant for $\mathrm{TH}$, which is generally applied in the hospital over 24-72 hours. One might hypothesize that particularly in infants or toddlers, where $\beta$-klotho is present, immediate IV injection of FGF21 could serve as a bridge to the induction of hypothermia-in some scenarios such as interhospital transport delaying the application of cooling, or simply augment the use of hypothermia. Thus, the direct neuroprotective effects of FGF21 may be more important in the setting of acute brain injury. Nevertheless, Xu et al. (2009) reported that a single FGF21 bolus decreased blood glucose within 1 hour after injection in obese diabetic mice. Thus, FGF21 therapy may prove useful to rapidly target glucose in the neuro-ICU, and possibly to target other peripherally mediated mechanisms, ultimately promoting neuronal survival.

\section{Irisin}

Fibronectin-like III domain containing 5 (FNDC5) is a single-pass transmembrane protein that is predominantly expressed in the muscle (Huh et al., 2012). Seminal work by Bostrom et al. (2012) reported that FNDC5 levels were increased twofold in blood plasma in adult humans after endurance exercise, which was mediated by upstream activation of peroxisome proliferator-activated receptor $\gamma$ coactivator- $1 \alpha(\mathrm{PGC}-1 \alpha)$. Treatment of adipose cells in vitro with recombinant full-length FNDC5 activated PPAR- $\alpha$, and increased UCP1 expression, oxygen consumption, and mitochondrial biogenesis (Bostrom et al., 2012). Finally, proteolytic cleavage at the c-terminus of full-length FNDC5 caused systemic release of a glycosylated protein fragment (irisin) during exercise, which mediated the aforementioned cell signaling changes in adipose cells in mice in vivo (Bostrom et al., 2012).

Irisin is increased by cooling. Lee et al. (2014) showed that cold shivering in humans significantly increased serum irisin levels. Moreover, stronger shivering responses were positively associated with higher irisin levels among study participants (Lee et al., 2014). Rhythmic muscle contractions occur during both exercise and shivering, and appear to be the link driving increased irisin expression/release. The authors also validated the authenticity of irisin by mass spectrometry; this merits additional discussion later and is expanded on below.

Irisin is also neuroprotective. Li et al. (2017a) reported that $200 \mu \mathrm{g} / \mathrm{kg}$ irisin via the tail vein, given 30 minutes after 
middle cerebral artery occlusion (MCAO) to model stroke, decreased cerebral infarct volume 3 days later. Similarly, Asadi et al. (2018) reported that administration of $7.5 \mu \mathrm{g} / \mathrm{kg}$ irisin directly into the brain (intracerebroventricular [ICV]) in MCAO-stroke-injured rats reduced neurological deficits, decreased infarct size, decreased brain edema, and decreased TUNEL staining and other markers of apoptosis. Curiously, BBB damage measured by Evans Blue extravasation was unaffected. In other studies, irisin directly increased brainderived neurotrophic factor (BDNF) in cortical neurons (Wrann et al., 2013). The Asadi study observed maximum benefit at a relatively high therapeutic dose $(7500 \mathrm{ng} / \mathrm{kg})$ (Asadi et al., 2018). For comparison, blood levels in humans after exercise is $\sim 4.3 \mathrm{ng} / \mathrm{mL}$ (Jedrychowski et al., 2015). Nevertheless, germane to its possible endogenous neuroprotective role, studies have detected irisin, using mass spectrometry, in cerebrospinal fluid (CSF) of humans in the range of $\sim 0.26-1.86 \mathrm{ng} / \mathrm{mL}$, but it has not been confirmed if it crosses the BBB or is produced locally (Ruan et al., 2018). Studies in rats and mice indicate that full-length FNDC5 protein (the precursor of irisin) is abundant in the neonatal developing brain but is almost absent in the adult rodent brain (Tanhaei et al., 2018); these findings parallel work from our group showing that protein levels of neuroprotective CSPs and $\beta$-klotho are high in the developing infant brain but absent in adults (Jackson et al., 2018). It remains to be elucidated if elevated brain FNDC5 levels during infancy represent yet another example of the manner in which the young brain is privileged to developmentally regulate neuroprotective cold stress defense mechanisms, which may uniquely communicate some of the benefits of $\mathrm{TH}$ at that age. Furthermore, it appears that differential expression of several microRNAs (miRNAs), in an agedependent manner, is partially responsible for blocking FNDC5 protein translation in the adult brain (Tanhaei et al., 2018). The FNDC5/miRNA regulatory mechanism is yet to be confirmed in humans, but studies show FNDC5 mRNA expression is extremely low in the human adult brain, whereas it is abundant in the muscle as expected (Huh et al., 2012). Thus, these findings support the notion that CSF-irisin may be derived from peripheral sources (at least in adults).

Implementing $\mathrm{TH}$ in patients involves careful attention to prevent shivering. The concern is that shivering leads to decreased brain tissue oxygenation due to higher consumption by muscle, and also increases metabolism, which might reverse a key mechanism mediating cooling-induced neuroprotection (Oddo et al., 2010). Thus, sedatives and neuromuscular blockers are routinely used to stabilize patients and control shivering (Choi et al., 2011a). Recent findings on irisin raise important questions relevant to shivering prevention protocols used during temperature management of the neurocritically ill-does sedation/neuromuscular blockade alter or prevent irisin release during TH? Might irisin represent an endogenous beneficial/neuroprotective cell signaling molecule activated by shivering that should be allowed to manifest? If so, is irisin supplementation in sedated patients during or after $\mathrm{TH}$ a reasonable alternative? Research is needed to address these and other critical questions, and to determine if they hold promise for novel solutions to better optimize $\mathrm{TH}$, particularly in adults. In addition, irisin administration decreased myocardial and pulmonary injury after ischemia in animal studies (Chen et al., 2017a; Wang et al., 2017). Thus, the benefits of irisin during $\mathrm{TH}$ extend beyond the brain, and its upregulation may be particularly advantageous in conditions where there is a risk of multiorgan injury, such as in cardiac arrest patients. Finally, germane to neurodegenerative diseases, muscle wasting is accelerated in Alzheimer's patients and is associated with brain atrophy (Burns et al., 2010). Future studies are needed to explore if irisin signaling is compromised in that population, and if it represents a potential therapeutic target.

We encourage future investigation on irisin in the setting of acute and chronic brain injury, but careful attention must be given to the methodologies used. Irisin levels are most commonly analyzed by enzyme-linked immunosorbent assay (ELISA). The limitations of ELISA, combined with questions surrounding the atypical translational start codon (ATA) of FNDC5 in humans (Raschke et al., 2013), and also other unique methodological challenges relevant to detecting irisin by Western blotting (see reference for more detailsJedrychowski et al., 2015), led to serious contestation on the existence of irisin, amid reports that the commercially available ELISAs detected artifacts and did not measure a bona fide signal (Atherton and Phillips, 2013; Albrecht et al., 2015). In recent years, independent groups have confirmed the existence of irisin, and quantified the levels in human samples using absolute quantification (AQUA) mass spectrometry (Lee et al., 2014; Jedrychowski et al., 2015; Chen et al., 2017a; Ruan et al., 2018). Thus, it is a genuine hormone that is increased in response to exercise and shivering (Lee et al., 2014). Nevertheless, concerns raised by the counter articles merit consideration. For instance, it has been shown by mass spectrometry that FNDC5 antibodies detect both nonspecific targets and bona fide irisin (Lee et al., 2014). Thus, given the controversy, it would be prudent at this investigative stage to use multiple techniques to confirm key findings on irisin levels in patient/subject samples, rather than rely exclusively on ELISAs, which preclude assessment of antibody specificity.

Exploration of irisin in the setting of neurocritical care and in chronic neurodegenerative disease is in its infancy; however, two studies in 2018, the first to our knowledge, have reported on serum irisin levels in humans with brain injury. Decreased irisin levels (i.e., lowest quartile among patients) were associated with worse short-term neurological outcome after ischemic stroke (odds ratio [OR] 1.94; 95\% confidence interval [CI] 1.19-3.42), increased mortality (OR 1.66; 95\% CI 1.11-3.07), and poststroke depression (OR 1.75; 95\% CI 1.15-2.65) (Tu et al., 2018a, 2018b). The results are intriguing, but it is unclear if stroke severity alters irisin levels, if levels directly contributed to outcome, or if irisin is a biomarker of individuals with unfavorable underlying physiology related to preexisting health problems before ischemic brain injury. Most importantly, irisin levels were measured only by ELISA in both studies, and the findings should be confirmed by mass spectrometry.

\section{Meteorin-like}

Peroxisome proliferator-activated receptor $\gamma$ coactivator$1 \alpha 4$ (PGC-1 $\alpha 4$ ) overexpressing mice have increased muscle strength (hypertrophy), energy expenditure, and decreased WAT depots (Rao et al., 2014; Ruas et al., 2012). Rao et al. (2014) identified the hormone Meteorin-like (Metrnl) in a screening assay to detect secreted factors involved in fat mobilization, downstream of PGC- $1 \alpha 4$ expression in muscle. They also found that acute environmental cold stress (24 hours $/ 4^{\circ} \mathrm{C}$ ) robustly increased Metrnl mRNA levels 
selectively in BAT/WAT, and increased protein levels in blood; the specificity of the anti-Metrnl antibody used to confirm changes in protein levels was validated in knockout (KO) mice in these studies (Rao et al., 2014).

Circulating Metrnl activates anti-inflammatory pathways in macrophages. Liver-specific Metrnl overexpressing mice had increased numbers of M2-type (Arg1+) macrophages in adipose tissue, as well as increased expression of antiinflammatory genes (IL-10, TGF- $\beta$, IL-4, and IL-13) (Rao et al., 2014). Furthermore, M2 macrophages secreted norepinephrine (>twofold increase) in the adipose tissue, which in turn stimulated thermogenic mechanisms in WAT. Metrnlinduced conversion of macrophages into an M2 phenotype was blocked by ablation of eosinophils in $\Delta$ dbIGATA transgenic mice (Rao et al., 2014).

CNS immune cells, including resident microglia and infiltrating macrophages, alter the extracellular microenvironment after a brain injury (Lan et al., 2017). M1-type (iNOS+) microglia/macrophages release proinflammatory cytokines, whereas M2 cells release anti-inflammatory factors. Truettner et al. (2017) demonstrated in rats that TH $\left(4\right.$ hours $\left./ 33^{\circ} \mathrm{C}\right)$ increased the ratio of M2:M1 microglia/lymphocytes in the injured cortex after a fluid percussion TBI. Furthermore, TH increased the expression of anti-inflammatory genes, including IL-10 and TGF- $\beta$. Because Metrnl causes similar phenotypic changes on peripheral immune cells and is induced by cold stress, future studies are needed to test if Metrnl (1) penetrates the BBB, (2) promotes conversion of M2 microglia in the CNS, and (3) if Metrnl administration might selectively boost the component of neuroprotective cooling, which targets toxic neuroinflammation in the brain.

There are little data on Metrnl signaling in brain, or in cells of the CNS such as neurons. A PubMed search on the terms "Meteorin-like AND Brain" yields three articles. None of these articles directly relate to Metrnl-regulated pathways in the brain. Furthermore, the search terms "Meteorin-like AND Neuroprotection" yield zero articles. To our knowledge, the only available data on the effect of Metrnl in neurons are found in the Supplementary section from the Rao study; the authors validated the activity of a recombinant Metrnl-Fc fusion protein on primary cortical neuron cultures in vitro, before testing its effects on signaling mechanisms in the muscle/adipose tissue in vivo (Rao et al., 2014). Metrnl-Fc dose dependently increased phosphorylation of signal transducer and activator of transcription-3 (STAT3) in primary neurons (Rao et al., 2014). Choi et al. (2011b) showed that hypothermia decreased STAT3 phosphorylation in the brain in a rat model of transient MCAO. This may be an undesirable effect of TH given that (1) increased STAT3 phosphorylation is vital for estradiolmediated CA1 hippocampal neuroprotection in a model of cerebral global ischemia, and (2) selective inhibition of astrocytic STAT3 in transgenic mice exacerbates white matter damage in a perinatal model of inflammation-mediated brain injury (Nobuta et al., 2012; Sehara et al., 2013). Thus, additional research is needed to test if cold stress-mediated Metrnl secretion might have desirable effects on STAT3 activation in the brain during hypothermia.

\section{Sex hormone binding globulin}

Sex hormone binding globulin (SHBG) is a major protein carrier of androgens and estrogens discovered in the 1960s
(Rosenbaum et al., 1966). While not a hormone per se, it merits discussion. SHBG binds with highest affinity to dihydrotestosterone (DHT), followed by 2-methoxyestradiol $>$ testosterone $>$ estradiol $>$ methyltrienolone $>$ cortisol (Hryb et al., 1990). Before the 1990s, the prevailing view was that SHBG limited the availability of free sex hormones in the blood (i.e., 1-2\% of circulating androgens/estrogens are in the unbound state (Dunn et al., 1981)). This led to the "free hormone hypothesis," which stipulated that only unbound hormones in plasma have biological activity, and thus, the main purpose of SHBG is to inhibit the effects of sex hormones (Giorgi, 1980; Mendel, 1989). Subsequent studies changed thinking. Hryb et al. (1985) showed that SHBG binds to high-affinity orphan receptors located on the membrane surface of prostate cells. Later, they developed a kinetic model to describe the interaction of unbound versus steroidbound SHBG with its orphan receptor (Hryb et al., 1990); SHBG prebound with hormone failed to attach to surface receptors (regardless of the occupying steroid). In contrast, hormone-free SHBG binds surface receptors with high affinity (receptor-primed SHBG), and on subsequent stimulation with steroids, increased the activation of intracellular cAMP (Hryb et al., 1990). Hammes et al. (2005) later elaborated on the upstream signaling mechanisms by showing that receptor-primed SHBG led to the endocytosis of testosterone in rat choriocarcinoma cells. Furthermore, megalin was identified as the SHBG orphan receptor (Hammes et al., 2005). Consistent with the notion that SHBG plays an important role in facilitating steroid activity rather than inhibiting it, megalin KO mice had severe developmental abnormalities in reproductive organs caused by deficiencies in sex hormone signaling (Hammes et al., 2005). Finally, SHBG is endocytosed in neuronal hippocampal HT22 cells in vitro, and in cells of the brain in vivo (Caldwell et al., 2007).

Two recent studies implicate SHBG as a potential target in neuroprotective cooling (Fig. 4). Deng et al. (2018) multiplexed lectin chromatography with mass spectrometry to analyze the glycoproteome in cardiac arrest patients treated with $\mathrm{TH}$, and compared the levels of identified proteins in patients who progressed to a good versus poor neurological outcome. Furthermore, two different lectins were used, concanavilin A (ConA) or wheat germ agglutinin (WGA), which preferentially bind different glycan moieties (i.e., enrich different subsets of glycated proteins). Twenty-three glycoproteins (out of 640) increased in TH-treated patients who had a good neurological outcome. SHBG was among the top 5 (i.e., highest relative levels) in patients with good neurological outcome, and surprisingly was detected by both the ConA and WGA enrichment techniques (Deng et al., 2018). Welinder et al. (2016) published the second notable study germane to SHBG and hypothermia. They analyzed the global proteome for the first time in awake versus hibernating subadult brown bears using Q-Exactive mass spectrometry. Subadult bears are roughly comparable with a 6-9-year-old child, based on the relative age of prepuberty. The largest hibernation-dependent change among all blood analytes was an enormous 45-fold increase in the protein levels of glycosylated SHBG (Welinder et al., 2016). Other proteins increased (or decreased) during hibernation, and the pattern of change was remarkably similar to the proteomic profile of adult cardiac arrest patients treated with $\mathrm{TH}$ who had a good 
neurological outcome (Welinder et al., 2016; Deng et al., 2018). The implications of these findings are unclear but raise important questions. Might TH produce the greatest neurological benefit in people (for unknown reasons), manifesting proteomic changes reminiscent of hibernation? Otherwise, could the short list of hibernation responsive proteins serve as a target engagement biomarker panel of neuroprotective $\mathrm{TH}$ in patients? Research is needed to address these questions. Also, bears are among the largest hibernating mammals, and $\mathrm{T}_{\mathrm{b}}$ during hibernation declines to a nadir of $\sim 30-32^{\circ} \mathrm{C}$ during winter, which is within the range of mild/moderate $\mathrm{TH}$ used for neuroprotection in humans (Toien et al., 2011; Welinder et al., 2016). In contrast, artic squirrels maintain a $\mathrm{T}_{\mathrm{b}}$ of $0^{\circ} \mathrm{C}$ or lower during hibernation (Barnes, 1989). Thus, adaptive cold stress mechanisms in hibernating bears may have more in common with hypothermic physiology in humans versus smaller mammals such as squirrels.

There is limited evidence to support a direct neuroprotective role of SHBG. For instance, a PubMed search on the terms "SHBG AND Neuroprotection" yields zero articles. This may be because studies have largely focused on the free hormones that SHBG regulates. A PubMed search on the terms "Testosterone AND Neuroprotection" yields 102 articles, and "Estrogen AND Neuroprotection" yields 906 articles. However, a 2017 subanalysis on data collected over 35 years, as part of The Coronary Artery Risk Development Young Adults Study (CARDIA), found an intriguing association in blood SHBG levels versus brain volume (magnetic resonance imaging [MRI]) in middle-aged men (Elbejjani et al., 2017). Specifically, higher SHBG levels correlated with increased total white matter in brain. The association was largest in temporal and frontal lobe white matter (Elbejjani et al., 2017). In contrast, higher SHBG levels correlated with decreased gray matter but only in the parietal lobe (Elbejjani et al., 2017). The consequence of SHBG levels on individual differences in gray versus white matter volume and on brain function merits additional study-particularly if SHBG is increased by TH and might influence white matter recovery.

\section{Induction of CSPs During Cold Stress: Potential Applications for Neuroprotection}

CSPs increase during cold stress and mediate cold adaptation in cells. They are usually retained intracellularly (i.e., not secreted), and levels progressively increase as core $\mathrm{T}_{\mathrm{b}}$ falls below thermoneutrality. Whereas CSHs are integral to cold defenses, CSPs are integral to cold tolerance and are potently recruited once adaptive thermogenesis mechanisms fail to maintain normothermia; however, activation of $\mathrm{CSH}$ versus CSP mechanisms overlaps to some extent. Coldinduced CSP expression appears to be intrinsic to most mammalian cell types (at least in vitro). Thus, CSP molecules have the capacity to affect signaling pathways in potentially any organ subjected to extended periods of hypothermia, which may be an important aspect of their benefit in the setting of total body cooling for neuroprotection. Recent studies, showing that overexpression of CSPs in the hippocampus mediates incredible and enduring histological and behavioral improvements in normothermic mice afflicted with severe neurodegenerative diseases, have intensified interest in cold-regulated cell signaling mechanisms in the brain. Here we review the three mammalian CSPs with the most clinical interest to date (Fig. 5).

\section{RNA binding motif 3}

Danno et al. (2000) were the first to show that cooling $\left(32^{\circ} \mathrm{C}\right.$ for 24 hours) increases RBM3 levels in mammalian cells. Subsequent studies confirmed that hypothermia increases RBM3 levels in primary neurons and in brain tissue, but the majority of evidence comes from in vitro and in vivo experiments that used models most relevant to the developing CNS. Chip et al. (2011) observed increased RBM3 mRNA levels in brain cortical organotypic slice cultures (COSCs) incubated at $32^{\circ} \mathrm{C}$ for 72 hours. Notably, RBM3 induction postcooling was blunted almost threefold in COSCs prepared from PND21 pups ( $\sim$ toddlers) versus cortices from PND4 neonates ( infants) (Chip et al., 2011). Furthermore, baseline RBM3 expression at $37^{\circ} \mathrm{C}$ was decreased in PND21 versus PND4 cortices (Chip et al., 2011). Thus, slight differences in postnatal age (by just a few weeks) profoundly altered the magnitude of RBM3 gene expression after cooling in the intact mouse brain ex vivo. This is a clear example as to why the Responsivity of Cold Stress Pathways is an important concept to consider germane to the efficacy of cooling.

Similarly, we reported that $33^{\circ} \mathrm{C}$ for 48 hours robustly increased RBM3 protein levels in cultured immature DIV6 primary rat cortical neurons but not in mature DIV26 neurons (Jackson et al., 2015). Cooling also increased RBM3 levels in pure primary rat astrocyte monocultures (Jackson et al., 2015). Larrayoz et al. (2016) reported that an environmental temperature of $8^{\circ} \mathrm{C}$ increased $\mathrm{RBM} 3$ protein levels in the rat eye; however, the magnitude of induction was greater in neonates versus adults. In neonates, RBM3 increased $\sim 30$ $40 \%$ above control levels 24 hours after exposure to $8^{\circ} \mathrm{C}$ for 15 minutes. In adults, RBM3 increased $\sim 10 \%$ above control levels 24 hours after exposure to $8^{\circ} \mathrm{C}$ for 3 hours (Larrayoz et al., 2016). Thus, a $12 \times$ shorter cold stress period induced a $4 \times$ greater RBM3 response in neonates. Of note, at normal ambient temperature $\left(24^{\circ} \mathrm{C}\right)$, baseline $\mathrm{T}_{\mathrm{b}}$ in neonates was $31^{\circ} \mathrm{C}$, whereas in adults $\mathrm{T}_{\mathrm{b}}$ was maintained at $37^{\circ} \mathrm{C}$ (Larrayoz et al., 2016). Also, 15 minutes at $8^{\circ} \mathrm{C}$ decreased core $\mathrm{T}_{\mathrm{b}}$ by $10^{\circ} \mathrm{C}$ in neonates (i.e., nadir of $21^{\circ} \mathrm{C}$ ). In contrast, 3 hours at $8^{\circ} \mathrm{C}$ decreased core $\mathrm{T}_{\mathrm{b}}$ in adults by $3^{\circ} \mathrm{C}$ (i.e., nadir of $34^{\circ} \mathrm{C}$ ) (Larrayoz et al., 2016). Newborns have a large surface area relative to volume, which makes them highly susceptible to hypothermia. Also, the large (uninsulated) head relative to body mass is a major source of heat loss (Karlsson, 1996). Thermoneutrality in a naked baby is achieved at an environmental temperature of $\sim 32^{\circ} \mathrm{C}$, whereas it ranges from $25^{\circ} \mathrm{C}$ to $28^{\circ} \mathrm{C}$ depending on age, weight, and levels of clothing (e.g., fully clothed in a cot) (Hey and O'Connell, 1970). Thus, heightened responsivity of CSP pathways in neonates may serve as a compensatory mechanism to combat cold stress, given the limited utility of nonshivering thermogenesis mechanisms to offset heat loss.

Time course studies on CSP expression profiles in normothermic brains of rats, mice, and in humans agree that RBM3 protein levels are highest in neonates/infants, rapidly decrease with increasing age, and are low or absent in adults (Pilotte et al., 2009; Chip et al., 2011; Jackson et al., 2018). Xia et al. (2018) reported that RBM3 KO mice have abnormal brain development and dysfunctional neuronal 


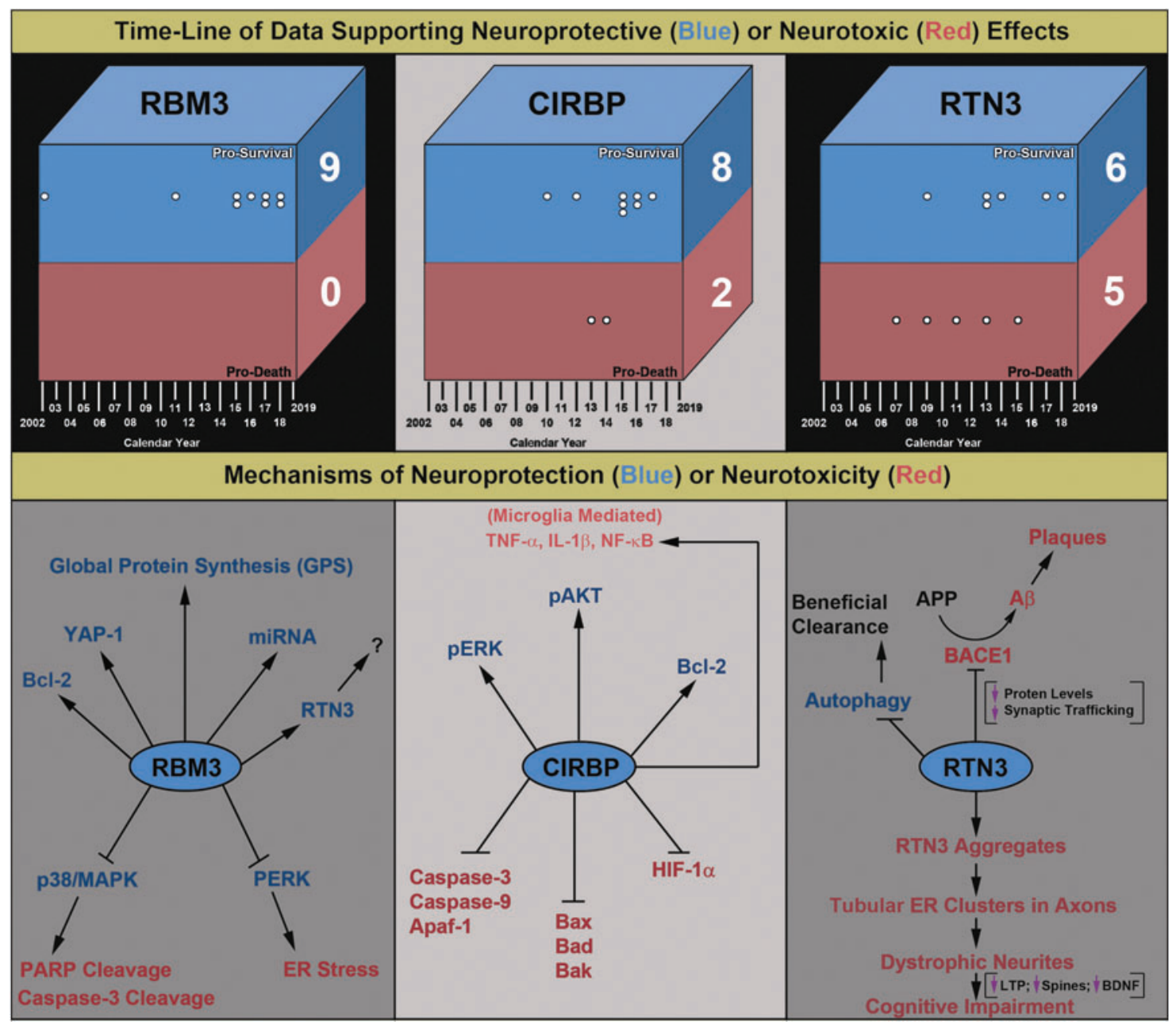

FIG. 5. Evidence supporting either a direct neuroprotective or neurotoxic function of RBM3, CIRBP, or RTN3 in the brain. Literature on RBM3, CIRBP, and RTN3 was obtained via PubMed. All articles were screened via an initial abstract review. A secondary search via Google was done to identify any additional articles not referenced in PubMed. Studies using in vitro neuronal injury paradigms (cell lines or primary neurons) or in vivo brain injury/disease models were analyzed indepth (i.e., if available). One article was in Chinese and converted to English using Google translate. Purely observational studies were identified and excluded. This figure incorporates studies that (1) overexpressed, (2) knocked down, or (3) incubated neuronal cells/tissues with a recombinant CSP (or any combination of the three) in vitro and/or in vivo, to generate a direct conclusion germane to a given CSP protective versus detrimental function(s). For the purpose of this review, we did not rate the "quality of the evidence" but noted that the scientific rigor varied considerably across studies. Top: findings were organized into "Battlefield Boxes," which summarize the opposing sides of evidence that support either neuroprotective (blue region) or neurotoxic (red region) roles of CSPs. White dots indicate individual studies and each is aligned with the year of publication. Stacked dots indicate multiple studies published in the same year. A total "Score" was given (large white numbers on the right side of the squares), which is the sum of all studies that supported either protective or detrimental functions of each CSP. The literature epoch spans approximately two decades from 2002 to 2019. Bottom: an overview of the diverse cell signaling mechanisms reported to mediate neuroprotective versus neurotoxic effects of CSPs. The proposed mechanisms are based on the experimental data presented by articles shown in the Battlefield Boxes. All articles are cited in the main text, and also listed here in order of publication date. RBM3: Kita et al., Chip et al., Zhu et al., Peretti et al., Yang et al., Bastide et al., Zhuang et al., Yang et al., Xia et al. CIRBP: Saito et al., Li et al., Rajayer et al., Zhou et al., Liu et al., Zhang et al., Li et al., Zhang et al., Wang et al., Chen et al. RTN3: Hu et al., Shi et al., Shi et al., Chen et al., Shi et al., Teng and Tang, Araki et al., Shi et al., Sharoar et al., Bastide et al., Zou et al. CIRBP, Cold inducible RNA binding protein; RTN3, reticulin-3.

differentiation only after an exposure to cold stress in utero. Thus, increased baseline RBM3 levels in the fetal brain may have evolved to protect neurodevelopmental processes against deleterious decreases in maternal temperature, such as due to sudden exposure to extreme weather conditions or periods of starvation (associated with hypothermia), which frequently impact mammals and likely were a common threat to early human ancestors. Interestingly, intrauterine hypoxia in pregnant mice decreased RBM3 mRNA levels in the unborn fetal brain (Trollmann et al., 2010). More studies are needed to determine if birth asphyxia induces long-term impairments to RBM3 cold adaptive mechanisms 
in surviving newborns, and what effect it might have on neurodevelopmental outcomes. It is important to note that, in the Xia study, cold stress was induced in pregnant mice by intraperitoneal (IP) 5-AMP bolus injection $(700 \mathrm{mg} / \mathrm{kg})$, followed by housing animals in a temperature-controlled chamber $\left(5-10^{\circ} \mathrm{C}\right)$ for 24 hours (Xia et al., 2018). The lethal dose (LD50) of 5-AMP in mice is $830 \mathrm{mg} / \mathrm{kg}$ (IV) and $4000 \mathrm{mg} / \mathrm{kg}$ (IP). At sublethal concentrations it induces a profound hypometabolic state characterized by hypothermia, decreased glycolysis, decreased oxidative phosphorylation, decreased oxygen delivery, decreased heart rate, and decreased blood pressure (Daniels et al., 2010; Zhang et al., 2013). These physiological changes are not benign. A $2000 \mathrm{mg} / \mathrm{kg}$ (IP) 5-AMP worsened histological/neurological outcomes and increased mortality in stroke-injured mice, despite inducing clinically relevant levels of hypothermia (Zhang et al., 2013). Severe hypotension induced by 5-AMP may have augmented ischemia and contributed to the exacerbation of acute brain injury. Thus, the combination of 5AMP plus environmental cooling, often referred to as a "hibernation-like" protocol, is distinct from classic "hypothermia" and does not necessarily reflect the normal sequelae of molecular events induced by $\mathrm{TH}$ in patients, to treat acute brain injury. Regardless, 5-AMP hibernation-like cooling may yield valuable molecular insights into the mechanisms of RBM3 induction and lead to better therapies targeting this pathway in the brain. Related to that point, Peretti et al. (2015) showed for the first time in a nonhibernating species that cooling mice to $16^{\circ} \mathrm{C}$ (via 5-AMP injection plus external cooling) increased RBM3 protein levels in the adult brain. Additional findings of their study are discussed later findings that have not been reported using hypothermia alone.

The depth of hypothermia also influences RBM3 expression. Tong et al. (2013) compared the effect of mild $\left(33.5^{\circ} \mathrm{C}\right)$ versus deep $\left(17^{\circ} \mathrm{C}\right)$ hypothermia on CSP expression in organotypic hippocampal slice cultures (OHSCs) prepared from P5 mouse pups. Cooling for 24 hours to $33.5^{\circ} \mathrm{C}$ potently increased RBM3 mRNA and protein expression, whereas cooling to $17^{\circ} \mathrm{C}$ did not. Likewise, recent characterization of RBM3 in the Pashmina goat revealed that moderate hypothermia to $30^{\circ} \mathrm{C}$ increased RBM3 mRNA levels, whereas deep hypothermia to $15^{\circ} \mathrm{C}$ did not (Zargar et al., 2015). Studies from our group found that hippocampal RBM3 levels in adult rats were not increased (i.e., below detection limits) immediately following 75 minutes of DHCA to $16^{\circ} \mathrm{C}$, and were also not increased 24 hours postresuscitation (presented abstract) (Drabek et al., 2017). Together the results suggest that deep hypothermic temperatures may preclude the induction of protective RBM3 mechanisms. However, as discussed above, 5-AMP-induced cooling uniquely appears to augment $\mathrm{RBM} 3$ at $16^{\circ} \mathrm{C}$ (Peretti et al., 2015) and merits additional investigation. Such an approach could have clinical utility in the setting of DHCA to promote neuroprotection during prolonged surgeries, necessitating a period of controlled ischemia, and in which patients are already on advanced life support thus reducing concerns related to managing the sequelae of 5-AMP overdose. Finally, although deep hypothermia is highly protective during ischemic insults, it is generally not effective when used after acute brain injury. One hour of mild or moderate hypothermia $\left(34^{\circ} \mathrm{C}\right.$ or $30^{\circ} \mathrm{C}$, respectively) immediately after $\mathrm{VF}$ cardiac arrest in dogs improved neurological outcomes, whereas deep hypo- thermia $\left(15^{\circ} \mathrm{C}\right)$ worsened outcomes (Weinrauch et al., 1992). It is unclear if RBM3-mediated survival mechanisms in the brain (or periphery) could have mediated some of the benefits of mild/moderate TH after cardiac arrest in these studies but were abrogated with deep cooling. Additional study is warranted.

RBM3 is a potent neuroprotectant. Kita et al. (2002) used high-throughput real-time polymerase chain reaction (RTPCR) to identify genes affected by Huntington's disease (HD) neuropathology in genetically modified rat neuronal PC12 cells. RBM3 mRNA decreased in cells expressing a toxic polyglutamine fragment (HD-74Q). Furthermore, exogenous RBM3 overexpression in human neuronal SK-N-SH cells inhibited HD-74Q-mediated cell death versus an empty vector control (Kita et al., 2002). To our knowledge, this is the only report on RBM3 in the setting of HD, and also happens to be the first study to show that RBM3 is neuroprotective. Recent work suggests that the therapeutic utility of RBM3 in HD merits further consideration. Mao et al. (2016) reported that overexpression of HD-104-Q in primary mouse cortical neurons induced a new type of necrosis (distinct from RIPK pathways), termed ballooning cell death. The upstream mechanisms involved inhibition of the transcription factor yes-associated protein (YAP), which normally promotes survival signaling. Specifically, aggregates of mutant Huntington sequestered YAP and prevented its nuclear activity; overexpression or KO of YAP inhibited or exacerbated HD-104-Q neuronal death, respectively (Mao et al., 2016). Mueller et al. (2018) recently confirmed that nuclear YAP localization is downregulated in cortical neurons of HD patients. As mentioned above, RBM3 KO mice exposed to cold stress in utero have neurodevelopmental abnormalities. The mechanism involves (loss of) RBM3 induction of the YAP (Xia et al., 2018). YAP levels are robustly increased in fetal brain after cold stress in wild type but not in RBM3 Kos (Xia et al., 2018). Furthermore, the 3'UTR of the YAP gene has seven RBM3 recognition sites, and binding to these cis-acting elements increases YAP mRNA half-life (Xia et al., 2018). Thus, evidence suggests that RBM3 targets crucial cell signaling pathways uniquely involved in the etiology of HD.

Chip et al. (2011) showed that pretreatment with hypothermia $\left(32^{\circ} \mathrm{C}\right)$ for 24 hours decreased PARP cleavage, DNA fragmentation, as well as LDH release in neuronal PC12 cells injured by staurosporine (i.e., an inducer of caspase-mediated cell death). Blocking RBM3 expression by RNA interference (RNAi) prevented the beneficial effects of hypothermia. Peretti et al. (2015) showed that hibernation-like cooling increased RBM3 levels in the brain of adult mice. Blocking RBM3 upregulation by RNAi prevented neuroprotective and cognitive improvements induced by hibernation-like cooling in transgenic mice afflicted with Alzheimer's disease (5XFAD) or inoculated with prions to induce severe neurodegeneration (tg37 mice) (Peretti et al., 2015). Remarkably, exogenous brain RBM3 overexpression in normothermic mice replicated the benefits of cooling in both disease models (Peretti et al., 2015). Zhu et al. (2016) demonstrated that ex vivo hippocampi (OHSCs) prepared from PND3 RBM3 KO pups had increased neuronal death 24 hours after thapsigargin (SERCA inhibitor) treatment to induce ER stress. Interestingly, thapsigargin-mediated neuronal death, involving PERK/CHOP activation and downregulation of Bcl-2, 
was exacerbated in Kos at $37^{\circ} \mathrm{C}$ but not at $32^{\circ} \mathrm{C}$ (Zhu et al., 2016). Infants uniquely express high levels of RBM3 in the normothermic hippocampus (Jackson et al., 2018). Thus, future studies are needed to test if the injured normothermic newborn brain might be more resilient to ER stress-mediated cell death mechanisms relative to adults due to higher baseline RBM3 levels. Moreover, Zhu et al. (2016) also observed that RBM3 Kos had increased hippocampal peIF2 $\alpha$ levels at baseline and during cold stress. Increased peIF $2 \alpha$ stimulates FGF21 gene expression in the hippocampus (Restelli et al., 2018). Moreover, we found that recombinant FGF21 increased RBM3 levels at $36^{\circ} \mathrm{C}$ in cortical neurons in vitro (Jackson et al., 2015). Thus, we speculate that FGF21 levels might be increased in RBM3 KO mice (i.e., a feedback mechanism).

Yang et al. (2017) showed that RBM3 overexpression in neuronal SHSY5Ys decreased nitric oxide (NO)-induced cell death. The mechanism of neuroprotection involved inhibition of p38 kinase, and was blocked by simultaneous overexpression of mir-143. Similarly, Zhuang et al. (2017) showed that RBM3 overexpression in SHSY5Ys decreased p38 activation, PARP cleavage, and caspase- 3 activation, and increased cell viability following ultraviolet radiation injury. Bastide et al. (2017) showed in a neurodegenerative model of prion disease that the neuroprotective effects of RBM3 in the hippocampus in vivo are mediated, in part, by the expression of reticulin-3 (RTN3). Yang et al. (2018) showed that RBM3 overexpression in neuronal SHSY5Ys decreased PARP cleavage and caspase $3 / 7$ activity after 24 hours $3 \mathrm{mM}$ MPP+ to model mechanisms of injury in Parkinson's disease. Finally, RBM3 may mediate neuroprotection by additional mechanisms as well. Acute brain injury is well-known to decrease GPS, which precedes the onset of delayed neuronal death (Neumar et al., 1998; de la Vega et al., 2001). RBM3 increases GPS in vitro and in the brain in vivo by a mechanism that involves upregulation of miRNAs (Dresios et al., 2005; Pilotte et al., 2011; Peretti et al., 2015). Preserving GPS likely promotes neuronal survival.

Although no detrimental effects of RBM3 overexpression have been reported in models of neuronal injury, there may be risks associated with pharmacologically increasing RBM3 systemically. Wong et al. (2016) reported that blood RBM3 mRNA levels decreased in febrile children (independent of the underlying illness) versus healthy controls or children with infections who did not have a fever. Thus, increased temperature, not infection or inflammation, mediated decreased RBM3 levels. Furthermore, RBM3 protein levels decreased sixfold in macrophages exposed to hyperthermia $\left(40^{\circ} \mathrm{C}\right)$ for 24 hours, in turn mediating an increase in expression of "thermomiRs," temperature sensitive miRNAs, and in turn downregulated pyrogenic genes (Wong et al., 2016). Thus, lowering RBM3 below baseline levels switches off fever-inducing pathways. The net implications or concern, germane to brain injury, is that in theory pharmacologically increasing RBM3 levels in the periphery for an extended period might increase circulating pyrogens and increase susceptibility to an acquired fever. Such a phenomenon (if confirmed) could be managed effectively in the neuro-ICU as cooling devices are routinely used to clamp temperature in patients with acute brain injury (i.e., $\mathrm{TH}$ or TTM). However, it might be problematic in normothermic patients with chronic neurodegenerative diseases, particu- larly given that even mild hyperthermia $\left(1-2^{\circ} \mathrm{C}\right)$ synergizes with CNS damage to devastating effect in models of brain injury (Baena et al., 1997; Sakurai et al., 2012).

There are few options (small molecules or biologics) to therapeutically increase RBM3 levels in neurons. Our group reported (2015) that FGF21 and melatonin augmented RBM3 protein levels in young primary cortical neurons cooled to $36^{\circ} \mathrm{C}$ for 24 hours but not in cells maintained to $37^{\circ} \mathrm{C}$, or in older cultures (Jackson et al., 2015). FGF21 may be useful to target RBM3 in infants/toddlers because $\beta$-klotho expression is abundant in the brain at those ages (Jackson et al., 2018). Papadima et al. (2017) showed in vitro that lithium (1 mM) for a week increased RBM3 mRNA aprpoximately 30-40\% above controls in human neural progenitor cells. Toxic compounds also increase RBM3 mRNA levels. Ryan et al. (2005) administered domoic acid to activate kainate receptormediated excitotoxicity in the mouse brain, and observed a transient increase in RBM3 mRNA 60 minutes postinjection. Baghdoyan et al. (2000) showed that RBM3 mRNA increased in human primary $\mathrm{CD} 34^{+}$macrophages in vitro after 8 hours of treatment with granulocyte/macrophage colony stimulating factor (GM-CSF). Finally, some compounds decrease RBM3 levels. Jo et al. (2012) reported that antifreeze protein III improved viability of vitrified mouse oocytes, and subsequently decreased RBM3 mRNA levels on rewarming (presumably caused by reduced cold stress). Laustriat et al. (2015) observed an approximately threefold decrease in RBM3 protein levels in human mesodermal precursor cells treated in vitro with metformin for 48 hours. Thus, more research is needed to elucidate drugs that target the RBM3 pathway in the brain.

\section{Cold inducible RNA binding protein}

Nishiyama et al. (1997) were the first to report that cold inducible RNA binding protein (CIRBP) is a mammalian CSP. Cooling $\left(32^{\circ} \mathrm{C}\right)$ increased CIRBP levels within 1 hour in mouse fibroblasts, and highest levels were achieved by $12-$ 24 hours. They also identified diurnal changes in CIRBP mRNA expression in the mouse brain; levels peaked at 6 p.m. and decreased to a nadir at 3 a.m. (Nishiyama et al., 1998). Furthermore, we reported that CIRBP is abundant in the normothermic human infant hippocampus and cortex but is absent in adolescents and in adults (Jackson et al., 2018). Thus, developmental age and circadian rhythm regulate baseline levels of CIRBP in the brain. More work is needed to test if CSHs regulate developmental and/or diurnal expression of CIRBP mRNA in the CNS. However, FGF21 or melatonin, compounds that are both endogenously regulated by circadian cycles in vivo, failed to augment CIRBP levels at $36^{\circ} \mathrm{C}$ in young DIV6 cortical neurons in vitro (Jackson et al., 2015).

Subsequent studies confirmed that hypothermia increases CIRBP levels in primary neurons in vitro and in the brain in vivo. Li et al. (2012) reported that exposure of cultured rat cortical neurons to $32^{\circ} \mathrm{C}$ for 2 hours increased CIRBP levels. Similarly, Zhang et al. (2015) reported that exposure of DIV7 cultured rat cortical neurons to $32^{\circ} \mathrm{C}$ for 12 hours increased CIRBP levels. In contrast, Tong et al. (2013) reported that exposure to $33.5^{\circ} \mathrm{C}$ failed to increase CIRBP levels 4,24 , or 48 hours in ex vivo PND5-derived mouse hippocampi, mouse neuronal HT22 cells, or in microglial BV-2 cells. However, 
CIRBP mRNA levels increased postcooling at all three time points in all three culture systems (Tong et al., 2013). Thus, rapid and sustained increases in CIRBP mRNA levels at $33.5^{\circ} \mathrm{C}$ did not translate to increased protein levels. We reported similar findings. Cooling to $33^{\circ} \mathrm{C}$ for $24-48$ hours failed to increase CIRBP levels in DIV10-11 rat cortical neuron cultures (Jackson et al., 2015). Additional work is needed to test if a $1^{\circ} \mathrm{C}$ difference in temperature used across studies (i.e., $32^{\circ} \mathrm{C}$ vs. $33^{\circ} \mathrm{C}$ ) could have affected CIRBP expression levels. Clarification of the temperature(s) and exposure time(s) required to increase neuronal CIRBP (and other CSPs) may impact study design of future in vivo investigations (Chandrasekaran et al., 2015). However, deep hypothermia to $15-17^{\circ} \mathrm{C}$ failed to increase mRNA or protein levels in fibroblasts, HT-22, BV-2 cells, or ex vivo hippocampi obtained from PND5 mouse pups (Nishiyama et al., 1997; Tong et al., 2013). Thus, it appears that the optimal depth of hypothermia to induce CIRBP falls within the mild/moderate range (much like RBM3).

Total body cooling also increases brain CIRBP expression in vivo. Wang et al. (2016) induced hypothermia $\left(31^{\circ} \mathrm{C}\right)$ in adult $\sim 3$-month-old rats under anesthesia for 48 hours, and observed increased CIRBP levels in the hypothalamus at 2448 hours postcooling. Wu et al. (2006) induced $\mathrm{TH}(\sim 32-$ $34^{\circ} \mathrm{C}$ ) for 6 hours immediately after ROSC in a rat model of VF cardiac arrest, and observed increased CIRBP levels in the hippocampus. Of note, normothermic VF cardiac arrestinjured controls also had increased hippocampal CIRBP levels versus shams, and cooling augmented the increased expression. The effect of increased brain CIRBP levels on histological and neurological outcomes was not elucidated. Kaneko and Kibayashi (2012) housed adolescent ( PND42) conscious mice in a temperature-controlled chamber set to $\sim 4^{\circ} \mathrm{C}$ for $24-48$ hours. Rectal temperature $\left(\mathrm{T}_{\mathrm{b}}\right)$ decreased to $\sim 33-35^{\circ} \mathrm{C} 24$ hours later, and CIRBP mRNA increased in the olfactory bulb and in the hypothalamus (Kaneko and Kibayashi, 2012). Similarly, Wang et al. (2015) observed increased CIRBP levels in the hippocampus, cortex, cerebellum, heart, muscle, liver, and BAT in adolescent ( PND42) conscious rats housed at $4{ }^{\circ} \mathrm{C}$ for 6 hours/d, for a total of 14 consecutive days. On experimental day 1 (PND42), 6 hours of cooling decreased rectal temperature to $\sim 32^{\circ} \mathrm{C}$. Each consecutive day thereafter, the decrease in $\mathrm{T}_{\mathrm{b}}$ was progressively smaller and absent on day 13 (PND55) (Wang et al., 2015). It remains to be determined if chronic environmental cold stress similarly increases CIRBP levels in the brain of adult rodents, and in which thermogenesis mechanisms have fully matured.

Studies suggest that CIRBP is neuroprotective. However, evidence is limited. Saito et al. (2010) reported that CIRBP knockdown in MEB5 mouse neural stem cells prevented hypothermia-mediated neuroprotection $\left(32^{\circ} \mathrm{C} / 24-48\right.$ hours $)$ induced by growth factor deprivation, and increased the number of apoptotic nuclei measured by Hoechst33342 staining. Li et al. (2012) observed an approximately twofold increase in CIRBP levels in primary rat cortical neurons after brief cooling ( 2 hours to $32^{\circ} \mathrm{C}$ ). Hypothermia prevented increased apoptotic Annexin/PI cell labeling (quantified by flow cytometry) and decreased caspase- 3 activation 2 hours after treatment with $100 \mu \mathrm{M} \mathrm{H}_{2} \mathrm{O}_{2}$, whereas CIRBP knockdown blocked cooling-induced neuroprotection (Li et al., 2012). Liu et al. (2015) treated mouse Neuro2a cells with
$100 \mathrm{ng} / \mathrm{mL}$ recombinant $\mathrm{CIRBP}$ at $37^{\circ} \mathrm{C}$ and after $60 \mu \mathrm{M}$ $\mathrm{H}_{2} \mathrm{O}_{2}$ injury, survival was increased $(\sim 15-20 \%)$ in cells treated versus controls. Treatment also increased phosphorylation (activation) of the protective kinases pERK and pAKT.

Neuronal culture age alters the expression of cell death proteins in vitro, and naive immature (young) neurons have the highest level of proapoptotic caspase-3 (Lesuisse and Martin, 2002; Kim et al., 2007). Zhang et al. (2015) quantified Annexin/PI staining by flow cytometry in uninjured primary rat cortical neuron cultures at DIV4, 7, and 10. DIV7 cultures maintained to $37^{\circ} \mathrm{C}$ had the largest fraction of PIstained neurons (late apoptosis) relative to other culture ages, and hypothermia ( 12 hours to $32^{\circ} \mathrm{C}$ ) decreased PI staining by $\sim 25 \%$. Furthermore, hypothermia increased protective proteins, including CIRBP, Bcl-2, and AKT-whereas it decreased apoptotic proteins, including Bax, Bad, Bak, caspase3, caspase-9, and Apaf1 (Zhang et al., 2015). The beneficial effects of cooling were blocked by CIRBP knockdown (Zhang et al., 2015). Li et al. (2015) reported similar findings. Hypothermia $\left(32^{\circ} \mathrm{C}\right)$ decreased baseline levels of developmentally regulated apoptosis in primary rat hippocampal neurons in vitro, and CIRBP knockdown blocked the prosurvival effects of cooling.

CIRBP is also neuroprotective after a TBI. Wang et al. (2016) maintained hypothermia $\left(31^{\circ} \mathrm{C}\right)$ for 48 hours in anesthetized adult rats administered food and water via gastrostomy. CIRBP levels increased in the hypothalamus within 6 hours of cooling and remained elevated 72 hours later. Furthermore, hypothermia decreased TUNEL staining (apoptosis) in the cortex, hippocampus, and hypothalamus 96 hours after a lateral fluid percussion TBI (Wang et al., 2016). Intrathecal injection of an adenoviral vector to knockdown CIRBP (before injury) decreased target protein levels after hypothermia, and worsened brain injury as indicated by increased TUNEL staining post-TBI (Wang et al., 2016). The lack of traditional preclinical TBI outcome measures prevented a direct comparison of CIRBP protective effects relative to other reports on neuroprotective strategies in this model. Nevertheless, the 48-hour hypothermia protocol is intriguing. In rodents, neuroprotection is achieved with short durations of cooling (e.g., 4 hours to $33^{\circ} \mathrm{C}$ in fluid percussion TBI) (Truettner et al., 2017). Thus, longer durations of hypothermia are uncommon. It would be interesting to test if other CSPs (e.g., RBM3) increased in the adult rat brain after an extended period of hypothermia.

Finally, CIRBP inhibits chronic hypoxia-induced neuronal death. Zhang et al. (2017) overexpressed CIRBP in a mouse cerebellum-derived neural progenitor cell line (C17.2). Hypoxia $\left(1 \% \mathrm{O}_{2} / 37^{\circ} \mathrm{C}\right.$ for 24 hours $)$ decreased proliferation (EdU staining) in cells transfected with an empty vector control plasmid but not in cells overexpressing CIRBP. Chen et al. (2017b) observed increased protein levels of HIF-1 $\alpha$, Bax, and cleaved caspase- 3 in neuronal SHSY5Ys subjected to hypoxia for 48 hours $\left(1 \% \mathrm{O}_{2} / 37^{\circ} \mathrm{C}\right)$. Apoptosis also increased 48 hours later as determined by Annexin/PI staining. CIRBP overexpression prevented the upregulation of prodeath protein targets, including HIF- $1 \alpha$ and decreased apoptosis.

However, CIRBP also has neurotoxic effects. Rajayer et al. (2013) observed increased brain CIRBP mRNA and protein levels 10 hours after alcohol intoxication in mice. 
Pro-inflammatory cytokines (TNF- $\alpha$ and IL- $1 \beta$ ) increased in the brain in wild-type mice but not in CIRBP Kos. Furthermore, CIRBP, TNF- $\alpha$, and IL- $1 \beta$ mRNA levels increased in microglial BV-2 cells treated with alcohol for 48 hours, and high levels of CIRBP were detected in the culture medium suggesting increased secretion (Rajayer et al., 2013). Zhou et al. (2014) reported that cerebral infarct volume (TTC staining) decreased approximately threefold in CIRBP KO versus Wt mice 30 hours after permanent MCAO to model stroke. Treating BV-2 cells with $1 \mu \mathrm{g} / \mathrm{mL}$ rCIRBP for 20 hours increased TNF- $\alpha$ protein levels in the culture medium, and increased $\mathrm{NF}-\kappa \mathrm{B}$ gene promoter activity on a reporter assay (Zhou et al., 2014). In contrast, $1 \mu \mathrm{g} / \mathrm{mL} \mathrm{rCIRBP}$ failed to significantly increase caspase activity in differentiated human neuronal SHSY5Ys versus untreated controls. However, in the same experiment, treatment with $5 \mathrm{ng} / \mathrm{mL}$ rTNF- $\alpha$ significantly increased caspase activity (Zhou et al., 2014). Thus, CIRBP does not appear to be directly toxic to neurons but rather promotes neuroinflammation (in the presence of microglia), which can indirectly augment neuronal injuryalthough both detrimental and beneficial effects of neuroinflammation are well described (Simon et al., 2017). We have found that treating mixed astrocyte/cortical neuron cocultures with $1 \mu \mathrm{g} / \mathrm{mL}$ rCIRBP immediately before a $75 \%$ mechanical stretch-injury, to model in vitro TBI, did not exacerbate (or improve) cell death 24 hours later, as measured by increased LDH release (unpublished observations).

Given these conflicting results, more work is needed to clarify the role of CIRBP on neuronal survival and neuroinflammation in vivo, particularly in the setting of TH. Indeed, $\mathrm{TH}$ has been shown in some studies to inhibit neuroinflammation in vivo, including downregulating TNF- $\alpha$ and IL$1 \beta$, which has been suggested to be an important mechanism mediating its protective effects on the brain (Meybohm et al., 2010; Tomura et al., 2012). However, as discussed previously in this review, the effects of TH on either neuroinflammation or systemic inflammation are conflicting and inhibitory effects are not always seen clinically (Buttram et al., 2007; Callaway et al., 2008). In addition, to the best of our knowledge, CIRBP has not been directly studied in chronic conditions such as Alzheimer's disease. However, Akila Parvathy Dharshini et al. (2018) identified CIRBP among a short list of genes harboring a nonsynonymous substitution selectively in the temporal lobe of Alzheimer's patients, but the implication of that finding remains to be determined. The role of CIRBP in both acute and chronic CNS insults remains to be elucidated.

There are several promising therapies to target CIRBP in vivo. Coderch et al. (2017) identified the first small-molecule CIRBP inducers. A single IP bolus of compound $\mathrm{Zr} 17-2$ ( $\sim 6.5 \mu \mathrm{g} / \mathrm{kg}$ ) increased CIRBP levels in the lung and in the pancreas 4 days later in normothermic rats and CIRBP levels modestly increased in the cerebral cortex. The mechanism(s) by which Zr17-2 upregulates CIRBP are unclear but may involve stabilization of flexible regions located at the terminal ends of the protein. It is also unclear if $\mathrm{Zr17}-2$ binding alters the functionality of CIRBP (i.e., increases or decreases target engagement). Nevertheless, Zr17-2 is a first step toward the development of drugs that target increased CSPs at $37^{\circ} \mathrm{C}$.

Dietary modification is also a potential approach to increase CIRBP levels in the brain. Oishi et al. (2013) showed that a 2 -week ketogenic diet decreased the average daily $\mathrm{T}_{\mathrm{b}}$ in mice by $1^{\circ} \mathrm{C}$ (i.e., within the range of $\mathrm{UMH}$ ). Furthermore, $\mathrm{T}_{\mathrm{b}}$ fluctuates in a diurnal pattern, and mice maintained on a ketogenic diet had the lowest absolute temperature late night (nadir to $\sim 35^{\circ} \mathrm{C}$ ) versus controls, and CIRBP/FGF21 mRNA levels increased in the liver at that time point (Oishi et al., 2013). Total calorie content was equivalent in mice fed a ketogenic versus standard diet, indicating that the induction of UMH, and increased CIRBP expression, was not due to caloric restriction. Exogenous administration of ketones, in some models, improves histological outcomes after an acute brain injury and decreases neuropathology/cognitive impairment in chronic neurodegenerative disease (Kashiwaya et al., 2013; Pawlosky et al., 2017; Lee et al., 2018a). It is unclear if neuronal CIRBP levels might be increased by administration of ketones in the setting of brain injury, and if it influences recovery (i.e., direct CIRBP-mediated neuroprotective effects versus harmful activation of proinflammatory microglia).

\section{Reticulon-3}

The RTN3 gene was identified by Moreira et al. (1999). The canonical sequence encodes a $\sim 25 \mathrm{kDa}$ protein (RTN3A1), and mRNA levels are highest in the brain. Di Scala et al. (2005) later reported additional RTN3 splice variants. Moreover, developmental age altered the protein levels of several isoforms in the cerebellum (E18-PND35). The smallest variant (RTN3C) migrated as a double band at $\sim 16 / 19 \mathrm{kDa}$ on SDSPAGE (Di Scala et al., 2005). The $16 \mathrm{kDa}$ protein decreased, whereas the $19 \mathrm{kDa}$ protein increased in PND35 mice. In contrast, canonical RTN3A1 levels were not altered by age (E18-PND35) in the cerebellum (Di Scala et al., 2005). Shi et al. (2009a) reported that RTN3A1 is stably expressed in the cerebellum in adult mice (2-24 months); however, levels increased in the hippocampus in an age-dependent manner. Conversely, Kumamaru et al. (2004) observed decreased RTN3A1 staining in the adult versus embryonic mouse retina. We also reported decreased levels of RTN3A1/RTN3C in the hippocampus/cortex in adults versus infants (Jackson et al., 2018). Thus, additional work is needed to clarify the levels of RTN3 protein variants in the brain across the life span in rodents and humans.

Bastide et al. (2017) reported that RTN3A1 is a novel CSP. Cooling 24 hours to $32^{\circ} \mathrm{C}$ increased RTN3A1 levels in neuronal SHSY5Ys. Moreover, hibernation-like cooling to $16^{\circ} \mathrm{C}$ increased RTN3A1 levels in an RBM3-dependent manner in the adult mouse hippocampus (Bastide et al., 2017). Also, hibernation-like cooling decreased neuropathology in mice with prion disease, but the beneficial effects of hypothermia were blocked by RTN3A1 knockdown in the hippocampus (Bastide et al., 2017). Conversely, Chen et al. (2011b) reported that RTN3A1 knockdown increased survival (rather than exacerbate damage) in an in vitro model of prion disease in neuronal N2a cells maintained to $37^{\circ} \mathrm{C}$. The mechanism of protection involved the activation of autophagy, which increased prion clearance. Finally, in the setting of apoptosisinducing stimuli, RTN3A1 overexpression decreased cell death after serum deprivation or chemical injury with staurosporine or etoposide in neuronal SHSY5Y cells (Teng and Tang, 2013).

RTN3A1 is a potent modulator of Alzheimer's disease pathogenesis. Beta-site amyloid precursor protein-cleaving 
enzyme 1 (BACE1) promotes processing of amyloid precursor protein (APP) into beta-amyloid $(\mathrm{A} \beta)$, which can form senile plaques in the brain (Masters et al., 2015). Inhibition of BACE1 is a putative therapy for Alzheimer's disease, and RTN3A1 indirectly inhibits BACE1 activity by two mechanisms. First, in vitro studies in hippocampal/cortical neurons show that RTN3A1 inhibits axonal transport of BACE1 into the synapse, which limits the interaction with APP, decreasing the levels of cleavage products (Deng et al., 2013). RTN3A1 also decreases the total levels of BACE1 in the brain (Shi et al., 2014). Consistent with these findings, Shi et al. (2009b) reported that $\mathrm{A} \beta$ plaque deposition in the cortex and in the hippocampus (CA3/DG) of 6-month-old APP/PS1 mice was decreased by overexpressing RTN3A1 in the brain. Multiple neurotoxic fragments $\left(\mathrm{A} \beta_{1-40}\right.$ and $\left.\mathrm{A} \beta_{1-42}\right)$ were decreased in the cortex in RTN3A1 overexpressing mice (Shi et al., 2009b). Similar results were reported by others (Araki et al., 2013). Conversely, RTN3A1 gene KO in 6-month-old AAP/PS1 mice increased the rate of APP processing, and increased $\mathrm{A} \beta$ plaque deposition in the forebrain (Shi et al., 2014). Finally, Zou et al. (2018) identified dysfunctional RTN3A1 mutants in Alzhermier's patients caused by singlenucleotide polymorphisms; overexpression of RTN3A1 mutants in vitro led to either decreased BACE1 gene expression or increased (i.e., aberrant) axonal transport in neurons. Thus, wild-type RTN3A1 is neuroprotective in the setting of Alzheimer's disease by targeting $\mathrm{A} \beta$ burden in critical brain structures.

RTN3 is also neurotoxic. Hu et al. (2007) reported that RTN3A1 overexpression in the normal adult mouse brain induced the formation of "RTN3 immunoreactive dystrophic neurites" (RIDNS). RIDNS are caused by polymerization of RTN3A1 monomers into toxic high-molecular-weight aggregates, which lead to the accumulation of abnormal tubular ER in axons (Sharoar et al., 2016). Interestingly, RTN3A1 aggregates are increased in cultured primary mouse neurons treated with $20 \mathrm{nM} \mathrm{A} \beta_{1-42}$, demonstrating a potentially vicious cycle between fibril plaque formation and RIDNS neuropathology (Hu et al., 2007). Increased RIDNS burden in the mouse brain correlated with greater learning impairment on the Barnes maze, and disrupted electrophysiology in hippocampal slices ex vivo (Hu et al., 2007). Furthermore, RIDNS develop naturally and are detected in the CA1 hippocampus in 24-month-old wild-type mice (Shi et al., 2009a). Neuronal spine density is decreased in the CA1 in mice with increased RINDS burden. Finally, preventing the formation of RTN3A1 aggregates in CA1, using a conditional $\mathrm{KO}$ approach, increased hippocampal BDNF levels, and preserved contextual-cued memory on a fear conditioning paradigm (Shi et al., 2013).

The complex interplay between the activation of RTN3mediated neuroprotective versus neurotoxic mechanisms suggests the need to elucidate the consequences of increased RTN3 expression in the setting of TH. It is unclear if RTN3 activates different cell signaling programs depending on the temperature (e.g., $37^{\circ} \mathrm{C}$ vs. $33^{\circ} \mathrm{C}$ vs. $16^{\circ} \mathrm{C}$ ) or age (e.g., adults vs. infants). Also, the benefits versus risks of increased RTN3 may differ depending on the type of acute brain insult. For instance, Zhao et al. (2013) reported that $300 \mu \mathrm{M} \mathrm{H}_{2} \mathrm{O}_{2}$ robustly increased high-molecular-weight (toxic) RTN3 aggregates in human neuronal SHSY5Ys. Oxidative stress is increased during a cardiac arrest, and the majority of oxida- tive brain damage occurs early after global ischemia (Wiklund et al., 2018). Studies in piglets showed that $\mathrm{TH}$ to $\sim 33^{\circ} \mathrm{C}$ had limited efficacy to prevent oxidative brain injury after a cardiac arrest if cooling was initiated 30 minutes postROSC (Wiklund et al., 2018). TH is generally applied within 6 hours post-ROSC clinically. Augmenting RTN3 in the setting of cardiac arrest may be detrimental because intracellular conditions already favor (before hypothermia) the formation of RTN3 aggregates. However, the development of IV therapies that immediately block oxidative brain damage before or early after reperfusion might prevent RTN3 aggregation and favor its neuroprotective effects. Another example is in the setting of a TBI, which is associated with increased $\mathrm{A} \beta$ plaques in the brain (Tran et al., 2011) [see Johnson et al. (2010) for additional review]. Inhibition of BACE1 by TH-induced RTN3 may represent a feasible therapeutic strategy to reduce $\mathrm{A} \beta$ deposition after CNS trauma. In summary, RTN3 is one of the newest members of the CSP family. More research is needed to clarify its potential role(s) in the setting of acute brain injury, to determine if it is induced by clinically relevant levels of hypothermia in vivo, and if it represents a beneficial or detrimental component of the cold shock response.

\section{Hypothermia in a Syringe: An Auxiliary Approach to Cooling in the Neuro-ICU and a Case Example in Managing the Sickness of Long-Duration Spaceflight}

A variety of approaches have been investigated to chemically induce hibernation-like physiology in humans. Safar et al. (2000) in the early 2000s reported remarkable brain tissue sparing effects of 60-120 minutes "suspended animation" (SA) also called EPR, by infusion of $2-4^{\circ} \mathrm{C}$ saline in exsanguinated dogs (Woods et al., 1999; Behringer et al., 2003). Woods et al. (2000) later tested if adenosine, a neuroactive compound that regulates hibernation in squirrels, augmented hypothermic neuroprotection with saline flush in that model (Jinka et al., 2011). Hydrogen sulfide $\left(\mathrm{H}_{2} \mathrm{~S}\right)$ is another promising agent to induce SA-like states (Blackstone et al., 2005). However, Hemelrijk et al. (2018) recently contested its long-assumed mechanism of action by showing that $\mathrm{H}_{2} \mathrm{~S}$ does not cause hypothermia in normoxic mice $\left(\mathrm{FiO}_{2}\right.$ 0.21 ) but rather augments hypoxia-induced anaprexia at an $\mathrm{FiO}_{2}$ of 0.17 or $0.05 . \mathrm{H}_{2} \mathrm{~S}$ also failed to induce hypothermia in large animals such as pigs or piglets (Li et al., 2008; Drabek et al., 2011).

How might "Hypothermia in a Syringe" differ from prior concepts to chemically induce neuroprotective cooling? A key difference is that cooling is not the main objective. Rather, the objective is to recreate the cell signaling environment activated by CSH/CSP responses during cold stress, but (optionally) with or without hypothermia. In this way Hypothermia in a Syringe could be applied to normothermic patients in whom complex cooling instrumentation is simply not practical (e.g., artic sun device in conscious Alzheimer's patients), or takes time to induce. Similarly, a Hypothermia in a Syringe approach, if accomplished at normothermia, could be implemented without any of the traditional side effects of cooling. Hypothermia in a Syringe might also be able to synergize with additional mechanisms of neuroprotection induced by TH in patients (Fig. 6). In theory, we envision a drug mixture that might comprise a combination of agents such as 


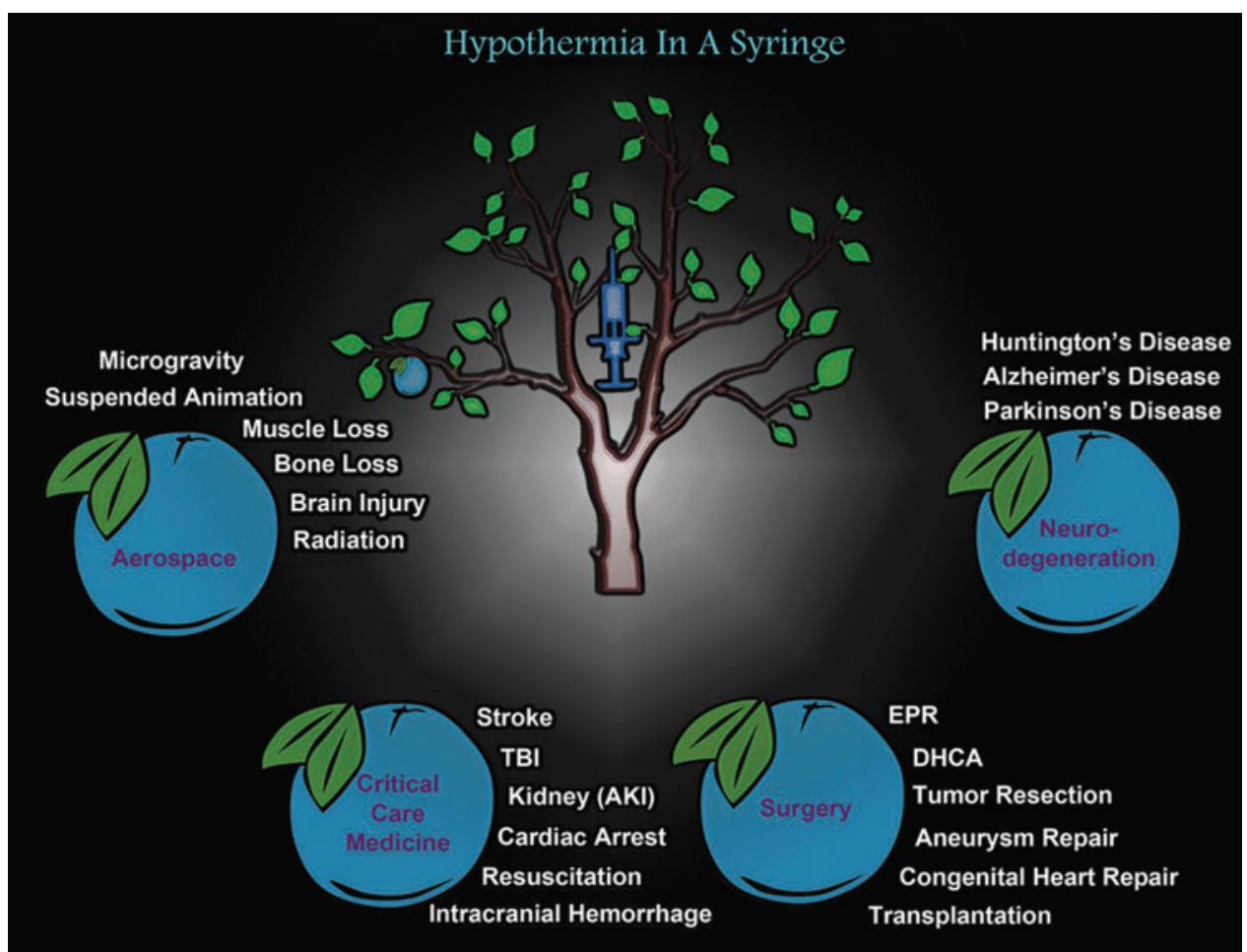

FIG. 6. Medical conditions amenable to a "Hypothermia in a Syringe" strategy. Hypothermia in a Syringe is the theoretical concept that CSH/CSP levels can be (collectively) pharmacologically manipulated in normothermic or hypothermic patients to mimic (or augment) aspects of beneficial cold response physiology and cell signaling cascades. The illustration shows examples of major research fields (individual fruits), and medical conditions relevant to each (white text), which may represent low-hanging fruit for clinical translation. Prioritization of the "lowest hanging fruit" is left to the reader to interpret given that the metaphor is context dependent (e.g., the lowest hanging fruit might represent a condition most applicable to a therapy, or alternatively a condition via which a therapy is able to translate into the clinic the fastest).

FGF21, Meternl, Irisin, SHBG, RBM3 agonist, CIRBP agonist, and/or an RTN3 agonist (and other components added or excluded). Notably, the concepts of "depth and duration" might also be relevant to Hypothermia in a Syringe. The magnitude increase (or decrease) of endogenous CSHs/CSPs varies based on the depth and duration of hypothermia in cells. Thus, target tissue levels achieved via an artificial approach (i.e., based on IV loading dose) might replicate unique states of altered cell signaling corresponding to specific hypothermic "depths," and would need to be optimized. The concept of Hypothermia in a Syringe is certainly speculative, but arguably, it dovetails with additional ideas to improve the efficacy of $\mathrm{TH}$ in the treatment of acute or chronic brain injury. It might take decades for such a combinatorial therapy to be developed, and other adjuncts beyond simply drug administration may be necessary. Recognizing the speculative nature of this concept, we discuss its potential utility in one of the most logical and potentially useful setting, namely, exploration of deep space.

NASA's Human Research Program is expected to publish the integrated findings on the Twins Study (www.nasa.gov/ feature/nasa-twins-study-investigators-to-release-integratedpaper-in-2018) in the coming months. This historic report represents the largest genomic analysis ever done to understand the long-term effects of space on the human body, and reinforces the extent that investments are being made to improve health care in astronauts. In addition, numerous stakeholders in the Aeronautics and Astronautics industry have proposed plans to travel to Mars by the late 2020-2030s, or to house tourists inside orbital or suborbital enclosures for extended excursions. For these efforts to succeed, medicines must be developed to combat the potentially harmful physiological changes induced by weightlessness, prevent tissue damage caused by increased exposure to radiation, and simplify the delivery of advanced medical techniques in microgravity. Kirkpatrick et al. (2009) speculated on the potential utility of chemically induced SA in astronauts in the setting of emergency surgical repair of traumatic injuries during exploration class missions. Similarly, Cerri et al. (2016) discussed the utility of adenosine precursor 5-AMP to induce hibernation-like torpor during long-distance space travel (Cerri et al., 2016). How might Hypothermia in a Syringe synergize with these concepts?

Multiple physiological changes or injury mechanisms induced by long-duration spaceflight are also modulated by $\mathrm{CSH} / \mathrm{CSP}$ pathways (Fig. 7). Muscle atrophy is a well-known consequence of long-duration spaceflight (Fitts et al., 2010). Overexpression of RBM3 in myoblasts inhibits cell death induced by $\mathrm{H}_{2} \mathrm{O}_{2}$ (necrosis) or staurosporine (apoptosis) (Ferry et al., 2011). Van Pelt et al. (2018) showed that RBM3 overexpression in the soleus muscle in rats increased muscle fiber size and decreased atrophy after 14 days of hind limb suspension. Furthermore, Metrnl is activated by upstream signaling pathways involved in muscle hypertrophy/strength, is secreted by the muscles during exercise, and increases the release of anti-inflammatory molecules (Rao et al., 2014). 


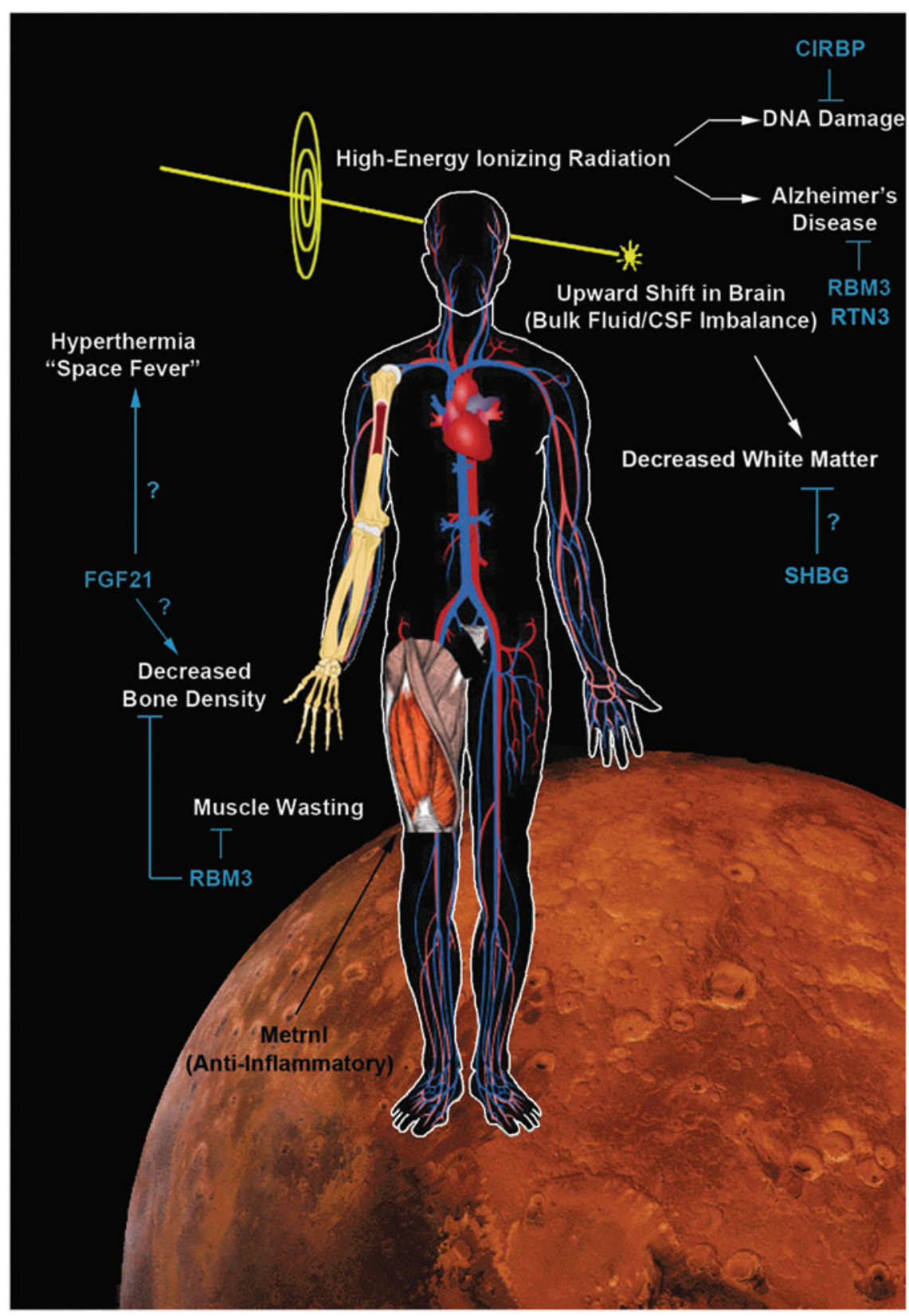

FIG. 7. Theoretical multiorgan benefits of Hypothermia in a Syringe in the setting of long-duration spaceflight. Astronauts exposed chronically to microgravity and increased levels of radiation have evidence of cumulative tissue damage, and show marked changes in baseline physiology that may predispose organs such as the brain to a state of enhanced vulnerability. The utility of protective cooling in astronauts is a well-recognized potential therapy to prevent tissue damage during longduration spaceflight. However, the technology involved in the implementation of cooling systems and protocols able to safely maintain a state of suspended animation in humans is incomplete. Moreover, adopting standard hypothermia equipment (e.g., the artic sun system) for a shuttle or medical module, and used for acute cooling in the event of an accidental injury (e.g., traumatic brain injury), will require overcoming design and training challenges to ensure patient safety in microgravity. Thus, in the relative near term, developing IV-based therapeutics that quickly and easily activate neuroprotective cold responsive signaling pathways in astronauts, and without the need for cooling, may represent a technically simpler approach for space travel (although not necessarily a replacement for the latter). Germane to that logic, key CSPs discussed in this review show promise in reversing physiological changes and cellular pathologies that appear to be associated with spaceflight. For instance, RBM3 (1) prevents cognitive impairment in models of Alzheimer's disease, (2) protects against muscle atrophy, and (3) may decrease bone loss. CIRBP promotes DNA repair mechanisms after ionizing radiation (but this effect is yet to be tested in neurons of the brain). Finally, RTN3 decreases A $\beta$ plaque burden in the brain. CSHs may also mediate beneficial and/or detrimental effects on altered physiology in astronauts. In particular, Metrnl is associated with pathways involved in muscle strength and anti-inflammatory signaling in WAT. In addition, higher SHBG plasma levels are associated with increased white matter in men, but whether that relationship is causative or correlative remains unclear, and also needs to be investigated in women. Finally, FGF21 may activate neuroprotective pathways in the brain, or conversely, further promote a detrimental "space fever" phenotype in astronauts by activating heat-generating thermogenesis mechanisms in BAT. A $\beta$, beta-amyloid; IV, intravenous. 
Bone loss is another complication of space travel (Smith et al., 1999). RBM3 overexpression in MC3T3-E1 osteoblasts increased mRNA and protein levels of Runx2 (a TF that stimulates osteoblast differentiation) (Kim et al., 2018). However, it is unclear if some CSH/CSP pathways may be detrimental in microgravity. Transgenic mice overexpressing FGF21 (fivefold higher levels vs. wild type) had decreased bone mass (Wei et al., 2012). However, this finding was not replicated by others, and bone homeostasis remained normal in mice administered $3 \mathrm{mg} / \mathrm{kg}$ rhFGF21 for 2 weeks (Li et al., 2017c). Also, bone mass was not increased in FGF21 KO mice (Li et al., 2017c).

Radiation from galactic cosmic rays (GCR) and solar energetic particles is a major health concern for astronauts. Zeitlin et al. (2013) analyzed data collected from the Mars Science Laboratory Spacecraft during its 253-day mission to Mars, and estimated that humans making the same journey would have an accumulative radiation exposure equivalent to 42-50 total body computed tomography scans (i.e., based on the standard exterior shielding technology used on spacecraft at the time of the study). Furthermore, Cherry et al. (2012) showed that clinically relevant GCR exposure levels (i.e., germane to astronauts) in 7-9.5-month-old APP/PS1 mice increased $\mathrm{A} \beta$ deposition in the brain, and exacerbated learning and memory impairments versus nonradiated controls. RBM3 overexpression in the brain decreased Alzheimer's disease neuropathology and cognitive impairment in 5XFAD mice (Peretti et al., 2015). Also, RTN3 overexpression in the brain decreased $\mathrm{A} \beta$ deposition. ${ }^{70,173}$ Thus, RBM3 and RTN3 may help to defend the brain against the development of Alzheimer's disease pathology during long missions. Furthermore, Chen et al. (2018c) demonstrated that CIRBP is an essential component of the molecular machinery that mediates DNA repair after ionizing radiation. Knockdown of CIRBP in U2OS cells inhibited double-strand break (DSB) repair by $\sim 50 \%$; both homologous recombination and nonhomologous end-joining mechanisms were negatively affected. We reported that CIRBP is absent in the hippocampus and in the cortex in adults (Jackson et al., 2018). Thus, CIRBP inducing drugs may augment DNA repair mechanisms in the brain (although more studies are needed to confirm that CIRBP regulates DSB repair in neurons).

Microgravity also causes (1) Spaceflight-Associated Neuro-ocular Syndrome (SANS), with accompanying increased ICP, and (2) emergent hyperthermia ("space fever") (Stahn et al., 2017; Zhang and Hargens, 2018). MRI of the brain in astronauts returning from long-duration missions revealed a surprising upward shift in the brain/brainstem, which compressed structures at the vertex, including the central sulcus (Roberts et al., 2017). This phenomenon may constrict venous/CSF drainage via the superior sagittal sinus and contribute to increased ICP. Also, CSF volume is increased in the subarachnoid space 7 months after returning to the Earth (Van Ombergen et al., 2018). Furthermore, MRI revealed a persistent decrease in cerebral white matter volume after long-duration missions (Van Ombergen et al., 2018). Prophylactically increasing neuroprotective CSPs may increase the threshold for secondary brain insults in the event of an accidental TBI. Studies are needed to test if SHBG might target white matter loss (Elbejjani et al., 2017). Interestingly, in vitro studies showed that simulated micro- gravity decreased SHBG levels in cultured Sertoli cells (Masini et al., 2011). However, SHBG blood levels in astronauts did not significantly change after 180 days on the international space station (Smith et al., 2012).

Resting body temperature gradually increases in microgravity and plateaus to $\sim 37.5-38^{\circ} \mathrm{C}$ by 75 days in spaceflight (Stahn et al., 2017). Furthermore, $\mathrm{T}_{\mathrm{b}}$ increases even further $\left(\sim 40^{\circ} \mathrm{C}\right)$ during strenuous excise (Stahn et al., 2017). This so-called space fever may result from a decreased capacity for convection/evaporative heat loss, and also by increased stimulation of heat generating mechanisms (e.g., chronic inflammation) (Sonnenfeld, 1994; Stahn et al., 2017). Small increases in $\mathrm{T}_{\mathrm{b}}$ exacerbate brain injury and decrease the levels of both RBM3 and CIRBP (Nishiyama et al., 1997; Sakurai et al., 2012; Wong et al., 2016). Thus, endogenous neuroprotective CSPs may be decreased in astronauts. Also, persistent hyperthermia might decrease the efficacy of CSP inducing drugs. Finally, it is unclear if CSHs (FGF21, Metrnl, or Irisin) might exacerbate hyperthermia in astronauts, by increasing the activation of nonshivering thermogenesis mechanisms, and thus impede their potential CNS benefits. The futuristic concept of Hypothermia in a Syringe may have applications in space travel. However, research is needed to define which cold stress targets offer the greatest therapeutic benefits with the lowest potential side effects.

\section{Concluding Remarks}

Hypothermia remains an important clinical tool for improving patient outcomes across a spectrum of medical conditions. In addition, significant technological and conceptual advances in the delivery of health care over the last century have dramatically decreased mortality in the hospital setting, and increased the life span at the population level. These remarkable societal achievements have raised the bar to detect a benefit of cooling in CNS injury when superimposed on the many other global improvements in medicine that represent the dynamism of modern background care. This has perhaps, in part, led to the dawn of the TTM era in critical care, and a growing recognition that preventing fever may be one of the most important effects mediated by TH (excluding infants with HIE) in patients in modern ICUs - an effect that can be achieved at temperatures well above levels classically defined as neuroprotective. At the same time, results of animal studies are undeniable - traditional levels of TH in young or adult rodents are remarkably protective during or after a brain injury and these effects are highly reproducible across time, disease models, and species. Whether or not TH can be further optimized in humans across the age spectrum is an open question. Many strategies to enhance neuroprotective cooling have been proposed and all of these deserve further exploration.

In this review, as stated in the Introduction, we have tried to accomplish several key goals. First, to link emerging evidence in endocrinology, hibernation, neurocritical care, and brain injury research, often viewed in isolation, but together suggesting novel approaches that may lead to unique understanding and utility of TH. Second, to focus the review on the heretofore understudied novel neuroprotective mechanisms activated by $\mathrm{TH}$, in preclinical and clinical models of acute CNS injury, and discuss how they may hold potential clues for improving the efficacy of $\mathrm{TH}$ in the treatment of acute and chronic CNS injury in humans, and beyond. These 
mechanisms, we believe hold promise for unique potential applications, including use and optimization of UMH, modulation of the endogenous Responsivity of Cold Stress Pathways, and finally, even potential development and application of the futuristic concept of Hypothermia in a Syringe. These novel concepts merit further investigation.

\section{Acknowledgments}

Figures were produced using Adobe Photoshop, Microsoft PowerPoint, and ePath3D software. This work was supported by NIH/NINDS grants R21NS098057 and R01NS105721 to T.C.J. and the Ake N. Grenvik Chair in Critical Care Medicine to P.M.K.

\section{Author Disclosure Statement}

T.C.J and P.M.K. are coinventors on a pending patent on the use of FGF21 therapy in temperature-managed patients titled: "Method to Improve Neurologic Outcomes in Temperature Managed Patients" (USPTO application No. 15/ 573,006). P.M.K. is also a copatent holder on an invention for the use of rapid induction of deep hypothermia after cardiopulmonary arrest titled "Method of Inducing EPR Following Cardiopulmonary Arrest”, (US 8,628,512 B2).

\section{References}

Adams AC, Cheng CC, Coskun T, Kharitonenkov A. FGF21 requires beta klotho to act in vivo. Plos One 2012;7:e49977.

Adelson PD, Wisniewski SR, Beca J, Brown SD, Bell M, Muizelaar JP, Okada P, Beers SR, Balasubramani GK, Hirtz D; Paediatric Traumatic Brain Injury Consortium. Comparison of hypothermia and normothermia after severe traumatic brain injury in children (Cool Kids): a phase 3, randomised controlled trial. Lancet Neurol 2013;12:546-553.

Akila Parvathy Dharshini S, Taguchi YH, Michael Gromiha M. Exploring the selective vulnerability in Alzheimer disease using tissue specific variant analysis. Genomics 2018; doi.org/10.1016/j.ygeno.2018.05.024.

Albrecht E, Norheim F, Thiede B, Holen T, Ohashi T, Schering L, Lee S, Brenmoehl J, Thomas S, Drevon CA, Erickson HP, Maak S. Irisin - a myth rather than an exercise-inducible myokine. Sci Rep 2015;5:8889.

Alonso-Alconada D, Broad KD, Bainbridge A, Chandrasekaran M, Faulkner SD, Kerenyi A, Hassell J, Rocha-Ferreira E, Hristova M, Fleiss B, Bennett K, Kelen D, Cady E, Gressens P, Golay X, Robertson NJ. Brain cell death is reduced with cooling by 3.5 degrees $\mathrm{C}$ to 5 degrees $\mathrm{C}$ but increased with cooling by 8.5 degrees $\mathrm{C}$ in a piglet asphyxia model. Stroke $2015 ; 46: 275-278$.

Amiri M, Braidy N, Aminzadeh M. Protective effects of fibroblast growth factor 21 against amyloid-beta1-42-induced toxicity in SH-SY5Y cells. Neurotox Res 2018;34:574-583.

Andrews PJD, Sinclair HL, Rodriguez A, Harris BA, Battison CG, Rhodes JKJ, Murray GD; Eurotherm3235 Trial Collaborators. Hypothermia for intracranial hypertension after traumatic brain injury. N Engl J Med 2015;373:2403-2412.

Ansari MA. Temporal profile of M1 and M2 responses in the hippocampus following early $24 \mathrm{~h}$ of neurotrauma. J Neurol Sci 2015;357:41-49.

Araki W, Oda A, Motoki K, Hattori K, Itoh M, Yuasa S, Konishi Y, Shin RW, Tamaoka A, Ogino K. Reduction of betaamyloid accumulation by reticulon 3 in transgenic mice. Curr Alzheimer Res 2013;10:135-142.
Asadi Y, Gorjipour F, Behrouzifar S, Vakili A. Irisin peptide protects brain against ischemic injury through reducing apoptosis and enhancing BDNF in a rodent model of stroke. Neurochem Res 2018;43:1549-1560.

Atherton PJ, Phillips BE. Greek goddess or Greek myth: the effects of exercise on irisin/FNDC5 in humans. J Physiol 2013;591:5267-5268.

Baena RC, Busto R, Dietrich WD, Globus MY, Ginsberg MD. Hyperthermia delayed by 24 hours aggravates neuronal damage in rat hippocampus following global ischemia. Neurology 1997; 48:768-773.

Baghdoyan S, Dubreuil P, Eberle F, Gomez S. Capture of cytokine-responsive genes (NACA and RBM3) using a gene trap approach. Blood 2000;95:3750-3757.

Barker-Haliski M, White HS. Glutamatergic mechanisms associated with seizures and epilepsy. Cold Spring Harb Perspect Med 2015;5:a022863.

Barnes BM. Freeze avoidance in a mammal: body temperatures below 0 degree $C$ in an Arctic hibernator. Science 1989;244: 1593-1595.

Bastide A, Peretti D, Knight JRP, Grosso S, Spriggs RV, Pichon X, Sbarrato T, Roobol A, Roobol J, Vito D, Bushell M, von der Haar T, Smales CM, Malluccil GR, Willis AE. RTN3 is a novel cold-induced protein and mediates neuroprotective effects of RBM3. Curr Biol 2017;27:638-650.

Bayir H, Adelson PD, Wisniewski SR, Shore P, Lai Y, Brown D, Janesko-Feldman KL, Kagan VE, Kochanek PM. Therapeutic hypothermia preserves antioxidant defenses after severe traumatic brain injury in infants and children. Crit Care Med 2009;37:689-695.

Behringer W, Safar P, Wu XR, Kentner R, Radovsky A, Kochanek PM, Dixon CE, Tisherman SA. Survival without brain damage after clinical death of 60-120 mins in dogs using suspended animation by profound hypothermia. Crit Care Med 2003;31:1523-1531.

Berntman L, Welsh FA, Harp JR. Cerebral protective effect of low-grade hypothermia. Anesthesiology 1981;55:495498.

Blackstone E, Morrison M, Roth MB. $\mathrm{H}_{2} \mathrm{~S}$ induces a suspended animation-like state in mice. Science 2005;308:518.

Boddaert J, Bielen K, 's Jongers B, Manocha E, Yperzeele L, Cras $\mathrm{P}$, Pirici D, Kumar-Singh S. CD8 signaling in microglia/ macrophage M1 polarization in a rat model of cerebral ischemia. PloS One 2018;13:e0186937.

BonDurant LD, Ameka M, Naber MC, Markan KR, Idiga SO, Acevedo MR, Walsh SA, Ornitz DM, Potthoff MJ. FGF21 regulates metabolism through adipose-dependent and -independent mechanisms. Cell Metab 2017;25:935.e4-944.e4.

Bookout AL, de Groot MHM, Owen BM, Lee S, Gautron L, Lawrence HL, Ding XS, Elmquist JK, Takahashi JS, Mangelsdorf DJ, Kliewer SA. FGF21 regulates metabolism and circadian behavior by acting on the nervous system. Nat Med 2013;19:1147-1152.

Bostrom P, Wu J, Jedrychowski MP, Korde A, Ye L, Lo JC, Rasbach KA, Bostrom EA, Choi JH, Long JZ, Kajimura S, Zingaretti MC, Vind BF, Tu H, Cinti S, Hojlund K, Gygi SP, Spiegelman BM. A PGC1-alpha-dependent myokine that drives brown-fat-like development of white fat and thermogenesis. Nature 2012;481:463-468.

Buki A, Koizumi H, Povlishock JT. Moderate posttraumatic hypothermia decreases early calpain-mediated proteolysis and concomitant cytoskeletal compromise in traumatic axonal injury. Exp Neurol 1999;159:319-328. 
Burns JM, Johnson DK, Watts A, Swerdlow RH, Brooks WM. Reduced lean mass in early Alzheimer disease and its association with brain atrophy. Arch Neurol 2010;67:428-433.

Buttram SD, Wisniewski SR, Jackson EK, Adelson PD, Feldman K, Bayir H, Berger RP, Clark RS, Kochanek PM. Multiplex assessment of cytokine and chemokine levels in cerebrospinal fluid following severe pediatric traumatic brain injury: effects of moderate hypothermia. J Neurotrauma 2007;24:1707-1717.

Caldwell JD, Shapiro RA, Jirikowski GF, Suleman F. Internalization of sex hormone-binding globulin into neurons and brain cells in vitro and in vivo. Neuroendocrinology 2007;86: 84-93.

Callaway CW, Donnino MW, Fink EL, Geocadin RG, Golan E, Kern KB, Leary M, Meurer WJ, Peberdy MA, Thompson TM, Zimmerman JL. Part 8: post-cardiac arrest care: 2015 American Heart Association guidelines update for cardiopulmonary resuscitation and emergency cardiovascular care. Circulation 2015;132:S465-S482.

Callaway CW, Rittenberger JC, Logue ES, McMichael MJ. Hypothermia after cardiac arrest does not alter serum inflammatory markers. Crit Care Med 2008;36:2607-2612.

Campos F, Perez-Mato M, Agulla J, Blanco M, Barral D, Almeida A, Brea D, Waeber C, Castillo J, Ramos-Cabrer P. Glutamate excitoxicity is the key molecular mechanism which is influenced by body temperature during the acute phase of brain stroke. PloS One 2012;7:e44191.

Carlos TM, Clark RS, Franicola-Higgins D, Schiding JK, Kochanek PM. Expression of endothelial adhesion molecules and recruitment of neutrophils after traumatic brain injury in rats. J Leukoc Biol 1997;61:279-285.

Cerri M, Tinganelli W, Negrini M, Helm A, Scifoni E, Tommasino F, Sioli M, Zoccoli A, Durante M. Hibernation for space travel: impact on radioprotection. Life Sci Space Res 2016;11:1-9.

Chamoun R, Suki D, Gopinath SP, Goodman JC, Robertson C. Role of extracellular glutamate measured by cerebral microdialysis in severe traumatic brain injury. J Neurosurg 2010;113:564-570.

Chandrasekaran PN, Dezfulian C, Polderman KH. What is the right temperature to cool post-cardiac arrest patients? Crit Care 2015;19:doi.org/10.1186/s13054-015-1134-z.

Chartoumpekis DV, Habeos IG, Ziros PG, Psyrogiannis AI, Kyriazopoulou VE, Papavassiliou AG. Brown adipose tissue responds to cold and adrenergic stimulation by induction of FGF21. Mol Med 2011;17:736-740.

Chatzipanteli K, Wada K, Busto R, Dietrich WD. Effects of moderate hypothermia on constitutive and inducible nitric oxide synthase activities after traumatic brain injury in the rat. J Neurochem 1999;72:2047-2052.

Chauvier D, Renolleau S, Holifanjaniaina S, Ankri S, Bezault M, Schwendimann L, Rousset C, Casimir R, Hoebeke J, Smirnova M, Debret G, Trichet AP, Carlsson Y, Wang X, Bernard E, Hebert M, Rauzier JM, Matecki S, Lacampagne A, Rustin P, Mariani J, Hagberg H, Gressens P, CharriautMarlangue $\mathrm{C}$, Jacotot E. Targeting neonatal ischemic brain injury with a pentapeptide-based irreversible caspase inhibitor. Cell Death Dis 2011;2:e203.

Chen GZ, Liu Y, Goetz R, Fu LL, Jayaraman S, Hu MC, Moe OW, Liang G, Li XK, Mohammadi M. alpha-Klotho is a nonenzymatic molecular scaffold for FGF23 hormone signalling. Nature 2018a;553:461-466.

Chen H, Yoshioka H, Kim GS, Jung JE, Okami N, Sakata H, Maier CM, Narasimhan P, Goeders CE, Chan PH. Oxidative stress in ischemic brain damage: mechanisms of cell death and potential molecular targets for neuroprotection. Antioxid Redox Signal 2011a;14:1505-1517.

Chen J, Hu J, Liu H, Xiong Y, Zou YC, Huang WT, Shao MJ, Wu JM, Yu L, Wang XJ, Wang X, Lin L. FGF21 protects the blood-brain barrier by upregulating PPAR via FGFR1/-klotho after traumatic brain injury. J Neurotrauma 2018b;35:20912103.

Chen JK, Lin WL, Chen Z, Liu HW. PARP-1-dependent recruitment of cold-inducible RNA-binding protein promotes double-strand break repair and genome stability. Proc Natl Acad Sci U S A 2018c;115:E1759-E1768.

Chen K, Xu Z, Liu Y, Wang Z, Li Y, Xu X, Chen C, Xia T, Liao Q, Yao Y, Zeng C, He D, Yang Y, Tan T, Yi J, Zhou J, Zhu H, Ma J, Zeng C. Irisin protects mitochondria function during pulmonary ischemia/reperfusion injury. Sci Transl Med 2017a;9:eaao6298.

Chen R, Jin R, Wu L, Ye X, Yang Y, Luo K, Wang W, Wu D, Ye X, Huang L, Huang T, Xiao G. Reticulon 3 attenuates the clearance of cytosolic prion aggregates via inhibiting autophagy. Autophagy 2011b;7:205-216.

Chen XM, Liu XQ, Li B, Zhang Q, Wang JY, Zhang WB, Luo WJ, Chen JY. Cold Inducible RNA binding protein is involved in chronic hypoxia induced neuron apoptosis by down-regulating HIF-1 alpha expression and regulated by microRNA-23a. Int J Biol Sci 2017b;13:518-531.

Cherry JD, Liu B, Frost JL, Lemere CA, Williams JP, Olschowka JA, O'Banion MK. Galactic cosmic radiation leads to cognitive impairment and increased abeta plaque accumulation in a mouse model of Alzheimer's disease. PloS One 2012;7:e53275.

Cheung I, Shulha HP, Jiang Y, Matevossian A, Wang J, Weng $\mathrm{Z}$, Akbarian S. Developmental regulation and individual differences of neuronal $\mathrm{H} 3 \mathrm{~K} 4 \mathrm{me} 3$ epigenomes in the prefrontal cortex. Proc Natl Acad Sci U S A 2010;107:88248829.

Chip S, Zelmer A, Ogunshola OO, Felderhoff-Mueser U, Nitsch C, Buhrer C, Wellmann S. The RNA-binding protein RBM3 is involved in hypothermia induced neuroprotection. Neurobiol Dis 2011;43:388-396.

Choi HA, Ko SB, Presciutti M, Fernandez L, Carpenter AM, Lesch C, Gilmore E, Malhotra R, Mayer SA, Lee K, Claassen J, Schmidt JM, Badjatia N. Prevention of shivering during therapeutic temperature modulation: the Columbia antishivering protocol. Neurocrit Care 2011a;14:389-394.

Choi JS, Park J, Suk K, Moon C, Park YK, Han HS. Mild hypothermia attenuates intercellular adhesion molecule-1 induction via activation of extracellular signal-regulated kinase- $1 / 2$ in a focal cerebral ischemia model. Stroke Res Treat 2011b;2011:846716.

Coderch C, Diaz de Cerio M, Zapico JM, Pelaez R, Larrayoz IM, Ramos A, Martinez A, de Pascual-Teresa B. In silico identification and in vivo characterization of small molecule therapeutic hypothermia mimetics. Bioorg Med Chem 2017; 25:6597-6604.

Colantuoni C, Lipska BK, Ye T, Hyde TM, Tao R, Leek JT, Colantuoni EA, Elkahloun AG, Herman MM, Weinberger DR, Kleinman JE. Temporal dynamics and genetic control of transcription in the human prefrontal cortex. Nature 2011; 478:519-523.

Coles JP, Fryer TD, Smielewski P, Chatfield DA, Steiner LA, Johnston AJ, Downey SP, Williams GB, Aigbirhio F, Hutchinson PJ, Rice K, Carpenter TA, Clark JC, Pickard JD, Menon DK. Incidence and mechanisms of cerebral ischemia 
in early clinical head injury. J Cereb Blood Flow Metab 2004;24:202-211.

Cooper DJ, Nichol AD, Bailey M, Bernard S, Cameron PA, Pili-Floury S, Forbes A, Gantner D, Higgins AM, Huet O, Kasza J, Murray L, Newby L, Presneill JJ, Rashford S, Rosenfeld JV, Stephenson M, Vallance S, Varma D, Webb SAR, Trapani T, McArthur C; POLAR Trial Investigators and the ANZICS Clinical Trials Group. Effect of early sustained prophylactic hypothermia on neurologic outcomes among patients with severe traumatic brain injury: the POLAR randomized clinical trial. JAMA 2018;320:2214-2223.

Cornelius C, Crupi R, Calabrese V, Graziano A, Milone P, Pennisi G, Radak Z, Calabrese EJ, Cuzzocrea S. Traumatic brain injury: oxidative stress and neuroprotection. Antioxid Redox Signal 2013;19:836-853.

Corry JJ, Dhar R, Murphy T, Diringer MN. Hypothermia for refractory status epilepticus. Neurocrit Care 2008;9:189-197.

Cueni-Villoz N, Devigili A, Delodder F, Cianferoni S, Feihl F, Rossetti AO, Eggimann P, Vincent JL, Taccone FS, Oddo M. Increased blood glucose variability during therapeutic hypothermia and outcome after cardiac arrest. Crit Care Med 2011;39:2225-2231.

Cunningham AS, Salvador R, Coles JP, Chatfield DA, Bradley PG, Johnston AJ, Steiner LA, Fryer TD, Aigbirhio FI, Smielewski P, Williams GB, Carpenter TA, Gillard JH, Pickard JD, Menon DK. Physiological thresholds for irreversible tissue damage in contusional regions following traumatic brain injury. Brain 2005;128:1931-1942.

Daniels IS, Zhang JF, O'Brien WG, Tao ZY, Miki T, Zhao ZY, Blackburn MR, Lee CC. A role of erythrocytes in adenosine monophosphate initiation of hypometabolism in mammals. J Biol Chem 2010;285:20716-20723.

Danno S, Itoh K, Matsuda T, Fujita J. Decreased expression of mouse Rbm3, a cold-shock protein, in Sertoli cells of cryptorchid testis. Am J Pathol 2000;156:1685-1692.

de la Vega CM, Burda J, Nemethova M, Quevedo C, Alcazar A, Martin ME, Danielisova V, Fando JL, Salinas M. Possible mechanisms involved in the down-regulation of translation during transient global ischaemia in the rat brain. Biochem $\mathbf{J}$ 2001;357:819-826.

De Sousa-Coelho AL, Relat J, Hondares E, Perez-Marti A, Ribas F, Villarroya F, Marrero PF, Haro D. FGF21 mediates the lipid metabolism response to amino acid starvation. J Lipid Res 2013;54:1786-1797.

Deng M, He W, Tan Y, Han H, Hu X, Xia K, Zhang Z, Yan R. Increased expression of reticulon 3 in neurons leads to reduced axonal transport of beta site amyloid precursor proteincleaving enzyme 1. J Biol Chem 2013;288:30236-30245.

Deng W, Cao J, Chen L, McMullin D, Januzzi JL, Jr., Buonanno FS, Lo EH, Ning M. Plasma glycoproteomic study of therapeutic hypothermia reveals novel markers predicting neurologic outcome post-cardiac arrest. Transl Stroke Res 2018;9:64-73.

Di Scala F, Dupuis L, Gaiddon C, De Tapia M, Jokic N, Gonzalez de Aguilar JL, Raul JS, Ludes B, Loeffler JP. Tissue specificity and regulation of the $\mathrm{N}$-terminal diversity of reticulon 3. Biochem J 2005;385:125-134.

Dietrich WD. Therapeutic Hypothermia in Experimental Models of Traumatic Brain Injury. Tokyo: Springer Japan, 2000, pp. 39-46.

Ditelberg JS, Sheldon RA, Epstein CJ, Ferriero DM. Brain injury after perinatal hypoxia-ischemia is exacerbated in copper-zinc superoxide-dismutase transgenic mice. Neurology 1995;45:A391.
Drabek T, Kochanek PM, Stezoski J, Wu X, Bayir H, Morhard $\mathrm{RC}$, Stezoski SW, Tisherman SA. Intravenous hydrogen sulfide does not induce hypothermia or improve survival from hemorrhagic shock in pigs. Shock 2011;35:67-73.

Drabek T, Snajdar E, Stezoski JP, Simqu KS, Kochanek PM, Jackson TC. Deep hypothermic circulatory arrest does not induce rna-binding motif protein 3 (RBM3) in hippocampus in adult rats. Anesth Analg 2017;124:667-668.

Dresios J, Aschrafi A, Owens GC, Vanderklish PW, Edelman GM, Mauro VP. Cold stress-induced protein Rbm3 binds 60S ribosomal subunits, alters microRNA levels, and enhances global protein synthesis. Proc Natl Acad Sci U S A 2005;102: 1865-1870.

Dunn JF, Nisula BC, Rodbard D. Transport of steroid-hormonesbinding of 21 endogenous steroids to both testosterone-binding globulin and corticosteroid-binding globulin in human-plasma. J Clin Endocr Metab 1981;53:58-68.

Edgar A, Bering J. Effect of body temperature change on cerebral oxygen consumption of the intact monkey. Am J Physiol Legacy Content 1961;200:417-419.

Edwards AD, Yue X, Squier MV, Thoresen M, Cady EB, Penrice J, Cooper CE, Wyatt JS, Reynolds EO, Mehmet H. Specific inhibition of apoptosis after cerebral hypoxiaischaemia by moderate post-insult hypothermia. Biochem Biophys Res Commun 1995;217:1193-1199.

Elbejjani M, Schreiner PJ, Siscovick DS, Sidney S, Lewis CE, Bryan NR, Launer LJ. Sex hormones and brain volumes in a longitudinal study of middle-aged men in the CARDIA study. Brain Behav 2017;7:e00765.

Ellenbroek B, Youn J. Rodent models in neuroscience research: is it a rat race? Dis Model Mech 2016;9:1079-1087.

Eroglu O, Deniz T, Kisa U, Atasoy P, Aydinuraz K. Effect of hypothermia on apoptosis in traumatic brain injury and hemorrhagic shock model. Injury 2017;48:2675-2682.

Fan P, Yamauchi T, Noble LJ, Ferriero DM. Age-dependent differences in glutathione peroxidase activity after traumatic brain injury. J Neurotrauma 2003;20:437-445.

Ferry AL, Vanderklish PW, Dupont-Versteegden EE. Enhanced survival of skeletal muscle myoblasts in response to overexpression of cold shock protein RBM3. Am J Physiol Cell Physiol 2011;301:C392-C402.

Fisher FM, Kleiner S, Douris N, Fox EC, Mepani RJ, Verdeguer F, Wu J, Kharitonenkov A, Flier JS, Maratos-Flier E, Spiegelman BM. FGF21 regulates PGC-1 alpha and browning of white adipose tissues in adaptive thermogenesis. Gene Dev 2012;26:271-281.

Fisher FM, Maratos-Flier E. Understanding the physiology of FGF21. Annu Rev Physiol 2016;78:223-241.

Fitts RH, Trappe SW, Costill DL, Gallagher PM, Creer AC, Colloton PA, Peters JR, Romatowski JG, Bain JL, Riley DA. Prolonged space flight-induced alterations in the structure and function of human skeletal muscle fibres. J Physiol 2010;588: 3567-3592.

Flynn LM, Rhodes J, Andrews PJ. Therapeutic hypothermia reduces intracranial pressure and partial brain oxygen tension in patients with severe traumatic brain injury: preliminary data from the Eurotherm 3235 trial. Ther Hypothermia Temp Manag 2015;5:143-151.

Forni AA, Rocchio MA, Szumita PM, Anger KE, Avery KR, Scirica BM. Evaluation of glucose management during therapeutic hypothermia at a Tertiary Academic Medical Center. Resuscitation 2015;89:64-69.

Frerichs KU, Smith CB, Brenner M, DeGracia DJ, Krause GS, Marrone L, Dever TE, Hallenbeck JM. Suppression of pro- 
tein synthesis in brain during hibernation involves inhibition of protein initiation and elongation. Proc Natl Acad Sci U S A 1998;95:14511-14516.

Frugier T, Morganti-Kossmann MC, O'Reilly D, McLean CA. In situ detection of inflammatory mediators in post mortem human brain tissue after traumatic injury. J Neurotrauma 2010;27:497-507.

Gaich G, Chien JY, Fu H, Glass LC, Deeg MA, Holland WL, Kharitonenkov A, Bumol T, Schilske HK, Moller DE. The effects of LY2405319, an FGF21 analog, in obese human subjects with type 2 diabetes. Cell Metab 2013;18:333-340.

Garcia JH, Liu KF, Yoshida Y, Lian J, Chen S, del Zoppo GJ. Influx of leukocytes and platelets in an evolving brain infarct (Wistar rat). Am J Pathol 1994;144:188-199.

Giorgi EP. The transport of steroid hormones into animal cells. Int Rev Cytol 1980;65:49-115.

Globus MY, Alonso O, Dietrich WD, Busto R, Ginsberg MD. Glutamate release and free radical production following brain injury: effects of posttraumatic hypothermia. J Neurochem 1995;65:1704-1711.

Gong P, Hua R, Zhang Y, Zhao H, Tang ZR, Mei X, Zhang MY, Cui J, Li CS. Hypothermia-induced neuroprotection is associated with reduced mitochondrial membrane permeability in a swine model of cardiac arrest. J Cereb Blood Flow Metab 2013;33:928-934.

Gouix E, Leveille F, Nicole O, Melon C, Had-Aissouni L, Buisson A. Reverse glial glutamate uptake triggers neuronal cell death through extrasynaptic NMDA receptor activation. Mol Cell Neurosci 2009;40:463-473.

Hackenhaar FS, Medeiros TM, Heemann FM, Behling CS, Putti JS, Mahl CD, Verona C, da Silva ACA, Guerra MC, Goncalves CAS, Oliveira VM, Riveiro DFM, Vieira SRR, Benfato MS. Therapeutic hypothermia reduces oxidative damage and alters antioxidant defenses after cardiac arrest. Oxid Med Cell Longev 2017;2017:8704352.

Hammes A, Andreassen TK, Spoelgen R, Raila J, Hubner N, Schulz H, Metzger J, Schweigert FJ, Luppa PB, Nykjaer A, Willnow TE. Role of endocytosis in cellular uptake of sex steroids. Cell 2005;122:751-762.

Han BH, Xu DG, Choi JJ, Han YX, Xanthoudakis S, Roy S, Tam J, Vaillancourt J, Colucci J, Siman R, Giroux A, Robertson GS, Zamboni R, Nicholson DW, Holtzman DM. Selective, reversible caspase-3 inhibitor is neuroprotective and reveals distinct pathways of cell death after neonatal hypoxic-ischemic brain injury. J Biol Chem 2002;277:30128-30136.

Hanel RA, Spetzler RF. Surgical treatment of complex intracranial aneurysms. Neurosurgery 2008;62:1289-1297; discussion 1297-1289.

Hardingham GE, Bading H. Synaptic versus extrasynaptic NMDA receptor signalling: implications for neurodegenerative disorders. Nat Rev Neurosci 2010;11:682-696.

Hardingham GE, Fukunaga Y, Bading H. Extrasynaptic NMDARs oppose synaptic NMDARs by triggering CREB shut-off and cell death pathways. Nat Neurosci 2002;5:405414.

Harting MT, Jimenez F, Adams SD, Mercer DW, Cox CS, Jr. Acute, regional inflammatory response after traumatic brain injury: implications for cellular therapy. Surgery 2008;144: 803-813.

Hartings JA, Strong AJ, Fabricius M, Manning A, Bhatia R, Dreier JP, Mazzeo AT, Tortella FC, Bullock MR; CoOperative Study of Brain Injury Depolarizations. Spreading depolarizations and late secondary insults after traumatic brain injury. J Neurotrauma 2009;26:1857-1866.
Hattori K, Ishikawa H, Sakauchi C, Takayanagi S, Naguro I, Ichijo H. Cold stress-induced ferroptosis involves the ASK1p38 pathway. EMBO Rep 2017;18:2067-2078.

Hayward MG, Keatinge WR. Roles of subcutaneous fat and thermoregulatory reflexes in determining ability to stabilize body temperature in water. J Physiol 1981;320:229-251.

Hemelrijk SD, Dirkes MC, van Velzen MHN, Bezemer R, van Gulik TM, Heger M. Exogenous hydrogen sulfide gas does not induce hypothermia in normoxic mice. Sci Rep 2018;8:3855.

Henson MA, Roberts AC, Salimi K, Vadlamudi S, Hamer RM, Gilmore JH, Jarskog LF, Philpot BD. Developmental regulation of the NMDA receptor subunits, NR3A and NR1, in human prefrontal cortex. Cereb Cortex 2008;18:2560-2573.

Hey EN, O'Connell B. Oxygen consumption and heat balance in the cot-nursed baby. Arch Dis Child 1970;45:335-343.

Hlatky R, Contant CF, Diaz-Marchan P, Valadka AB, Robertson CS. Significance of a reduced cerebral blood flow during the first 12 hours after traumatic brain injury. Neurocrit Care 2004;1:69-83.

Hondares E, Iglesias R, Giralt A, Gonzalez FJ, Giralt M, Mampel $\mathrm{T}$, Villarroya $\mathrm{F}$. Thermogenic activation induces FGF21 expression and release in brown adipose tissue. J Biol Chem 2011;286:12983-12990.

Hondares E, Rosell M, Gonzalez FJ, Giralt M, Iglesias R, Villarroya F. Hepatic FGF21 expression is induced at birth via PPAR alpha in response to milk intake and contributes to thermogenic activation of neonatal brown fat. Cell Metab 2010;11:206-212.

Hryb DJ, Khan MS, Romas NA, Rosner W. The control of the interaction of sex hormone-binding globulin with its receptor by steroid hormones. J Biol Chem 1990;265:6048-6054.

Hryb DJ, Khan MS, Rosner W. Testosterone-estradiol-binding globulin binds to human prostatic cell-membranes. Biochem Biophys Res Commun 1985;128:432-440.

Hsuchou H, Pan W, Kastin AJ. The fasting polypeptide FGF21 can enter brain from blood. Peptides 2007;28:2382-2386.

Hu X, Shi Q, Zhou X, He W, Yi H, Yin X, Gearing M, Levey A, Yan R. Transgenic mice overexpressing reticulon 3 develop neuritic abnormalities. EMBO J 2007;26:2755-2767.

Hu XM, Li PY, Guo YL, Wang HY, Leak RK, Chen SE, Gao YQ, Chen J. Microglia/macrophage polarization dynamics reveal novel mechanism of injury expansion after focal cerebral ischemia. Stroke 2012;43:3063-3070.

Huh JY, Panagiotou G, Mougios V, Brinkoetter M, Vamvini MT, Schneider BE, Mantzoros CS. FNDC5 and irisin in humans: I. Predictors of circulating concentrations in serum and plasma and II. mRNA expression and circulating concentrations in response to weight loss and exercise. Metabolism 2012;61:1725-1738.

Inagaki T, Dutchak P, Zhao G, Ding X, Gautron L, Parameswara V, Li Y, Goetz R, Mohammadi M, Esser V, Elmquist JK, Gerard RD, Burgess SC, Hammer RE, Mangelsdorf DJ, Kliewer SA. Endocrine regulation of the fasting response by PPARalpha-mediated induction of fibroblast growth factor 21. Cell Metab 2007;5:415-425.

Iordanova B, Li L, Clark RSB, Manole MD. Alterations in cerebral blood flow after resuscitation from cardiac arrest. Front Pediatr 2017;5:174.

Irazuzta JE, Olson J, Kiefaber MP, Wong H. Hypothermia decreases excitatory neurotransmitter release in bacterial meningitis in rabbits. Brain Res 1999a;847:143-148.

Irazuzta JE, Pretzlaff R, Rowin M, Milam K, Zemlan FP, Zingarelli B. Hypothermia as an adjunctive treatment for severe bacterial meningitis. Brain Res 2000;881:88-97. 
Irazuzta JE, Zingarelli B, Milam K, Kiefaber M, Kamdar T. Hypothermia attenuates inflammation in bacterial meningitis. Pediatr Res 1999b;45:41a.

Itoh N, Ornitz DM. Functional evolutionary history of the mouse Fgf gene family. Dev Dyn 2008;237:18-27.

Jackson TC, Kotermanski SE, Kochanek PM. Infants uniquely express high levels of RBM3 and other cold-adaptive neuroprotectant proteins in the human brain. Dev Neurosci 2018; 40:325-336.

Jackson TC, Manole MD, Kotermanski SE, Jackson EK, Clark RS, Kochanek PM. Cold stress protein RBM3 responds to temperature change in an ultra-sensitive manner in young neurons. Neuroscience 2015;305:268-278.

Jacobs SE, Berg M, Hunt R, Tarnow-Mordi WO, Inder TE, Davis PG. Cooling for newborns with hypoxic ischaemic encephalopathy. Cochrane Database Syst Rev 2013;1:CD003311.

Jedrychowski MP, Wrann CD, Paulo JA, Gerber KK, Szpyt J, Robinson MM, Nair KS, Gygi SP, Spiegelman BM. Detection and quantitation of circulating human Irisin by tandem mass spectrometry. Cell Metab 2015;22:734-740.

Jiang Y, Liu N, Wang Q, Yu Z, Lin L, Yuan J, Guo S, Ahn BJ, Wang XJ, Li X, Lo EH, Sun X, Wang X. Endocrine regulator rFGF21 (recombinant human fibroblast growth factor 21) improves neurological outcomes following focal ischemic stroke of type 2 diabetes mellitus male mice. Stroke 2018;49: 3039-3049.

Jinka TR, Toien O, Drew KL. Season primes the brain in an arctic hibernator to facilitate entrance into torpor mediated by adenosine A(1) receptors. J Neurosci 2011;31:10752-10758.

Jo JW, Jee BC, Suh CS, Kim SH. The beneficial effects of antifreeze proteins in the vitrification of immature mouse oocytes. PloS One 2012;7:e37043.

Johnson VE, Stewart W, Smith DH. Traumatic brain injury and amyloid-beta pathology: a link to Alzheimer's disease? Nat Rev Neurosci 2010;11:361-370.

Kanazawa H, Kawai M, Niwa F, Hasegawa T, Iwanaga K, Ohata K, Tamaki A, Heike T. Subcutaneous fat accumulation in early infancy is more strongly associated with motor development and delay than muscle growth. Acta Paediatr 2014;103:E262-E267.

Kaneko T, Kibayashi K. Mild hypothermia facilitates the expression of cold-inducible RNA-binding protein and heat shock protein 70.1 in mouse brain. Brain Res 2012;1466: 128-136.

Kariholu U, Montaldo P, Markati T, Lally PJ, Pryce R, Teiserskas J, Liow N, Oliveira V, Soe A, Shankaran S, Thayyil S. Therapeutic hypothermia for mild neonatal encephalopathy: a systematic review and meta-analysis. Arch Dis Child Fetal Neonatal Ed 2018; doi: 10.1136/archdischild-2018-315711.

Karlsson H. Skin to skin care: heat balance. Arch Dis Child 1996;75:F130-F132.

Karnatovskaia LV, Wartenberg KE, Freeman WD. Therapeutic hypothermia for neuroprotection: history, mechanisms, risks, and clinical applications. Neurohospitalist 2014;4: 153-163.

Kashiwaya Y, Bergman C, Lee JH, Wan R, King MT, Mughal MR, Okun E, Clarke K, Mattson MP, Veech RL. A ketone ester diet exhibits anxiolytic and cognition-sparing properties, and lessens amyloid and tau pathologies in a mouse model of Alzheimer's disease. Neurobiol Aging 2013;34: 1530-1539.

Kaufmann AM, Firlik AD, Fukui MB, Wechsler LR, Jungries $\mathrm{CA}$, Yonas H. Ischemic core and penumbra in human stroke. Stroke 1999;30:93-99.
Kharitonenkov A, Wroblewski VJ, Koester A, Chen YF, Clutinger CK, Tigno XT, Hansen BC, Shanafelt AB, Etgen GJ. The metabolic state of diabetic monkeys is regulated by fibroblast growth factor-21. Endocrinology 2007;148:774-781.

Kil HY, Zhang J, Piantadosi CA. Brain temperature alters hydroxyl radical production during cerebral ischemia/reperfusion in rats. J Cereb Blood Flow Metab 1996;16:100-106.

Kim DY, Kim KM, Kim EJ, Jang WG. Hypothermia-induced RNA-binding motif protein 3 (RBM3) stimulates osteoblast differentiation via the ERK signaling pathway. Biochem Biophys Res Commun 2018;498:459-465.

Kim MJ, Oh SJ, Park SH, Kang HJ, Won MH, Kang TC, Park JB, Kim JI, Kim J, Lee JY. Neuronal loss in primary longterm cortical culture involves neurodegeneration-like cell death via calpain and p35 processing, but not developmental apoptosis or aging. Exp Mol Med 2007;39:14-26.

Kirkpatrick AW, Ball CG, Campbell M, Williams DR, Parazynski SE, Mattox KL, Broderick TJ. Severe traumatic injury during long duration spaceflight: light years beyond ATLS. J Trauma Manag Outcomes 2009;3:4.

Kita H, Carmichael J, Swartz J, Muro S, Wyttenbach A, Matsubara K, Rubinsztein DC, Kato K. Modulation of polyglutamine-induced cell death by genes identified by expression profiling. Hum Mol Genet 2002;11:2279-2287.

Kobata H, Sugie A, Suehiro E, Dohi K, Kaneko T, Fujita M, Oda Y, Kuroda Y, Yamashita S, Maekawa T. Association between blood glucose levels the day after targeted temperature initiation and outcome in traumatic brain injury: a posthoc analysis of the B-HYPO study. J Neurotrauma 2017;34: 987-995.

Kohen R, Nyska A. Oxidation of biological systems: oxidative stress phenomena, antioxidants, redox reactions, and methods for their quantification. Toxicol Pathol 2002;30:620-650.

Koizumi H, Fujisawa H, Ito H, Maekawa T, Di X, Bullock R. Effects of mild hypothermia on cerebral blood flowindependent changes in cortical extracellular levels of amino acids following contusion trauma in the rat. Brain Res 1997; 747:304-312.

Kristensson K. Microbes' roadmap to neurons. Nat Rev Neurosci 2011;12:345-357.

Kumamaru E, Kuo CH, Fujimoto T, Kohama K, Zeng LH, Taira E, Tanaka H, Toyoda T, Miki N. Reticulon3 expression in rat optic and olfactory systems. Neurosci Lett 2004;356: 17-20.

Kumral E, Yuksel M, Buket S, Yagdi T, Atay Y, Guzelant A. Neurologic complications after deep hypothermic circulatory arrest: types, predictors, and timing. Tex Heart Inst J 2001; 28:83-88.

Kurisu K, Abumiya T, Nakamura H, Shimbo D, Shichinohe H, Nakayama N, Kazumata K, Shimizu H, Houkin K. Transarterial regional brain hypothermia inhibits acute aquaporin-4 surge and sequential microvascular events in ischemia/reperfusion injury. Neurosurgery 2016;79:125-134.

Kuroda M, Muramatsu R, Maedera N, Koyama Y, Hamaguchi M, Fujimura H, Yoshida M, Konishi M, Itoh N, Mochizuki H, Yamashita T. Peripherally derived FGF21 promotes remyelination in the central nervous system. J Clin Invest 2017; 127:3496-3509.

Kurosu H, Choi M, Ogawa Y, Dickson AS, Goetz R, Eliseenkova AV, Mohammadi M, Rosenblatt KP, Kliewer SA, Kuro-o M. Tissue-specific expression of beta Klotho and fibroblast growth factor (FGF) receptor isoforms determines metabolic activity of FGF19 and FGF21. J Biol Chem 2007; 282:26687-26695. 
Kutcher ME, Forsythe RM, Tisherman SA. Emergency preservation and resuscitation for cardiac arrest from trauma. Int $\mathrm{J}$ Surg 2016;33:209-212.

Kwon MM, O'Dwyer SM, Baker RK, Covey SD, Kieffer TJ. FGF21-mediated improvements in glucose clearance require uncoupling protein 1. Cell Rep 2015;13:1521-1527.

Lan X, Han X, Li Q, Yang QW, Wang J. Modulators of microglial activation and polarization after intracerebral haemorrhage. Nat Rev Neurol 2017;13:420-433.

Larrayoz IM, Rey-Funes M, Contartese DS, Rolon F, Sarotto A, Dorfman VB, Loidl CF, Martinez A. Cold shock proteins are expressed in the retina following exposure to low temperatures. PloS One 2016;11:e0161458.

Laustriat D, Gide J, Barrault L, Chautard E, Benoit C, Auboeuf D, Boland A, Battail C, Artiguenave F, Deleuze JF, Benit P, Rustin P, Franc S, Charpentier G, Furling D, Bassez G, Nissan X, Martinat C, Peschanski M, Baghdoyan S. In vitro and in vivo modulation of alternative splicing by the biguanide metformin. Mol Ther Nucleic Acids 2015;4:e262.

Lee BS, Woo DC, Woo CW, Kim KS. Exogenous betahydroxybutyrate treatment and neuroprotection in a suckling rat model of hypoxic-ischemic encephalopathy. Dev Neurosci 2018a;40:73-83.

Lee JE, Yoon YJ, Moseley ME, Yenari MA. Reduction in levels of matrix metalloproteinases and increased expression of tissue inhibitor of metalloproteinase- 2 in response to mild hypothermia therapy in experimental stroke. J Neurosurg 2005;103:289-297.

Lee P, Brychta RJ, Linderman J, Smith S, Chen KY, Celi FS. Mild cold exposure modulates fibroblast growth factor 21 (FGF21) diurnal rhythm in humans: relationship between FGF21 levels, lipolysis, and cold-induced thermogenesis. J Clin Endocrinol Metab 2013;98:E98-E102.

Lee P, Linderman JD, Smith S, Brychta RJ, Wang J, Idelson C, Perron RM, Werner CD, Phan GQ, Kammula US, Kebebew E, Pacak K, Chen KY, Celi FS. Irisin and FGF21 are coldinduced endocrine activators of brown fat function in humans. Cell Metab 2014;19:302-309.

Lee S, Choi J, Mohanty J, Sousa LP, Tome F, Pardon E, Steyaert J, Lemmon MA, Lax I, Schlessinger J. Structures of beta-klotho reveal a "zip code"-like mechanism for endocrine FGF signalling. Nature 2018b;553:501-505.

Lei $\mathrm{B}$, Adachi N, Arai T. The effect of hypothermia on $\mathrm{H}_{2} \mathrm{O}_{2}$ production during ischemia and reperfusion: a microdialysis study in the gerbil hippocampus. Neurosci Lett 1997;222:91-94.

Lei B, Tan X, Cai H, Xu Q, Guo Q. Effect of moderate hypothermia on lipid peroxidation in canine brain tissue after cardiac arrest and resuscitation. Stroke 1994;25:147-152.

Leng Y, Wang Z, Tsai LK, Leeds P, Fessler EB, Wang J, Chuang DM. FGF-21, a novel metabolic regulator, has a robust neuroprotective role and is markedly elevated in neurons by mood stabilizers. Mol Psychiatr 2015;20:215-223.

Lesuisse C, Martin LJ. Immature and mature cortical neurons engage different apoptotic mechanisms involving caspase-3 and the mitogen-activated protein kinase pathway. J Cereb Blood Flow Metab 2002;22:935-950.

Li DJ, Li YH, Yuan HB, Qu LF, Wang P. The novel exerciseinduced hormone irisin protects against neuronal injury via activation of the Akt and ERK1/2 signaling pathways and contributes to the neuroprotection of physical exercise in cerebral ischemia. Metabolism 2017a;68:31-42.

Li H, Colbourne F, Sun P, Zhao Z, Buchan AM, Iadecola C. Caspase inhibitors reduce neuronal injury after focal but not global cerebral ischemia in rats. Stroke 2000;31:176-182.
Li HT, Wu GY, Fang QC, Zhang ML, Hui XY, Sheng B, Wu L, Bao YQ, Li P, Xu AM, Jia WP. Fibroblast growth factor 21 increases insulin sensitivity through specific expansion of subcutaneous fat. Nat Commun 2018;9:272.

Li J, Li C, Yuan W, Wu J, Li J, Li Z, Zhao Y. Mild hypothermia alleviates brain oedema and blood-brain barrier disruption by attenuating tight junction and adherens junction breakdown in a swine model of cardiopulmonary resuscitation. PloS One 2017b;12:e0174596.

Li J, Zhang G, Cai S, Redington AN. Effect of inhaled hydrogen sulfide on metabolic responses in anesthetized, paralyzed, and mechanically ventilated piglets. Pediatr Crit Care Med 2008; 9:110-112.

Li JH, Zhang X, Meng Y, Li CS, Ji H, Yang HM, Li SZ. Cold inducible RNA-binding protein inhibits hippocampal neuronal apoptosis under hypothermia by regulating redox system [in Chinese]. Sheng Li Xue Bao 2015;67:386-392.

Li S, Zhang Z, Xue J, Liu A, Zhang H. Cold-inducible RNA binding protein inhibits $\mathrm{H}(2) \mathrm{O}(2)$-induced apoptosis in rat cortical neurons. Brain Res 2012;1441:47-52.

Li X, Stanislaus S, Asuncion F, Niu QT, Chinookoswong N, Villasenor K, Wang J, Wong P, Boyce R, Dwyer D, Han CY, Chen MM, Liu B, Stolina M, Ke HZ, Ominsky MS, Veniant $\mathrm{MM}, \mathrm{Xu}$ J. FGF21 is not a major mediator for bone homeostasis or metabolic actions of PPARalpha and PPARgamma agonists. J Bone Miner Res 2017c;32:834-845.

Liang QN, Zhong L, Zhang JL, Wang Y, Bornstein SR, Triggle CR, Ding H, Lam KSL, Xu AM. FGF21 maintains glucose homeostasis by mediating the cross talk between liver and brain during prolonged fasting. Diabetes 2014;63:4064-4075.

Liebetrau M, Burggraf D, Martens HK, Pichler M, Hamann GF. Delayed moderate hypothermia reduces calpain activity and breakdown of its substrate in experimental focal cerebral ischemia in rats. Neurosci Lett 2004;357:17-20.

Lipovich L, Tarca AL, Cai J, Jia H, Chugani HT, Sterner KN, Grossman LI, Uddin M, Hof PR, Sherwood CC, Kuzawa CW, Goodman M, Wildman DE. Developmental changes in the transcriptome of human cerebral cortex tissue: long noncoding RNA transcripts. Cereb Cortex 2014;24:1451-1459.

Liu J, Xue J, Zhang H, Li S, Liu Y, Xu D, Zou M, Zhang Z, Diao J. Cloning, expression, and purification of cold inducible RNA-binding protein and its neuroprotective mechanism of action. Brain Res 2015;1597:189-195.

Liu LQ, Liu XR, Zhao JY, Yan F, Wang RL, Wen SH, Wang L, Luo YM, Ji XM. Brain-selective mild hypothermia promotes long-term white matter integrity after ischemic stroke in mice. CNS Neurosci Ther 2018;24:1275-1285.

Liu T, Zhao DX, Cui H, Chen L, Bao YH, Wang Y, Jiang JY. Therapeutic hypothermia attenuates tissue damage and cytokine expression after traumatic brain injury by inhibiting necroptosis in the rat. Sci Rep 2016;6:24547.

Liu YC, Lee YD, Wang HL, Liao KH, Chen KB, Poon KS, Pan YL, Lai TW. Anesthesia-induced hypothermia attenuates early-phase blood-brain barrier disruption but not infarct volume following cerebral ischemia. PloS One 2017;12: e0170682.

Loane DJ, Kumar A. Microglia in the TBI brain: the good, the bad, and the dysregulated. Exp Neurol 2016;275(Pt 3):316-327.

Lotocki G, Vaccari JPD, Perez ER, Sanchez-Molano J, Furones-Alonso O, Bramlett HM, Dietrich WD. Alterations in blood-brain barrier permeability to large and small molecules and leukocyte accumulation after traumatic brain injury: effects of post-traumatic hypothermia. J Neurotrauma 2009;26:1123-1134. 
Lu J, Qian HY, Liu LJ, Zhou BC, Xiao Y, Mao JN, An GY, Rui MZ, Wang T, Zhu CL. Mild hypothermia alleviates excessive autophagy and mitophagy in a rat model of asphyxial cardiac arrest. Neurol Sci 2014;35:1691-1699.

Maekawa T, Yamashita S, Nagao S, Hayashi N, Ohashi Y; Brain-Hypothermia Study Group. Prolonged mild therapeutic hypothermia versus fever control with tight hemodynamic monitoring and slow rewarming in patients with severe traumatic brain injury: a randomized controlled trial. J Neurotrauma 2015;32:422-429.

Mao Y, Chen X, Xu M, Fujita K, Motoki K, Sasabe T, Homma H, Murata M, Tagawa K, Tamura T, Kaye J, Finkbeiner S, Blandino G, Sudol M, Okazawa H. Targeting TEAD/ YAP-transcription-dependent necrosis, TRIAD, ameliorates Huntington's disease pathology. Hum Mol Genet 2016;25: 4749-4770.

Markan KR, Naber MC, Small SM, Peltekian L, Kessler RL, Potthoff MJ. FGF21 resistance is not mediated by downregulation of beta-klotho expression in white adipose tissue. Mol Metab 2017;6:602-610.

Martinello K, Hart AR, Yap S, Mitra S, Robertson NJ. Management and investigation of neonatal encephalopathy: 2017 update. Arch Dis Child Fetal Neonatal Ed 2017;102:F346F358.

Masini MA, Prato P, Scarabelli L, Lanza C, Palmero S, Pointis G, Ricci F, Strollo F. In vitro effects of simulated microgravity on Sertoli cell function. Adv Space Res 2011;47:575-581.

Masters CL, Bateman R, Blennow K, Rowe CC, Sperling RA, Cummings JL. Alzheimer's disease. Nat Rev Dis Primers 2015;1:15056.

Mendel CM. The free hormone hypothesis: a physiologically based mathematical model. Endocr Rev 1989;10:232-274.

Mestas J, Hughes CC. Of mice and not men: differences between mouse and human immunology. J Immunol 2004;172: 2731-2738.

Metz C, Holzschuh M, Bein T, Woertgen C, Frey A, Frey I, Taeger K, Brawanski A. Moderate hypothermia in patients with severe head injury: cerebral and extracerebral effects. J Neurosurg 1996;85:533-541.

Meybohm P, Gruenewald M, Zacharowski KD, Albrecht M, Lucius R, Fosel N, Hensler J, Zitta K, Bein B. Mild hypothermia alone or in combination with anesthetic post-conditioning reduces expression of inflammatory cytokines in the cerebral cortex of pigs after cardiopulmonary resuscitation. Crit Care 2010;14:R21.

Mitani A, Kataoka K. Critical levels of extracellular glutamate mediating gerbil hippocampal delayed neuronal death during hypothermia: brain microdialysis study. Neuroscience 1991; 42:661-670.

Moler FW, Silverstein FS, Holubkov R, Slomine BS, Christensen JR, Nadkarni VM, Meert KL, Browning B, Pemberton VL, Page K, Gildea MR, Scholefield BR, Shankaran S, Hutchison JS, Berger JT, Ofori-Amanfo G, Newth CJ, Topjian A, Bennett KS, Koch JD, Pham N, Chanani NK, Pineda JA, Harrison R, Dalton HJ, Alten J, Schleien CL, Goodman DM, Zimmerman JJ, Bhalala US, Schwarz AJ, Porter MB, Shah S, Fink EL, McQuillen P, Wu T, Skellett S, Thomas NJ, Nowak JE, Baines PB, Pappachan J, Mathur M, Lloyd E, van der Jagt EW, Dobyns EL, Meyer MT, Sanders RC, Jr., Clark AE, Dean JM; THAPCA Trial Investigators. Therapeutic hypothermia after in-hospital cardiac arrest in children. N Engl J Med 2017;376:318-329.

Moler FW, Silverstein FS, Holubkov R, Slomine BS, Christensen JR, Nadkarni VM, Meert KL, Clark AE, Browning B,
Pemberton VL, Page K, Shankaran S, Hutchison JS, Newth CJ, Bennett KS, Berger JT, Topjian A, Pineda JA, Koch JD, Schleien CL, Dalton HJ, Ofori-Amanfo G, Goodman DM, Fink EL, McQuillen P, Zimmerman JJ, Thomas NJ, van der Jagt EW, Porter MB, Meyer MT, Harrison R, Pham N, Schwarz AJ, Nowak JE, Alten J, Wheeler DS, Bhalala US, Lidsky K, Lloyd E, Mathur M, Shah S, Wu T, Theodorou AA, Sanders RC, Jr., Dean JM; THAPCA Trial Investigators. Therapeutic hypothermia after out-of-hospital cardiac arrest in children. N Engl J Med 2015;372:1898-1908.

Montenegro MF, Sundqvist ML, Nihlen C, Hezel M, Carlstrom M, Weitzberg E, Lundberg JO. Profound differences between humans and rodents in the ability to concentrate salivary nitrate: implications for translational research. Redox Biol 2016;10:206-210.

Moreira EF, Jaworski CJ, Rodriguez IR. Cloning of a novel member of the reticulon gene family (RTN3): gene structure and chromosomal localization to 11q13. Genomics 1999;58:73-81.

Mori K, Maeda M, Miyazaki M, Iwase H. Effects of mild and moderate hypothermia on cerebral metabolism and glutamate in an experimental head injury. Acta Neurochir Suppl 1998; 71:222-224.

Mueller KA, Glajch KE, Huizenga MN, Wilson RA, Granucci EJ, Dios AM, Tousley AR, Iuliano M, Weisman E, LaQuaglia MJ, DiFiglia M, Kegel-Gleason K, Vakili K, SadriVakili G. Hippo signaling pathway dysregulation in human Huntington's disease brain and neuronal stem cells. Sci Rep 2018;8:11355.

Nanda D, Tolputt J, Collard KJ. Changes in brain glutathione levels during postnatal development in the rat. Brain Res Dev Brain Res 1996;94:238-241.

Nelson BT, Ding XS, Boney-Montoya J, Gerard RD, Kliewer SA, Andrews MT. Metabolic hormone FGF21 is induced in ground squirrels during hibernation but its overexpression is not sufficient to cause torpor. PloS One 2013;8:e53574.

Neumar RW, DeGracia DJ, Konkoly LL, Khoury JI, White BC, Krause GS. Calpain mediates eukaryotic initiation factor $4 \mathrm{G}$ degradation during global brain ischemia. J Cereb Blood Flow Metab 1998;18:876-881.

Nielsen N, Wettersley J, Cronberg T, Erlinge D, Gasche Y, Hassager C, Horn J, Hovdenes J, Kjaergaard J, Kuiper M, Pellis T, Stammet P, Wanscher M, Wise MP, Aneman A, AlSubaie N, Boesgaard S, Bro-Jeppesen J, Brunetti I, Bugge JF, Hingston CD, Juffermans NP, Koopmans M, Kober L, Langorgen J, Lilja G, Moller JE, Rundgren M, Rylander C, Smid O, Werer C, Winkel P, Friberg H; TTM Trial Investigators. Targeted temperature management at 33 degrees c versus 36 degrees c after cardiac arrest. N Engl J Med 2013;369:2197-2206.

Niquet J, Baldwin R, Gezalian M, Wasterlain CG. Deep hypothermia for the treatment of refractory status epilepticus. Epilepsy Behav 2015;49:313-317.

Nishiyama H, Itoh K, Kaneko Y, Kishishita M, Yoshida O, Fujita J. A glycine-rich RNA-binding protein mediating coldinducible suppression of mammalian cell growth. J Cell Biol 1997;137:899-908.

Nishiyama H, Xue JH, Sato T, Fukuyama H, Mizuno N, Houtani T, Sugimoto T, Fujita J. Diurnal change of the coldinducible RNA-binding protein (Cirp) expression in mouse brain. Biochem Biophys Res Commun 1998;245:534-538.

Nobuta H, Ghiani CA, Paez PM, Spreuer V, Dong H, Korsak RA, Manukyan A, Li J, Vinters HV, Huang EJ, Rowitch DH, Sofroniew MV, Campagnoni AT, de Vellis J, Waschek JA. STAT3-mediated astrogliosis protects myelin development in neonatal brain injury. Ann Neurol 2012;72:750-765. 
Noyes AM, Lundbye JB. Managing the complications of mild therapeutic hypothermia in the cardiac arrest patient. J Intensive Care Med 2015;30:259-269.

Nozari A, Safar P, Stezoski SW, Wu X, Kostelnik S, Radovsky A, Tisherman S, Kochanek PM. Critical time window for intra-arrest cooling with cold saline flush in a dog model of cardiopulmonary resuscitation. Circulation 2006;113:26902696.

Obrist WD, Langfitt TW, Jaggi JL, Cruz J, Gennarelli TA. Cerebral blood flow and metabolism in comatose patients with acute head injury. Relationship to intracranial hypertension. J Neurosurg 1984;61:241-253.

Oddo M, Frangos S, Maloney-Wilensky E, Andrew Kofke W, Le Roux PD, Levine JM. Effect of shivering on brain tissue oxygenation during induced normothermia in patients with severe brain injury. Neurocrit Care 2010;12:10-16.

Oishi K, Yamamoto S, Uchida D, Doi R. Ketogenic diet and fasting induce the expression of cold-inducible RNA-binding protein with time-dependent hypothermia in the mouse liver. FEBS Open Bio 2013;3:192-195.

Ooboshi H, Ibayashi S, Takano K, Sadoshima S, Kondo A, Uchimura H, Fujishima M. Hypothermia inhibits ischemiainduced efflux of amino acids and neuronal damage in the hippocampus of aged rats. Brain Res 2000;884:23-30.

Ornitz DM, Itoh N. The fibroblast growth factor signaling pathway. Wiley Interdiscip Rev Dev Biol 2015;4:215-266.

Palmer AM, Marion DW, Botscheller ML, Redo EE. Therapeutic hypothermia is cytoprotective without attenuating the traumatic brain injury-induced elevations in interstitial concentrations of aspartate and glutamate. J Neurotrauma 1993; 10:363-372.

Papadima EM, Niola P, Melis C, Pisanu C, Congiu D, Cruceanu C, Lopez JP, Turecki G, Ardau R, Severino G, Chillotti C, Del Zompo M, Squassina A. Evidence towards RNA binding motif (RNP1, RRM) Protein 3 (RBM3) as a potential biomarker of lithium response in bipolar disorder patients. J Mol Neurosci 2017;62:304-308.

Pawlosky RJ, Kemper MF, Kashiwaya Y, King MT, Mattson MP, Veech RL. Effects of a dietary ketone ester on hippocampal glycolytic and tricarboxylic acid cycle intermediates and amino acids in a 3xTgAD mouse model of Alzheimer's disease. J Neurochem 2017;141:195-207.

Peretti D, Bastide A, Radford H, Verity N, Molloy C, Martin MG, Moreno JA, Steinert JR, Smith T, Dinsdale D, Willis AE, Mallucci GR. RBM3 mediates structural plasticity and protective effects of cooling in neurodegeneration. Nature 2015;518:236-239.

Phelps C. Principles of treatment. In: Traumatic Injuries of the Brain and Its Membranes. New York, NY: D. Appleton \& Co., 1897. https://archive.org/details/traumaticinjurie00phel/page/n17

Pilotte J, Cunningham BA, Edelman GM, Vanderklish PW. Developmentally regulated expression of the cold-inducible RNA-binding motif protein 3 in euthermic rat brain. Brain Res 2009;1258:12-24.

Pilotte J, Dupont-Versteegden EE, Vanderklish PW. Widespread regulation of miRNA biogenesis at the Dicer step by the cold-inducible RNA-binding protein, RBM3. PloS One 2011;6:e28446.

Polderman KH. Mechanisms of action, physiological effects, and complications of hypothermia. Crit Care Med 2009;37: S186-S202.

Price CJ, Menon DK, Peters AM, Ballinger JR, Barber RW, Balan KK, Lynch A, Xuereb JH, Fryer T, Guadagno JV, Warburton EA. Cerebral neutrophil recruitment, histology, and outcome in acute ischemic stroke: an imaging-based study. Stroke 2004;35:1659-1664.

Rajayer SR, Jacob A, Yang WL, Zhou MA, Chaung WN, Wang $\mathrm{P}$. Cold-inducible RNA-binding protein is an important mediator of alcohol-induced brain inflammation. PloS One 2013;8:e79430.

Ramlackhansingh AF, Brooks DJ, Greenwood RJ, Bose SK, Turkheimer FE, Kinnunen KM, Gentleman S, Heckemann RA, Gunanayagam K, Gelosa G, Sharp DJ. Inflammation after trauma: microglial activation and traumatic brain injury. Ann Neurol 2011;70:374-383.

Ramoa AS, Mccormick DA. Enhanced activation of NMDA receptor responses at the immature retinogeniculate synapse. J Neurosci 1994;14:2098-2105.

Rao RR, Long JZ, White JP, Svensson KJ, Lou J, Lokurkar I, Jedrychowski MP, Ruas JL, Wrann CD, Lo JC, Camera DM, Lachey J, Gygi S, Seehra J, Hawley JA, Spiegelman BM. Meteorin-like is a hormone that regulates immune-adipose interactions to increase beige fat thermogenesis. Cell 2014; 157:1279-1291.

Raschke S, Elsen M, Gassenhuber H, Sommerfeld M, Schwahn U, Brockmann B, Jung R, Wisloff U, Tjonna AE, Raastad T, Hallen J, Norheim F, Drevon CA, Romacho T, Eckardt K, Eckel J. Evidence against a beneficial effect of Irisin in humans. PloS One 2013;8:e73680.

Reitman ML. Of mice and men-environmental temperature, body temperature, and treatment of obesity. FEBS Lett 2018; 592:2098-2107.

Restelli LM, Oettinghaus B, Halliday M, Agca C, Licci M, Sironi L, Savoia C, Hench J, Tolnay M, Neutzner A, Schmidt A, Eckert A, Mallucci G, Scorrano L, Frank S. Neuronal mitochondrial dysfunction activates the integrated stress response to induce fibroblast growth factor 21. Cell Rep 2018; 24:1407-1414.

Rifkind JM, Mohanty JG, Nagababu E. The pathophysiology of extracellular hemoglobin associated with enhanced oxidative reactions. Front Physiol 2014;5:500.

Roberts DR, Albrecht MH, Collins HR, Asemani D, Chatterjee AR, Spampinato MV, Zhu X, Chimowitz MI, Antonucci MU. Effects of spaceflight on astronaut brain structure as indicated on MRI. N Engl J Med 2017;377:1746-1753.

Rocha-Ferreira E, Kelen D, Faulkner S, Broad KD, Chandrasekaran M, Kerenyi A, Kato T, Bainbridge A, Golay X, Sullivan M, Kramer BW, Robertson NJ. Systemic proinflammatory cytokine status following therapeutic hypothermia in a piglet hypoxia-ischemia model. J Neuroinflammation 2017;14:44.

Rocha-Ferreira E, Vincent A, Bright S, Peebles DM, Hristova $M$. The duration of hypothermia affects short-term neuroprotection in a mouse model of neonatal hypoxic ischaemic injury. PloS One 2018;13:e0199890.

Rodriguez-Rodriguez P, Sandebring-Matton A, Merino-Serrais P, Parrado-Fernandez C, Rabano A, Winblad B, Avila J, Ferrer I, Cedazo-Minguez A. Tau hyperphosphorylation induces oligomeric insulin accumulation and insulin resistance in neurons. Brain 2017;140:3269-3285.

Rosenbaum W, Christy NP, Kelly WG. Electrophoretic evidence for the presence of an estrogen-binding beta-globulin in human plasma. J Clin Endocrinol Metab 1966;26:1399-1403.

Ruan Q, Zhang L, Ruan J, Zhang X, Chen J, Ma C, Yu Z. Detection and quantitation of irisin in human cerebrospinal fluid by tandem mass spectrometry. Peptides 2018;103:60-64.

Ruas JL, White JP, Rao RR, Kleiner S, Brannan KT, Harrison BC, Greene NP, Wu J, Estall JL, Irving BA, Lanza IR, Rasbach KA, Okutsu M, Sreekumaran Nair K, Yan Z, 
Leinwand LA, Spiegelman BM. A PGC- $1 \alpha$ Isoform Induced by Resistance Training Regulates Skeletal Muscle Hypertrophy. Cell 2012;151:1319-1331.

Ruderman NB, Ross PS, Berger M, Goodman MN. Regulation of glucose and ketone-body metabolism in brain of anaesthetized rats. Biochem J 1974;138:1-10.

Ryan JC, Morey JS, Ramsdell JS, Van Dolah FM. Acute phase gene expression in mice exposed to the marine neurotoxin domoic acid. Neuroscience 2005; 136:1121-1132.

Safar P, Tisherman SA, Behringer W, Capone A, Prueckner S, Radovsky A, Stezoski WS, Woods RJ. Suspended animation for delayed resuscitation from prolonged cardiac arrest that is unresuscitable by standard cardiopulmonary-cerebral resuscitation. Crit Care Med 2000;28:N214-N218.

Saito K, Fukuda N, Matsumoto T, Iribe Y, Tsunemi A, Kazama T, Yoshida-Noro C, Hayashi N. Moderate low temperature preserves the stemness of neural stem cells and suppresses apoptosis of the cells via activation of the coldinducible RNA binding protein. Brain Res 2010;1358: 20-29.

Sakurai A, Atkins CM, Alonso OF, Bramlett HM, Dietrich WD. Mild hyperthermia worsens the neuropathological damage associated with mild traumatic brain injury in rats. J Neurotrauma 2012;29:313-321.

Salman MM, Kitchen P, Woodroofe MN, Brown JE, Bill RM, Conner AC, Conner MT. Hypothermia increases aquaporin 4 (AQP4) plasma membrane abundance in human primary cortical astrocytes via a calcium/transient receptor potential vanilloid 4 (TRPV4)- and calmodulin-mediated mechanism. Eur J Neurosci 2017;46:2542-2547.

Salter MG, Fern R. NMDA receptors are expressed in developing oligodendrocyte processes and mediate injury. Nature 2005;438:1167-1171.

Sanchez-Infantes D, Gallego-Escuredo JM, Diaz M, Aragones G, Sebastiani G, Lopez-Bermejo A, de Zegher F, Domingo P, Villarroya F, Ibanez L. Circulating FGF19 and FGF21 surge in early infancy from infra- to supra-adult concentrations. Int J Obes 2015;39:742-746.

Schiefecker AJ, Kofler M, Gaasch M, Beer R, Unterberger I, Pfausler B, Broessner G, Lackner P, Rhomberg P, Gizewski E, Hackl WO, Mulino M, Ortler M, Thome C, Schmutzhard E, Helbok R. Brain temperature but not core temperature increases during spreading depolarizations in patients with spontaneous intracerebral hemorrhage. J Cereb Blood Flow Metab 2018;38:549-558.

Schober A, Warenits AM, Testori C, Weihs W, Hosmann A, Hogler S, Sterz F, Janata A, Scherer T, Magnet IAM, Ettl F, Laggner AN, Herkner H, Zeitlinger M. Microdialysis assessment of cerebral perfusion during cardiac arrest, extracorporeal life support and cardiopulmonary resuscitation in rats-a pilot trial. PloS One 2016;11:e0155303.

Schubert GA, Poli S, Mendelowitsch A, Schilling L, Thome C. Hypothermia reduces early hypoperfusion and metabolic alterations during the acute phase of massive subarachnoid hemorrhage: a laser-Doppler-flowmetry and microdialysis study in rats. J Neurotrauma 2008;25:539-548.

Sehara Y, Sawicka K, Hwang JY, Latuszek-Barrantes A, Etgen AM, Zukin RS. Survivin is a transcriptional target of STAT3 critical to estradiol neuroprotection in global ischemia. J Neurosci 2013;33:12364-12374.

Sharoar MG, Shi Q, Ge Y, He W, Hu X, Perry G, Zhu X, Yan R. Dysfunctional tubular endoplasmic reticulum constitutes a pathological feature of Alzheimer's disease. Mol Psychiatry 2016;21:1263-1271.
Shi Q, Ge Y, Sharoar MG, He W, Xiang R, Zhang Z, Hu X, Yan R. Impact of RTN3 deficiency on expression of BACE1 and amyloid deposition. J Neurosci 2014;34:13954-13962.

Shi Q, Hu X, Prior M, Yan R. The occurrence of agingdependent reticulon 3 immunoreactive dystrophic neurites decreases cognitive function. J Neurosci 2009a;29:51085115 .

Shi Q, Prior M, He WX, Tang XY, Hu XY, Yan RQ. Reduced amyloid deposition in mice overexpressing RTN3 is adversely affected by preformed dystrophic neurites. J Neurosci 2009b;29:9163-9173.

Shi Q, Prior M, Zhou X, Tang X, He W, Hu X, Yan R. Preventing formation of reticulon 3 immunoreactive dystrophic neurites improves cognitive function in mice. J Neurosci 2013;33:3059-3066.

Shimohama S, Tanino H, Fujimoto S. Differential expression of rat brain caspase family proteins during development and aging. Biochem Biophys Res Commun 2001;289:1063-1066.

Shuaib A, Kanthan R, Goplen G, Griebel R, el-Azzouni H, Miyashita H, Liu L, Hogan T. In-vivo microdialysis study of extracellular glutamate response to temperature variance in subarachnoid hemorrhage. Acta Neurochir Suppl 1996;67: 53-58.

Simon DW, McGeachy MJ, Bayir H, Clark RS, Loane DJ, Kochanek PM. The far-reaching scope of neuroinflammation after traumatic brain injury. Nat Rev Neurol 2017;13:171191.

Smith SL, Hall ED. Mild pre- and posttraumatic hypothermia attenuates blood-brain barrier damage following controlled cortical impact injury in the rat. J Neurotrauma 1996;13:1-9.

Smith SM, Heer M, Wang Z, Huntoon CL, Zwart SR. Longduration space flight and bed rest effects on testosterone and other steroids. J Clin Endocrinol Metab 2012;97:270-278.

Smith SM, Wastney ME, Morukov BV, Larina IM, Nyquist LE, Abrams SA, Taran EN, Shih CY, Nillen JL, Davis-Street JE, Rice BL, Lane HW. Calcium metabolism before, during, and after a 3-mo spaceflight: kinetic and biochemical changes. Am J Physiol 1999;277:R1-R10.

So WY, Cheng Q, Xu A, Lam KS, Leung PS. Loss of fibroblast growth factor 21 action induces insulin resistance, pancreatic islet hyperplasia and dysfunction in mice. Cell Death Dis 2015;6:e1707.

Soane L, Siegel ZT, Schuh RA, Fiskum G. Postnatal developmental regulation of $\mathrm{Bcl}-2$ family proteins in brain mitochondria. J Neurosci Res 2008;86:1267-1276.

Song F, Guo C, Geng Y, Wu X, Fan W. Therapeutic time window and regulation of autophagy by mild hypothermia after intracerebral hemorrhage in rats. Brain Res 2018;1690: $12-22$.

Sonnenfeld G. Effect of space flight on cytokine production. Acta Astronaut 1994;33:143-147.

Srivastava RAK, Bhasin N, Srivastava N. Apolipoprotein E gene expression in various tissues of mouse and regulation by estrogen. Biochem Mol Biol Int 1996;38:91-101.

Stahn AC, Werner A, Opatz O, Maggioni MA, Steinach M, von Ahlefeld VW, Moore A, Crucian BE, Smith SM, Zwart SR, Schlabs T, Mendt S, Trippel T, Koralewski E, Koch J, Chouker A, Reitz G, Shang P, Rocker L, Kirsch KA, Gunga HC. Increased core body temperature in astronauts during long-duration space missions. Sci Rep 2017;7:16180.

Steen PA, Newberg L, Milde JH, Michenfelder JD. Hypothermia and barbiturates: individual and combined effects on canine cerebral oxygen consumption. Anesthesiology 1983;58:527-532. 
Suehiro E, Fujisawa H, Ito H, Ishikawa T, Maekawa T. Brain temperature modifies glutamate neurotoxicity in vivo. J Neurotrauma 1999;16:285-297.

Sweeney MD, Zhao Z, Montagne A, Nelson AR, Zlokovic BV. Blood-brain barrier: from physiology to disease and back. Physiol Rev 2019;99:21-78.

Tacer KF, Bookout AL, Ding XS, Kurosu H, John GB, Wang L, Goetz R, Mohammadi M, Kuro-o M, Mangelsdorf DJ, Kliewer SA. Research resource: comprehensive expression atlas of the fibroblast growth factor system in adult mouse. Mol Endocrinol 2010;24:2050-2064.

Takaoka S, Pearlstein RD, Warner DS. Hypothermia reduces the propensity of cortical tissue to propagate direct current depolarizations in the rat. Neurosci Lett 1996;218:25-28.

Takata K, Takeda Y, Sato T, Nakatsuka H, Yokoyama M, Morita K. Effects of hypothermia for a short period on histologic outcome and extracellular glutamate concentration during and after cardiac arrest in rats. Crit Care Med 2005;33: 1340-1345.

Takenouchi T, Sugiura Y, Morikawa T, Nakanishi T, Nagahata Y, Sugioka T, Honda K, Kubo A, Hishiki T, Matsuura T, Hoshino T, Takahashi T, Suematsu M, Kajimura M. Therapeutic hypothermia achieves neuroprotection via a decrease in acetylcholine with a concurrent increase in carnitine in the neonatal hypoxia-ischemia. J Cereb Blood Flow Metab 2015; 35:794-805.

Tang XN, Liu L, Koike MA, Yenari MA. Mild hypothermia reduces tissue plasminogen activator-related hemorrhage and blood brain barrier disruption after experimental stroke. Ther Hypothermia Temp Manag 2013;3:74-83.

Tanhaei S, Nikpour P, Ghaedi K, Rabiee F, Homayouni Moghadam F, Nasr-Esfahani MH. RNA/protein discordant expression of Fndc5 in central nervous system is likely to be mediated through microRNAs. DNA Cell Biol 2018;37:373-380.

Teng FY, Tang BL. Nogo/RTN4 isoforms and RTN3 expression protect SH-SY5Y cells against multiple death insults. Mol Cell Biochem 2013;384:7-19.

Thompson LD, Pantoliano MW, Springer BA. Energetic characterization of the basic fibroblast growth factor-heparin interaction: identification of the heparin binding domain. Biochemistry 1994;33:3831-3840.

Tian DH, Wan B, Bannon PG, Misfeld M, LeMaire SA, Kazui T, Kouchoukos NT, Elefteriades JA, Bavaria J, Coselli JS, Griepp RB, Mohr FW, Oo A, Svensson LG, Hughes GC, Yan TD. A meta-analysis of deep hypothermic circulatory arrest versus moderate hypothermic circulatory arrest with selective antegrade cerebral perfusion. Ann Cardiothorac Surg 2013;2:148-158.

Toien O, Blake J, Edgar DM, Grahn DA, Heller HC, Barnes BM. Hibernation in black bears: independence of metabolic suppression from body temperature. Science 2011;331:906-909.

Tomura S, de Rivero Vaccari JP, Keane RW, Bramlett HM, Dietrich WD. Effects of therapeutic hypothermia on inflammasome signaling after traumatic brain injury. J Cereb Blood Flow Metab 2012;32:1939-1947.

Tong G, Endersfelder S, Rosenthal LM, Wollersheim S, Sauer IM, Buhrer C, Berger F, Schmitt KRL. Effects of moderate and deep hypothermia on RNA-binding proteins RBM3 and CIRP expressions in murine hippocampal brain slices. Brain Res 2013;1504:74-84.

Tonnies E, Trushina E. Oxidative stress, synaptic dysfunction, and Alzheimer's disease. J Alzheimers Dis 2017;57:11051121.

Torre-Healy A, Marko NF, Weil RJ. Hyperosmolar therapy for intracranial hypertension. Neurocrit Care 2012;17:117-130.
Tran HT, LaFerla FM, Holtzman DM, Brody DL. Controlled cortical impact traumatic brain injury in $3 \times \mathrm{Tg}-\mathrm{AD}$ mice causes acute intra-axonal amyloid-beta accumulation and independently accelerates the development of tau abnormalities. J Neurosci 2011;31:9513-9525.

Trollmann R, Rehrauer H, Schneider C, Krischke G, Huemmler N, Keller S, Rascher W, Gassmann M. Late-gestational systemic hypoxia leads to a similar early gene response in mouse placenta and developing brain. Am J Physiol Regul Integr Comp Physiol 2010;299:R1489-R1499.

Truettner JS, Bramlett HM, Dietrich WD. Posttraumatic therapeutic hypothermia alters microglial and macrophage polarization toward a beneficial phenotype. J Cereb Blood Flow Metab 2017;37:2952-2962.

Tu WJ, Qiu HC, Cao JL, Liu Q, Zeng XW, Zhao JZ. Decreased concentration of irisin is associated with poor functional outcome in ischemic stroke. Neurotherapeutics 2018a;15: 1158-1167.

Tu WJ, Qiu HC, Liu Q, Li XM, Zhao JZ, Zeng XW. Decreased level of irisin, a skeletal muscle cell-derived myokine, is associated with post-stroke depression in the ischemic stroke population. J Neuroinflamm 2018b;15:doi: 10.1186/s12974018-1177-6.

van der Worp HB, Sena ES, Donnan GA, Howells DW, Macleod MR. Hypothermia in animal models of acute ischaemic stroke: a systematic review and meta-analysis. Brain 2007; 130:3063-3074.

Van Ombergen A, Jillings S, Jeurissen B, Tomilovskaya E, Ruhl RM, Rumshiskaya A, Nosikova I, Litvinova L, Annen J, Pechenkova EV, Kozlovskaya IB, Sunaert S, Parizel PM, Sinitsyn V, Laureys S, Sijbers J, Zu Eulenburg P, Wuyts FL. Brain tissue-volume changes in cosmonauts. N Engl J Med 2018;379:1678-1680.

Van Pelt DW, Confides AL, Judge AR, Vanderklish PW, Dupont-Versteegden EE. Cold shock protein RBM3 attenuates atrophy and induces hypertrophy in skeletal muscle. J Muscle Res Cell Motil 2018;39:35-40.

Walhovd KB, Krogsrud SK, Amlien IK, Bartsch H, Bjornerud A, Due-Tonnessen P, Grydeland H, Hagler DJ, Haberg AK, Kremen WS, Ferschmann L, Nyberg L, Panizzon MS, Rohani DA, Skranes J, Storsve AB, Solsnes AE, Tamnes CK, Thompson WK, Reuter C, Dale AM, Fjell AM. Neurodevelopmental origins of lifespan changes in brain and cognition. Proc Natl Acad Sci U S A 2016;113:9357-9362.

Wang G, Zhang JN, Guo JK, Cai Y, Sun HS, Dong K, Wu CG. Neuroprotective effects of cold-inducible RNA-binding protein during mild hypothermia on traumatic brain injury. Neural Regen Res 2016;11:771-778.

Wang H, Olivero W, Wang D, Lanzino G. Cold as a therapeutic agent. Acta Neurochir (Wien) 2006;148:565-570.

Wang H, Zhao YT, Zhang S, Dubielecka PM, Du J, Yano N, Chin YE, Zhuang S, Qin G, Zhao TC. Irisin plays a pivotal role to protect the heart against ischemia and reperfusion injury. J Cell Physiol 2017;232:3775-3785.

Wang X, Che H, Zhang W, Wang J, Ke T, Cao R, Meng S, Li $\mathrm{D}$, Weiming $\mathrm{O}$, Chen J, Luo W. Effects of mild chronic intermittent cold exposure on rat organs. Int J Biol Sci 2015; 11:1171-1180.

Wei W, Dutchak PA, Wang X, Ding X, Wang X, Bookout AL, Goetz R, Mohammadi M, Gerard RD, Dechow PC, Mangelsdorf DJ, Kliewer SA, Wan Y. Fibroblast growth factor 21 promotes bone loss by potentiating the effects of peroxisome proliferator-activated receptor gamma. Proc Natl Acad Sci U S A 2012;109:3143-3148. 
Weinrauch V, Safar P, Tisherman S, Kuboyama K, Radovsky A. Beneficial effect of mild hypothermia and detrimental effect of deep hypothermia after cardiac arrest in dogs. Stroke 1992;23:1454-1462.

Welinder KG, Hansen R, Overgaard MT, Brohus M, Sonderkaer M, von Bergen M, Rolle-Kampczyk U, Otto W, Lindahl TL, Arinell K, Evans AL, Swenson JE, Revsbech IG, Frobert O. Biochemical Foundations of Health and Energy Conservation in Hibernating Free-ranging Subadult Brown Bear Ursus arctos. J Biol Chem 2016;291:2250922523.

Wennberg RP, Hance AJ. Experimental bilirubin encephalopathy: importance of total bilirubin, protein binding, and blood-brain barrier. Pediatr Res 1986;20:789-792.

Wiklund L, Patnaik R, Sharma A, Miclescu A, Sharma HS. Cerebral tissue oxidative ischemia-reperfusion injury in connection with experimental cardiac arrest and cardiopulmonary resuscitation: effect of mild hypothermia and methylene blue. Mol Neurobiol 2018;55:115-121.

Willette AA, Bendlin BB, Starks EJ, Birdsill AC, Johnson SC, Christian BT, Okonkwo OC, La Rue A, Hermann BP, Koscik RL, Jonaitis EM, Sager MA, Asthana S. Association of insulin resistance with cerebral glucose uptake in late middleaged adults at risk for Alzheimer disease. JAMA Neurol 2015;72:1013-1020.

Wisnowski JL, Wu TW, Reitman AJ, McLean C, Friedlich P, Vanderbilt D, Ho E, Nelson MD, Panigrahy A, Bluml S. The effects of therapeutic hypothermia on cerebral metabolism in neonates with hypoxic-ischemic encephalopathy: an in vivo $1 \mathrm{H}-$ MR spectroscopy study. J Cereb Blood Flow Metab 2016;36: 1075-1086.

Wong JJ, Au AY, Gao D, Pinello N, Kwok CT, Thoeng A, Lau KA, Gordon JE, Schmitz U, Feng Y, Nguyen TV, Middleton R, Bailey CG, Holst J, Rasko JE, Ritchie W. RBM3 regulates temperature sensitive miR-142-5p and miR-143 (thermomiRs), which target immune genes and control fever. Nucleic Acids Res 2016;44:2888-2897.

Woods RJ, Prueckner S, Safar P, Radovsky A, Takasu A, Stezoski SW, Stezoski J, Tisherman SA. Hypothermic aortic arch flush for preservation during exsanguination cardiac arrest of 15 minutes in dogs. J Trauma 1999;47:1028-1036; discussion 1036-1028.

Woods RJ, Prueckner S, Safar P, Takasu A, Tisherman SA, Jackson EK, Radovsky A, Kochanek P, Behringer W, Stezoski SW, Hans R. Adenosine by aortic flush fails to augment the brain preservation effect of mild hypothermia during exsanguination cardiac arrest in dogs-an exploratory study. Resuscitation 2000;44:47-59.

Wrann CD, White JP, Salogiannnis J, Laznik-Bogoslavski D, Wu J, Ma D, Lin JD, Greenberg ME, Spiegelman BM. Exercise induces hippocampal BDNF through a PGC-1 alpha/FNDC5 pathway. Cell Metab 2013;18:649-659.

Wroge CM, Hogins J, Eisenman L, Mennerick S. Synaptic NMDA receptors mediate hypoxic excitotoxic death. J Neurosci 2012;32:6732-6742.

Wu X, Drabek T, Kochanek PM, Henchir J, Stezoski SW, Stezoski J, Cochran K, Garman R, Tisherman SA. Induction of profound hypothermia for emergency preservation and resuscitation allows intact survival after cardiac arrest resulting from prolonged lethal hemorrhage and trauma in dogs. Circulation 2006;113:1974-1982.

Xia W, Su L, Jiao J. Cold-induced protein RBM3 orchestrates neurogenesis via modulating YAP mRNA stability in cold stress. J Cell Biol 2018;217:3464-3479.
Xu J, Stanislaus S, Chinookoswong N, Lau YY, Hager T, Patel J, Ge H, Weiszmann J, Lu SC, Graham M, Busby J, Hecht R, Li YS, Li Y, Lindberg R, Veniant MM. Acute glucoselowering and insulin-sensitizing action of FGF21 in insulinresistant mouse models-association with liver and adipose tissue effects. Am J Physiol Endocrinol Metab 2009;297: E1105-E1114.

Xu Q, Bernardo A, Walker D, Kanegawa T, Mahley RW, Huang Y. Profile and regulation of apolipoprotein E (ApoE) expression in the CNS in mice with targeting of green fluorescent protein gene to the ApoE locus. J Neurosci 2006;26: 4985-4994.

Yamaguchi Y, Miura M. Programmed cell death in neurodevelopment. Dev Cell 2015;32:478-490.

Yang HJ, Ju F, Guo XX, Ma SP, Wang L, Cheng BF, Zhuang RJ, Zhang BB, Shi X, Feng ZW, Wang M. RNA-binding protein RBM3 prevents NO-induced apoptosis in human neuroblastoma cells by modulating p38 signaling and miR143. Sci Rep 2017;7:41738.

Yang HJ, Shi X, Ju F, Hao BN, Ma SP, Wang L, Cheng BF, Wang M. Cold shock induced protein RBM3 but not mild hypothermia protects human SH-SY5Y neuroblastoma cells from MPP(+)-induced neurotoxicity. Front Neurosci 2018; 12:298.

Yarchoan M, Arnold SE. Repurposing diabetes drugs for brain insulin resistance in Alzheimer disease. Diabetes 2014;63: 2253-2261.

Yu HY, Xia FZ, Lam KSL, Wang Y, Bao YQ, Zhang JL, Gu YJ, Zhou PC, Lu JX, Jia WP, Xu AM. Circadian rhythm of circulating fibroblast growth factor 21 is related to diurnal changes in fatty acids in humans. Clin Chem 2011;57:691-700.

Zargar R, Urwat U, Malik F, Shah RA, Bhat MH, Naykoo NA, Khan F, Khan HM, Ahmed SM, Vijh RK, Ganai NA. Molecular characterization of RNA binding motif protein 3 (RBM3) gene from Pashmina goat. Res Vet Sci 2015;98:51-58.

Zeitlin C, Hassler DM, Cucinotta FA, Ehresmann B, WimmerSchweingruber RF, Brinza DE, Kang S, Weigle G, Bottcher S, Bohm E, Burmeister S, Guo J, Kohler J, Martin C, Posner A, Rafkin S, Reitz G. Measurements of energetic particle radiation in transit to Mars on the Mars Science Laboratory. Science 2013;340:1080-1084.

Zhang HT, Xue JH, Zhang ZW, Kong HB, Liu AJ, Li SC, Xu DG. Cold-inducible RNA-binding protein inhibits neuron apoptosis through the suppression of mitochondrial apoptosis. Brain Res 2015;1622:474-483.

Zhang LF, Hargens AR. Spaceflight-induced intracranial hypertension and visual impairment: pathophysiology and countermeasures. Physiol Rev 2018;98:59-87.

Zhang MJ, Li WJ, Niu GM, Leak RK, Chen J, Zhang F. ATP induces mild hypothermia in rats but has a strikingly detrimental impact on focal cerebral ischemia. J Cereb Blood Flow Metab 2013;33:157-158.

Zhang Q, Wang YZ, Zhang W, Chen X, Wang J, Chen J, Luo $\mathrm{W}$. Involvement of cold inducible RNA-binding protein in severe hypoxia-induced growth arrest of neural stem cells in vitro. Mol Neurobiol 2017;54:2143-2153.

Zhao B, Pan BS, Shen SW, Sun X, Hou ZZ, Yan R, Sun FY. Diabetes-induced central neuritic dystrophy and cognitive deficits are associated with the formation of oligomeric reticulon-3 via oxidative stress. J Biol Chem 2013;288: 15590-15599.

Zhou M, Baudry M. Developmental changes in NMDA neurotoxicity reflect developmental changes in subunit composition of NMDA receptors. J Neurosci 2006;26:2956-2963. 
Zhou M, Wang P, Yang Z, Wu H, Huan Z. Spontaneous hypothermia ameliorated inflammation and neurologic deficit in rat cardiac arrest models following resuscitation. Mol Med Rep 2018;17:2127-2136.

Zhou M, Yang WL, Ji Y, Qiang X, Wang P. Cold-inducible RNA-binding protein mediates neuroinflammation in cerebral ischemia. Biochim Biophys Acta 2014;1840:2253-2261.

Zhu XZ, Zelmer A, Kapfhammer JP, Wellmann S. Cold-inducible RBM3 inhibits PERK phosphorylation through cooperation with NF90 to protect cells from endoplasmic reticulum stress. FASEB J 2016;30:624-634.

Zhuang RJ, Ma J, Shi X, Ju F, Ma SP, Wang L, Cheng BF, Ma YW, Wang M, Li T, Feng ZW, Yang HJ. Cold-inducible protein RBM3 protects UV irradiation-induced apoptosis in neuroblastoma cells by affecting p38 and JNK pathways and Bcl2 family proteins. J Mol Neurosci 2017;63:142-151.
Zou Y, He W, Wang K, Han H, Xiao T, Chen X, Zhou B, Tan J, Xia K, Tang B, Chen C, Shen L, Yan R, Zhang Z. Identification of rare RTN3 variants in Alzheimer's disease in Han Chinese. Hum Genet 2018;137:141-150.

Address correspondence to: Travis C. Jackson, PhD John G. Rangos Research Center UPMC Children's Hospital of Pittsburgh Safar Center for Resuscitation Research University of Pittsburgh, School of Medicine 6th Floor, 4401 Penn Avenue Pittsburgh, PA 15224

E-mail: jacksontc@upmc.edu; jacksontc@outlook.com 